\title{
The interactions of cisplatin and model proteins studied by electrospray ionization mass spectrometry and tandem mass spectrometry
}

Ting Zhao

West Virginia University

Follow this and additional works at: https://researchrepository.wvu.edu/etd

\section{Recommended Citation}

Zhao, Ting, "The interactions of cisplatin and model proteins studied by electrospray ionization mass spectrometry and tandem mass spectrometry" (2009). Graduate Theses, Dissertations, and Problem Reports. 2874.

https://researchrepository.wvu.edu/etd/2874

This Dissertation is protected by copyright and/or related rights. It has been brought to you by the The Research Repository @ WVU with permission from the rights-holder(s). You are free to use this Dissertation in any way that is permitted by the copyright and related rights legislation that applies to your use. For other uses you must obtain permission from the rights-holder(s) directly, unless additional rights are indicated by a Creative Commons license in the record and/ or on the work itself. This Dissertation has been accepted for inclusion in WVU Graduate Theses, Dissertations, and Problem Reports collection by an authorized administrator of The Research Repository @ WVU.

For more information, please contact researchrepository@mail.wvu.edu. 


\title{
The Interactions of Cisplatin and Model Proteins Studied by Electrospray Ionization Mass Spectrometry and Tandem Mass Spectrometry
}

\author{
Ting Zhao \\ Dissertation submitted to the Eberly College of Arts and Sciences \\ at West Virginia University \\ in partial fulfillment of the requirements \\ for the degree of \\ Doctor of Philosophy \\ in \\ Chemistry \\ Approved by \\ Fred L. King, Ph. D., Chair \\ Ronald B. Smart, Ph. D. \\ Kenneth Showalter, Ph. D. \\ Xiaodong Shi, Ph. D. \\ Patrick S. Callery, Ph. D. \\ C. Eugene Bennett Department of Chemistry \\ Morgantown, West Virginia \\ 2009 \\ Keywords: Cisplatin, Proteins, Interactions, \\ Electrospray ionization, Mass spectrometry \\ Copyright 2009 Ting Zhao
}




\title{
ABSTRACT \\ The Interactions of Cisplatin and Model Proteins Studied by Electrospray Ionization Mass Spectrometry and Tandem Mass Spectrometry
}

\author{
Ting Zhao
}

\begin{abstract}
Protein-cisplatin interactions lie at the heart of both the effectiveness of cisplatin as an anticancer drug and side effects associated with cisplatin treatment. A greater understanding of the protein-cisplatin interactions at the molecular level can not only improve our understanding of the action of cisplatin as an anticancer drug but also inform the design of cisplatin-like agents for future use. Therefore, the interactions of cisplatin with three different model proteins were studied, which may provide theoretical basis for predicating mechanistically relevant protein-cisplatin interactions in biological fluids.
\end{abstract}

Cytochrome c (cyt c) was used as a model protein to develop a mass spectrometric approach to determine the primary binding site of cisplatin on proteins by coupling Fourier transform mass spectrometry (FT-MS) and tandem mass spectrometry (MS/MS and $\mathrm{MS}^{3}$ ). FT-MS permits identification of unique fragments in the adduct digest, characterized by MS/MS and $\mathrm{MS}^{3}$ to indicate that Met65 is the primary binding site for cisplatin on cyt c.

The interactions of cisplatin and transplatin with myoglobin $(\mathrm{Mb})$ were compared in 
order to gain insights into similarities and differences between cisplatin and transplatin in their interactions with globular proteins. Prior to this research, the conditions for $\mathrm{Mb}$ denaturation were optimized to obtain the $\mathrm{Mb}$ digests for MS/MS and $\mathrm{MS}^{3}$.

Cisplatin and transplatin exhibit similar interactions with $\mathrm{Mb}$. Monoadducts and diadducts were the primary adducts observed in both the interactions. MS/MS and $\mathrm{MS}^{3}$ analyses of the observed unique fragments in the digests of both the Mb-cisplatin and Mb-transplatin adducts indicate a common binding site for cisplatin and transplatin on the His116-His119 residues of Mb. This result coupled with a study of the interactions of cisplatin and transplatin with a dipeptide His $\sim$ Ser and the three dimensional (3-D) structure of native $\mathrm{Mb}$ shows that cisplatin and transplatin coordinate to the His116 and His119 residues on $\mathrm{Mb}$.

The binding sites of cisplatin on native ubiquitin $(\mathrm{Ub})$ and denatured $\mathrm{Ub}$ were compared in order to investigate the effect of protein conformation on the cisplatin binding sites on a protein. Results suggest that cisplatin has more binding sites on the native $\mathrm{Ub}$ than on the denatured $\mathrm{Ub}$ due to conformation effect. Three cisplatin binding sites are determined on the native $\mathrm{Ub}$, in which two threonines are the primary binding site of cisplatin. On the denatured $\mathrm{Ub}$, the Met1 residue is the specific binding site of cisplatin. 
To My Parents and My Husband

With Love 


\section{Acknowledgements}

I would like to thank God for blessing me to complete my Ph.D. studies.

I am indebted to my advisor Dr. Fred L. King. His guidance has not only led me to completing my PhD studies, but also equipped me with skills and abilities to pursue a chemistry career as an independent researcher.

I am grateful to my committee members Dr. Ronald Smart, Dr. Kenneth Showalter, Dr. Patrick S. Callery, and Dr. Xiaodong Shi for taking time to be involved in my graduate studies. They have challenged me to learn and think in a logical way. I will always be thankful for all their help over these years.

I also want to express my gratitude to all the other faculties, staff, and students at WVU who have taught me and helped me during my Ph.D. studies. Special thanks to Dr. Aaron Timperman, Dr. Harry Finklea, and Dr. Lisa Holland. I am grateful to their help and their knowledge passed on me through classes and my research. I also want to express my gratitude to Brent Robert Reschke, Kathleen Kelly, Ruijuan Luo, and Dr. Yuchen Lu for their assistance in my research.

I would like to thank the entire members of the King Group for their friendship and assistance throughout these years. My Ph.D. studies would have been more difficult without their friendship and assistance. Special thanks to Megan DeJesus and Dr. Jennifer Robertson for their time and efforts to help me with my writing. 
I wish to acknowledge financial support from the Eberly College of Arts and Sciences at WVU and C. Eugene Bennett Chemistry Department at WVU. Thermo Finnigan's gift of the LCQ-MS to WVU was essential to my work. I appreciate the funding from the NSF EPSCoR program for purchasing the LTQ-FT mass spectrometer. I wish to thank Dr. Zhongqi Zhang for kindly providing the MagTran software used in my research.

Finally, I would like to express my appreciation to the support from my family. My parents and my siblings give me endless love and encouragement over my life. My husband, Bo Wen, has given me boundless love, constant help, and encouragement throughout my chemistry career. Without their love and encouragement, I would not be where I am today. 


\section{Table of Contents}

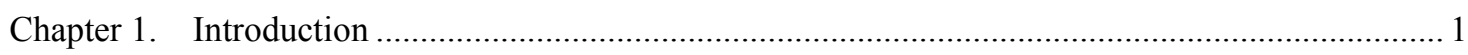

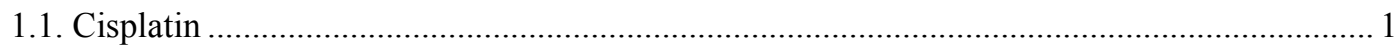

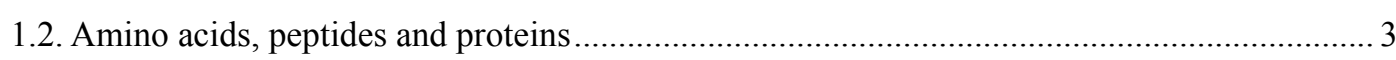

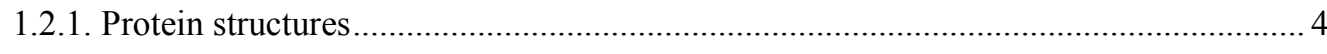

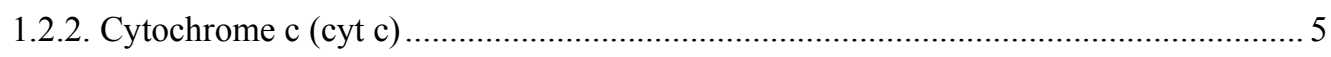

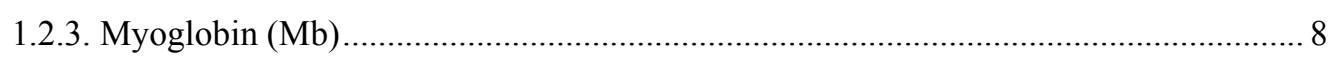

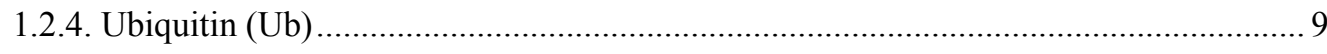

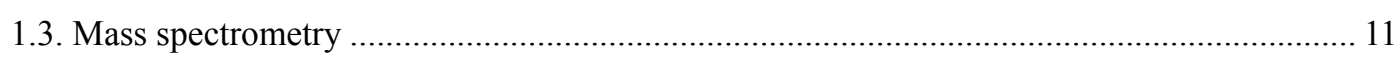

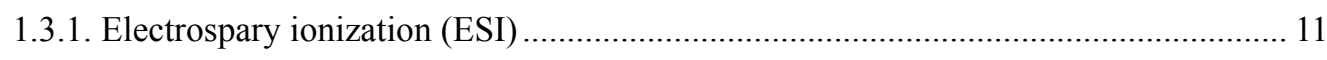

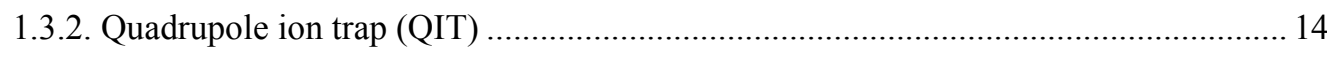

1.3.3. Tandem mass spectrometry (MS/MS) and multiple stages of mass spectrometry $\left(\mathrm{MS}^{\mathrm{n}}\right)$

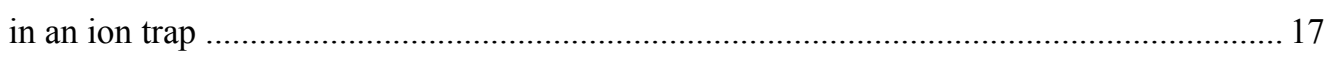

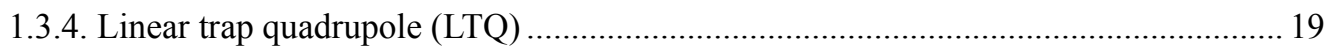

1.3.5. Identification of covalent modification sites of a protein or peptide by MS/MS and

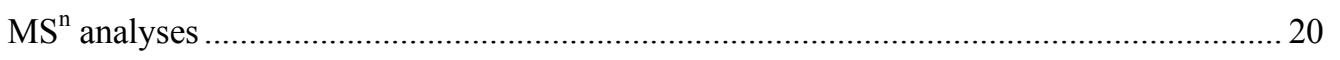

1.3.6. Fourier transform mass spectrometry (FT-MS) ……………………………….... 22

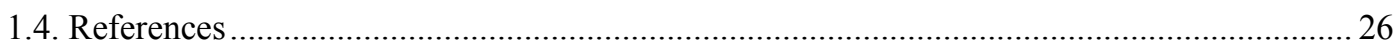

Chapter 2. Direct Determination of the Primary Binding Site of Cisplatin on Cytochrome c by Mass

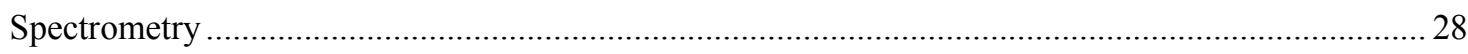

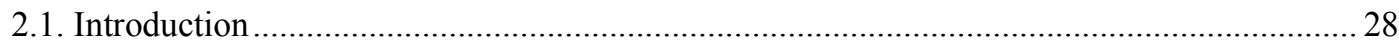

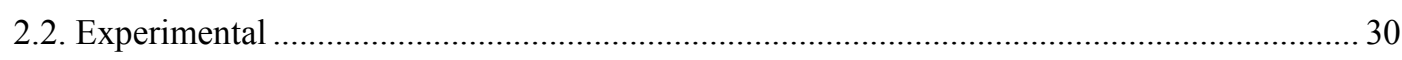

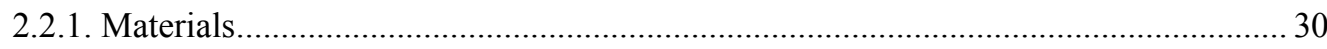

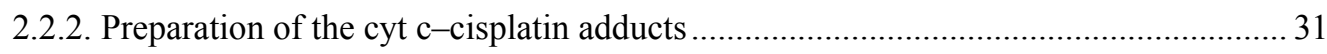

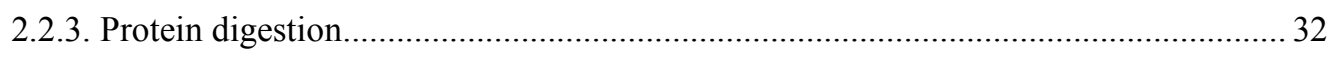

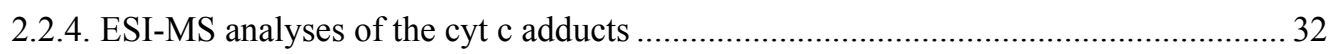

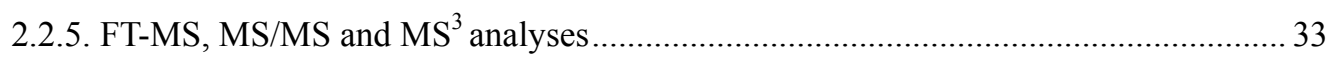

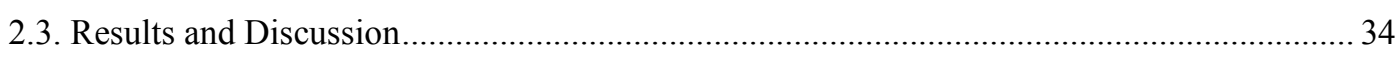

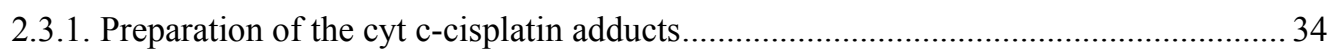

2.3.2. Determination of the primary binding site of cisplatin on cyt $\mathrm{c}$................................. 37

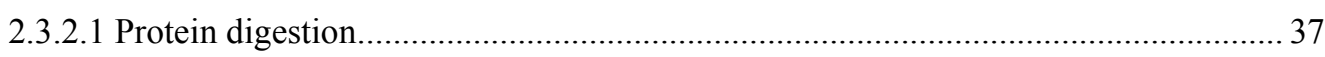

2.3.2.2. Determination of the primary binding site from Fragment \#1 and Fragment \#2 ..... 41

2.3.2.3. Identification of Fragment \#3 and Fragment \#4 ................................................... 46

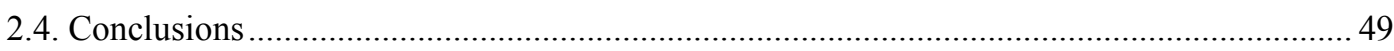




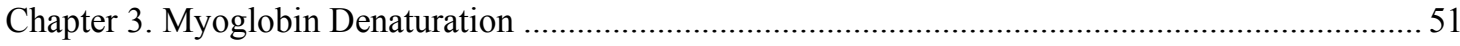

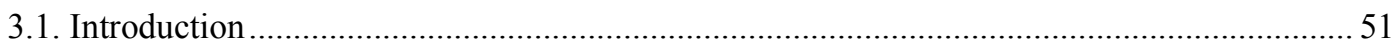

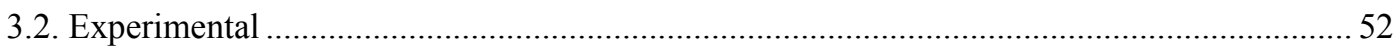

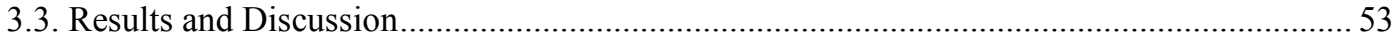

3.3.1. Tryptic digestion of free $\mathrm{Mb}$ under native conditions ............................................. 53

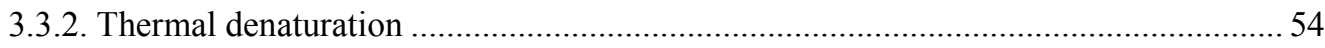

3.3.3. Protein denaturation by a mixed methanol-aqueous solvent ................................. 57

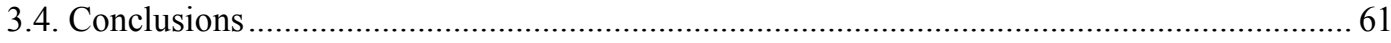

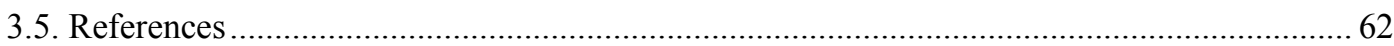

Chapter 4. A Mass Spectrometric Comparison of the Interactions of Cisplatin and Transplatin with

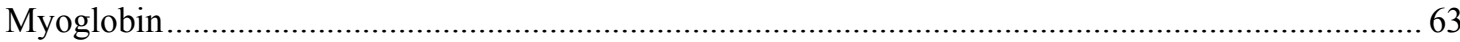

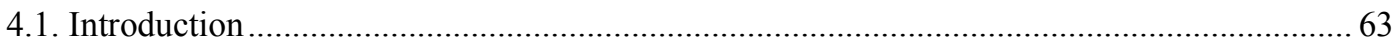

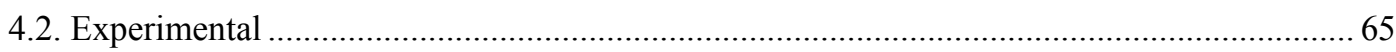

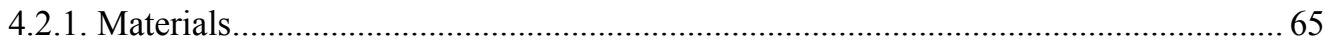

4.2.2. The kinetics studies of Mb-cisplatin and Mb-transplatin interactions....................... 66

4.2.3. The digestion of Mb-cisplatin and Mb-transplatin adducts ..................................... 67

4.2.4. Reactions of the Mb-cisplatin and Mb-transplatin adducts with 5'-GDP ................. 67

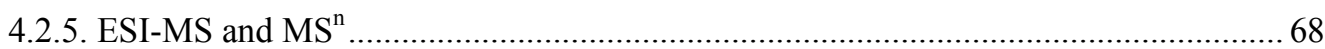

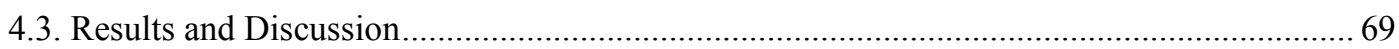

4.3.1. The kinetics of the Mb-cisplatin and Mb-transplatin interactions............................ 69

4.3.2. The Mb-cisplatin and Mb-transplatin adducts................................................... 71

4.3.3. Determination of the cisplatin and transplatin binding sites on $\mathrm{Mb}$........................... 73

4.3.3.1. The digestion of the Mb-cisplatin and Mb-transplatin adducts ............................. 73

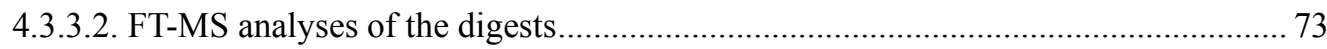

4.3.3.3. Identification of the peptide sequence of the $1313.27^{5+}$ ion.................................. 79

4.3.3.4. Determination of the $\mathrm{Pt}\left(\mathrm{NH}_{3}\right)$ binding site on His97-Gly153 .............................. 84

4.3.3.5. The assignment of the residues coordinated to $\mathrm{Pt}\left(\mathrm{NH}_{3}\right)$ in the HSKH residues....... 88

4.3.4. The stability of the Mb-cisplatin and the Mb-transplatin adducts............................. 90

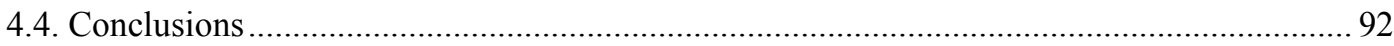

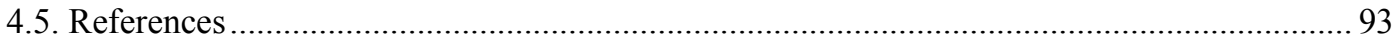

Chapter 5. A Mass Spectrometric Comparison of the Binding Sites of Cisplatin on Native and Denatured Ub: Evidence of the Effect of Protein Conformation on Protein Platination...................... 94

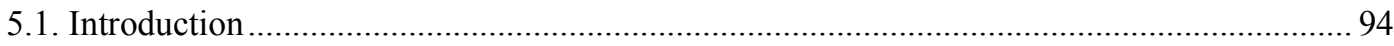

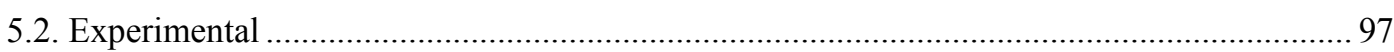


5.2.1. Materials 97

5.2.2. Formation of native and denatured Ub-cisplatin adducts ...................................... 97

5.2.3. Trypsin digestion of the Ub-cisplatin adducts ....................................................... 98

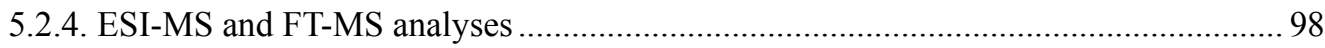

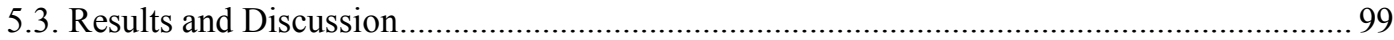

5.3.1. Formation of the Ub-cisplatin adducts under the native and denatured conditions .... 99 5.3.2. Determination of the cisplatin binding sites on $\mathrm{Ub}$ under the native and denatured

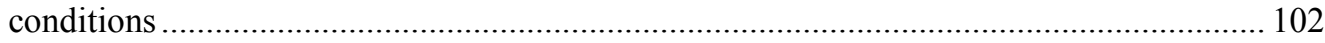

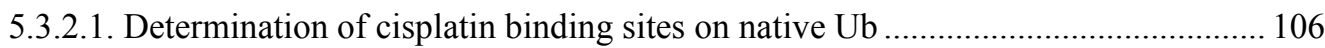

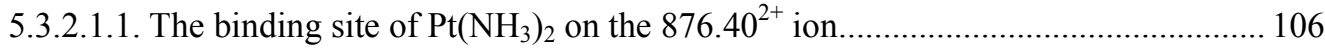

5.3.2.1.2. The binding sites of $\mathrm{Pt}\left(\mathrm{NH}_{3}\right)$ on the $975.41^{+}$ion........................................... 109

5.3.2.1.3. The $\operatorname{Pt}\left(\mathrm{NH}_{3}\right)_{2}$ binding sites on the $1008.47^{2+}$ ion.......................................... 110

5.3.2.2. Determination of the cisplatin binding site on denatured $\mathrm{Ub}$.............................. 112

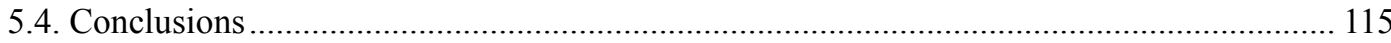

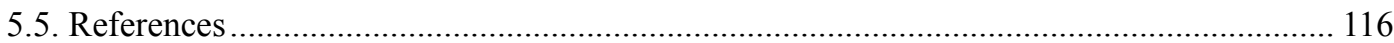

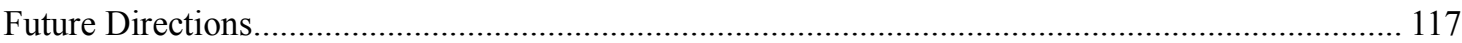




\section{List of Figures}

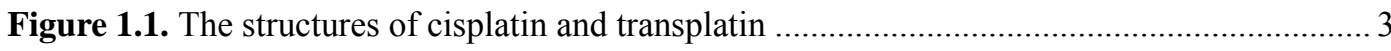

Figure 1.2. The structures of (A) an amino acid and (B) a tripeptide........................................... 4

Figure 1.3. The 3-D structure of cyt $\mathrm{c}$ and the structure of the heme group.................................. 7

Figure 1.4. The $\mathrm{Mb}$ structure $(\mathrm{A}) \mathrm{The} 3-\mathrm{D}$ structure of $\mathrm{Mb}$ in which the polypeptide is blue and the heme group is red. (B) The structure of the active site when $\mathrm{CO}$ binds to $\mathrm{Fe}$ in the heme

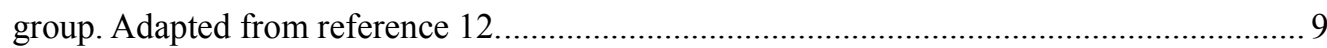

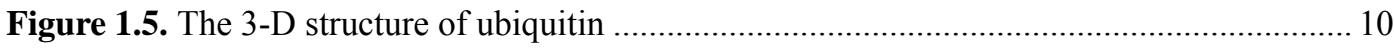

Figure 1.6. Schematic of the ESI processes, adapted from reference 19................................... 13

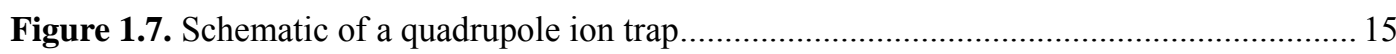

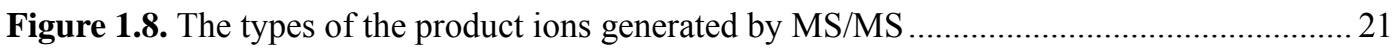

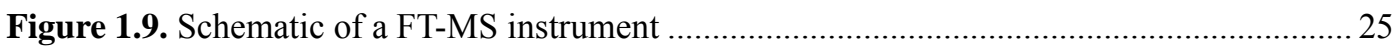

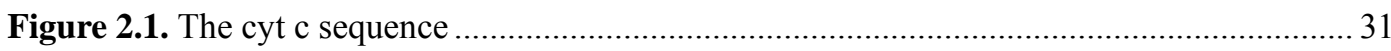

Figure 2.2. The percentage of cyt c- $\mathrm{Pt}\left(\mathrm{NH}_{3}\right)_{2}\left(\mathrm{H}_{2} \mathrm{O}\right)$ in three cyt c-cisplatin solutions: ( $\bullet$ ) 1:4 cyt c:cisplatin; ( 1 ) 1:8 cyt c: cisplatin; $(\bullet)$ 1:12 cyt c:cisplatin at different time intervals over 30 hours.

Figure 2.3. Deconvoluted ESI-MS spectra of free cyt $\mathrm{c}$ and the cyt c-cisplatin adducts obtained by incubating cyt $\mathrm{c}$ and cisplatin at different molar ratios for $24 \mathrm{~h}$ under native conditions. The assignment of individual peaks: A) cyt c; B) cyt c- $\mathrm{H}_{2} \mathrm{O}$; C) cyt c- $\left(\mathrm{H}_{2} \mathrm{O}\right)_{2} ; \ldots \ldots \ldots \ldots \ldots \ldots . . . . . . . .36$

Figure 2.4. The FT-MS spectrum of the free cyt $\mathrm{c}$ digest.............................................................. 39

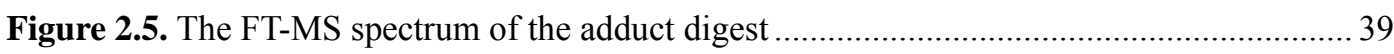

Figure 2.6. The product-ion spectrum of the MS/MS analysis of the $1507.777^{4+}$ ion and zoom scans of the product ions $1456.27^{2+}$ and $1558.18^{2+}$

Figure 2.7. The product-ion spectrum of the $\mathrm{MS}^{3}$ analysis of the $1507.777^{4+}$ ion at $\mathrm{m} / \mathrm{z} 1456.27$. The peptide sequence of the $1456.27^{2+}$ ion : (Met80-Glu104) MIFAGIKKKTEREDLI AYL KKA

Figure 2.8. The product-ion spectrum of the $\mathrm{MS}^{3}$ analysis of the $1507.777^{4+}$ ion at $\mathrm{m} / \mathrm{z}$ 1558.18 The peptide sequence of the $1558.18^{2+}$ ion: (Gly56-Lys79) GITWKEETLMEYLENPKKY IPGTK

Figure 2.9. The product-ion spectrum of the MS/MS analysis of the $1568.311^{4+}$ ion and zoom scan of the product ion $1679.27^{2+}$ 
Figure 2.10. The product-ion spectrum of the MS/MS analysis of the $1275.037^{5+}$ ion. The peptide sequence of the $1275.037^{5+}$ ion: (Acetyl-Gly1-Lys53) Acetyl-GDVEKGKKIFVQKCA QCHTVEKGGKHKTGPNLHGLFGRKTGQAPGFTYTDANK

Figure 2.11. The product-ion spectrum of the MS/MS analysis of the $1323.463^{5+}$ ion. The peptide sequence of the $1323.463^{5+}$ ion: (Acetyl-Gly1-Lys55) Acetyl-GDVEKGKKIFVQKCAQ CHTVEKGGKHKTGPNLHGLFGRKTGQAPGFTYTDANKNK 48

Figure 3.1. The native $\mathrm{Mb}$ digest after tryptic digestion for $21 \mathrm{~h}$ 54

Figure 3.2. The free $\mathrm{Mb}$ digest obtained by trypsin digestion for $17 \mathrm{~h}$ after thermal denaturation 56

Figure 3.3. The Mb-cisplatin adduct digest obtained by trypsin digestion for $17 \mathrm{~h}$ after thermal denaturation 56

Figure 3.4. The $\mathrm{Mb}$ digest obtained by trypsin digestion after denaturation in a $50 \%$ $\mathrm{MeOH}-25 \mathrm{mM} \mathrm{NH}_{4} \mathrm{HCO}_{3}$ solvent . 59

Figure 3.5. The $\mathrm{Mb}$ digest obtained by trypsin digestion after denaturation in a $60 \%$ $\mathrm{MeOH}-25 \mathrm{mM} \mathrm{NH}_{4} \mathrm{HCO}_{3}$ solvent. 59

Figure 3.6. The $\mathrm{Mb}$ digest obtained by trypsin digestion after denaturation in a $70 \%$ $\mathrm{MeOH}-25 \mathrm{mM} \mathrm{NH}_{4} \mathrm{HCO}_{3}$ solvent

Figure 3.7. The $\mathrm{Mb}$ adduct digest obstained by trypsin digestion after solvent denaturation with a $70 \% \mathrm{MeOH}-25 \mathrm{mM} \mathrm{NH}_{4} \mathrm{HCO}_{3}$ solvent

Figure 4.1. The structures of cisplatin, transplatin, guanosine 5'-monophosphate, and the $\mathrm{Mb}$ sequence. 66

Figure 4.2. The kinetics plots for the Mb-cisplatin and Mb-transplatin solutions obtained by monitoring the percentages of the $\mathrm{Mb}$ species in the respective solutions as a function of time:(a) The Mb-cisplatin solution; (b) The Mb-transplatin solution .71

Figure 4.3. Deconvoluted ESI-QITMS spectra of free $\mathrm{Mb}$ and the Mb-cisplatin and $\mathrm{Mb}$-transplatin adducts obtained by reacting $\mathrm{Mb}$ with cisplatin and transplatin for 27 hours 72

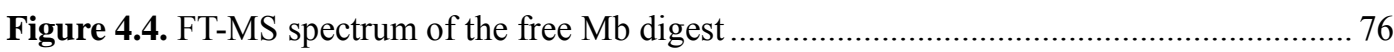

Figure 4.5. FT-MS spectrum of the Mb-cisplatin adduct digest................................................ 76

Figure 4.6. FT-MS spectrum of the Mb-transplatin adduct digest................................................. 76

Figure 4.7. Expanded FT-MS spectrum of the free Mb digest ........................................................ 77

Figure 4.8. Expanded FT-MS spectra of the Mb-cisplatin digest ................................................. 77

Figure 4.9. Expanded FT-MS spectra of the Mb-transplatin digest.............................................. 77

Figure 4.10. The product-ion spectrum of the $1313.27^{5+}$ ion. The peptide sequence of the $1313.27^{5+}$ ion: (His97-Gly153) HKIPIKYLEFISDAI IHVLHSKHPGDFGADAQGAMTK

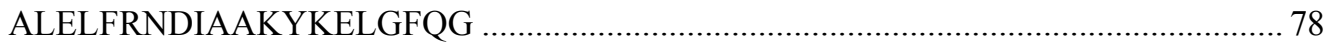


Figure 4.11. The product-ion spectrum of the $1316.68^{5+}$ ion. The peptide sequence of the $1316.68^{5+}$ ion: (His97-Gly153) HKIPIKYLEFISDAIIHVLHSKHPGDFGADAQGAMTK ALELFRNDIAAKYKELGFQG

Figure 4.12. The product-ion spectrum of the $\mathrm{MS}^{3}$ analysis of the $1313.27^{5+}$ ion at the $\mathrm{y}_{27}{ }^{2+}$ ion. The peptide sequence of the $y_{27}{ }^{2+}$ ion: AQGAMTKALELFRNDIAAKYKELGFQG ..........8 80

Figure 4.13. The product-ion spectrum of the $\mathrm{MS}^{3}$ analysis of the $1313.27^{5+}$ ion at the $\mathrm{y}_{31}{ }^{2+}$ ion. The peptide sequence of the $\mathrm{y}_{31}{ }^{2+}$ ion: FGADAQGAMTKALELFRNDIAAKYKELGFQG

Figure 4.14. The product-ion spectrum of the $\mathrm{MS}^{3}$ analysis of the $1313.27^{5+}$ ion at the $\mathrm{y}_{34}{ }^{2+}$ ion. The peptide sequence of the $\mathrm{y}_{34}{ }^{2+}$ ion: PGDFGADAQGA MTKALELFRNDIAAKYKEL GFQG 81

Figure 4.15. The isotope distributions of the $1542.00^{4+}$ and $1570.45^{4+}$ ions in Figure $4.10 \ldots \ldots \ldots . .83$

Figure 4.16. The product-ion spectrum of the $\mathrm{MS}^{3}$ analysis of the $1313.27^{5+}$ ion at $\mathrm{m} / \mathrm{z} 1542.00$. The peptide sequence of the $1542.00^{4+}$ ion: PIKYLEFISDAIHVLHSKHPGDFGADA QGAMTKALELFRNDIAA KYKELGFQG

Figure 4.17. The product-ion spectrum of the $\mathrm{MS}^{3}$ analysis of the $1313.27^{5+}$ ion at $\mathrm{m} / \mathrm{z} 1570.45$. The peptide sequence of the $1570.45^{4+}$ ion: IPIKYLEFISDAIIHVLHSKHPGDFGAD AQGAMTKALELFRNDIAAKYKELGFQG

Figure 4.18. The isotope distribution of the $972.15^{3+}$ ion and the $\mathrm{MS}^{3}$ analysis of the $1313.27^{5+}$ ion at $\mathrm{m} / \mathrm{z}$ 972.15. The peptide sequence of the $972.15^{3+}$ ion: (His97-His119) HKIPIKYLEFISD AIIHVLHSKH

Figure 4.19. The isotope distribution of the $1444.45^{3+}$ ion and the $\mathrm{MS}^{3}$ analysis of the $1313.27^{5+}$ ion at $\mathrm{m} / \mathrm{z} 1444.45$ and. The peptide sequence of the $1444.45^{3+}$ ion: (His116-Gly153) HSKHPGDFGADAQGAMTKALELFRNDIAAKYKELGFQG

Figure 4.20. The Ribbon diagram of the 3-D structures of the Mb polypeptide chain under native conditions with the side chains of the HSKH residues displayed ${ }^{12}$..... 89

Figure 4.21. The percentage of each $\mathrm{Mb}$ species after reacting the Mb adducts with 5'-GMP for different hours over 3 days: (a) The reaction of Mb-cisplatin adducts with 5'-GMP; (b) The reaction of Mb-transplatin adducts with 5'-GMP . .91

Figure 5.1. The Ub sequence 97

Figure 5.2. The percentages of the formed Ub-cisplatin monoadducts under the native and denatured conditions in 30 hours 100

Figure 5.3. The deconvoluted ESI mass spectra of the Ub monoadducts yielded by the Ub-cisplatin interactions under native and denatured conditions over $12 \mathrm{~h}$ and $24 \mathrm{~h}$, respectively. Peak assignment: (a) free Ub; (b) Ub-Pt; (c) Ub-Pt( $\left(\mathrm{NH}_{3}\right)$; (d) $\mathrm{Ub}-\mathrm{Pt}\left(\mathrm{NH}_{3}\right)_{2}$; (e) $\mathrm{Ub}-\mathrm{Pt}\left(\mathrm{NH}_{3}\right)_{2}\left(\mathrm{H}_{2} \mathrm{O}\right)$; (f) Ub-Pt $\left(\mathrm{NH}_{3}\right)_{2}\left(\mathrm{H}_{2} \mathrm{O}\right)_{2} ;$ (g) Ub-Pt $\left(\mathrm{NH}_{3}\right)\left(\mathrm{CH}_{3} \mathrm{CO}_{2}\right)$. 102 


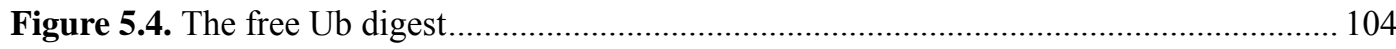

Figure 5.5. The digest of the Ub adduct obtained under the native conditions .......................... 104

Figure 5.6. The digest of the $\mathrm{Ub}$ adduct obtained under the denatured conditions ..................... 104

Figure 5.7. The isotope distributions of three Pt-compound containing fragments, the $876.40^{2+}$, $975.41^{+}$, and $1008.47^{2+}$ ions, in the native Ub adduct digest.

Figure 5.8. The isotope distributions of three Pt-compound containing fragments, the $975.41^{+}$, $1148.92^{3+}$, and $1631.83^{2+}$ ions, in the denatured Ub adduct digest 106

Figure 5.9. The product-ion spectrum of the MS/MS analysis of the $876.40^{2+}$ ion, overlaid with the isotope distribution of the $977.36^{+}$product ion. The peptide sequence of the $876.40^{2+}$ ion: (I30-R42) IQDKEGIPPDQQR 108

Figure 5.10. The product-ion spectrum of the $\mathrm{MS}^{3}$ analysis of the $876.40^{2+}$ ion at $\mathrm{m} / \mathrm{z} 977.36$. The peptide sequence of the $977.36^{+}$ion: (I30-I36) IQDKEGI 108

Figure 5.11. The product-ion spectrum of the MS/MS analysis of the $975.41^{+}$ion. The peptide sequence of the $975.41^{+}$ion: (M1-K6) MQIFVK 110

Figure 5.12. The product-ion spectrum of MS/MS analysis of the $1008.47^{2+}$ ion, overlaid with the isotope distribution with the product ion $622.18^{+}$. The sequence of the $1008.47^{2+}$ ion: (T12-K27) TITLEVEPSDTIENVK 112

Figure 5.13. The product-ion spectrum of the MS/MS analysis of the $1148.92^{3+}$ ion. The peptide sequence of the $1148.92^{3+}$ ion: M1-K29 MQIFVKTLTGKTITLEVEPSDTIENVKAK ... 113

Figure 5.14. The product-ion spectrum of the MS/MS analysis of the $1623.32^{2+}$ ion. The peptide sequence of the $1623.32^{2+}$ ion: M1-K27 MQIFVKTLTGKTITLEVEPSDTIENVK .......... 114 


\section{List of Table}

Table 2.1. Four new fragments in the FT-MS spectrum of the adduct digest identified by MS/MS and $\mathrm{MS}^{3}$ analyses

40 


\section{Chapter 1. Introduction}

\subsection{Cisplatin}

Cisplatin, cis-diamminedichloroplatinum, is an effective anticancer drug, particularly for testicular and ovarian cancers. It was first synthesized by Michel Peyrone in 1845. But its anti-tumor activity was not discovered until the early $1960 \mathrm{~s}^{1}$, when Barnett Rosenberg studied how an electric field affects bacterial cell growth using a platinum electrode. He found that the cell division stopped but continued to grow. It was concluded that cell division ceased due to the formation of cisplatin produced by the reaction between the Pt electrode and the bacterial solution. This discovery led to the consideration of cisplatin as an anticancer agent. The anticancer activity of cisplatin was tested against mice tumors, from which it was discovered that cisplatin was highly effective in cancer treatment. Cisplatin's use in chemotherapy began in the $1970 \mathrm{~s}^{2}$.

It is believed that the anticancer activity of cisplatin arises from its binding to DNA, thereby interrupting DNA replication and stopping cell division. Intact cisplatin enters the tumor cells mainly by diffusion through the membrane ${ }^{3}$. Studies also indicated that copper-transporting proteins can transport cisplatin into tumor cells ${ }^{4}$. 
Because there is a low chloride concentration inside the tumor cells, the highly reactive complex $\mathrm{Pt}\left(\mathrm{NH}_{3}\right)_{2} \mathrm{Cl}\left(\mathrm{H}_{2} \mathrm{O}\right)^{+}$is produced by displacing one chloride with one water. The highly reactive $\mathrm{Pt}\left(\mathrm{NH}_{3}\right)_{2} \mathrm{Cl}\left(\mathrm{H}_{2} \mathrm{O}\right)^{+}$species usually binds to the $\mathrm{N} 7$ atom on guanine $(\mathrm{G})$ base in DNA. After the remaining chloride is substituted by water, the N7 atom on the adjacent guanine displaces the water and binds to $\mathrm{Pt}$, resulting in the formation of an intrastrand-crosslink DNA-Pt $\left(\mathrm{NH}_{3}\right)_{2}$ adduct. Then, a high mobility group (HMG)-domain protein recognizes the DNA-Pt $\left(\mathrm{NH}_{3}\right)_{2}$ complex and binds to it. The formation of DNA-Pt $\left(\mathrm{NH}_{3}\right)_{2}-\mathrm{HMG}$ adducts cause distortion of the double stranded DNA helix, which stops DNA replication and induces cell apoptosis.

Before reaching DNA, cisplatin interacts with proteins, particularly sulfur containing proteins, in blood plasma due to a high affinity between cisplatin and sulfur-containing species. One day after injection, 65\%-98\% of cisplatin was reported to be associated with blood plasma proteins ${ }^{5}$. Because cisplatin has a high affinity for sulfur-containing proteins, some cisplatin ends up accumulating in non-malignant cells. Such irreversible protein-cisplatin interactions are blamed for side effects of cisplatin. However, studies indicate that the blood plasma proteins might be responsible for transporting cisplatin to its DNA target ${ }^{6}$. The exact role that the cisplatin-blood plasma protein adducts play in cisplatin action remains ambiguous.

Transplatin (trans-diamminedichloroplatinum) ${ }^{7}$ is the geometric isomer of cisplatin. But transplatin has no anticancer activity because the binding of transplatin to DNA cannot form an intrastrand crosslink. Therefore, the HMG-domain protein 
cannot bind to transplatin-modified DNA to stop cell devision.

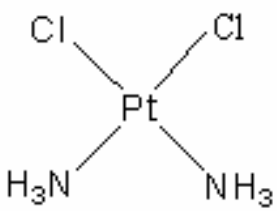

Cisplatin

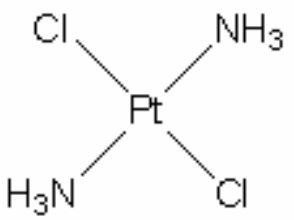

Transplatin

Figure 1.1. The structures of cisplatin and transplatin

\subsection{Amino acids, peptides and proteins}

There are 20 amino acids, the general structures of which are shown in Figure 1.2. All of the amino acids have three common components: a primary amino group, a carboxylic acid, and a central carbon with an attached hydrogen atom. The difference in the structures of the amino acids lies only in the structure of their side chains $(\mathrm{R})$. Therefore, the properties of amino acids are determined by their side chains ${ }^{8}$.

Proteins and peptides are linear polymers of the amino acid residues, connected by peptide bonds formed by condensation reactions between the amino group of one amino acid and the carboxylic group of the adjacent amino acid. Peptides consist of two or more amino acid residues, and proteins consist of one or more peptides with a total number of amino acid residues ranging from 40 to 4000 . Figure 1.2. shows the 
structure of a tripeptide. The amino acid residues in the middle of the peptide chain are linked to neighbors by two peptide bonds. Two amino acids at the two terminals form only one peptide bond. The terminal residue with the free amino group is called the $\mathrm{N}$ terminus of the peptide and the terminal residue with the free carboxylic acid is called the $\mathrm{C}$ terminus of the peptide. The direction of polypeptide chains is defined from the $\mathrm{N}$ terminus to the $\mathrm{C}$ terminus.

(A)<smiles>[R]C(N)C(=O)O</smiles>

(B) $\mathrm{N}$ terminus<smiles>[R3]C(N)C(=O)NC([R9])C(=O)NC([R3])C(=O)OCc1ccccc1</smiles>

Figure 1.2. The structures of (A) an amino acid and (B) a tripeptide

\subsubsection{Protein structures}

Proteins carry out various functions in biological processes, such as catalyzing biochemical reactions, transporting and storing biologically important molecules, serving as messengers in signal transduction, and so on. The function of a protein is dictated by its structure, described by a four-level hierarchy ${ }^{9}$ :

A protein's primary structure is the amino acid sequence from the $\mathrm{N}$ terminus to the $\mathrm{C}$ terminus. The primary structure of each protein dictates its higher order protein structure.

A protein's secondary structure describes the spatial arrangement of the atoms on the polypeptide backbones. Hydrogen bonds are formed between $\mathrm{NH}$ and $\mathrm{C}=\mathrm{O}$ on the 
protein backbone in order to stabilize the structure of the protein. $\alpha$-Helices and $\beta$ sheets are the most common spatial backbone arrangement caused by the formation of the hydrogen bond. On the same peptide chain, the hydrogen bonds are formed by interactions of the $\mathrm{C}=\mathrm{O}$ group on the $\mathrm{nth}$ amino acid residue with the $\mathrm{N}-\mathrm{H}$ group on the $(n+4)$ th amino acid residue. Such hydrogen bonds drive the entire backbone to fold into an $\alpha$-helix. $\beta$-Sheets are formed due to the hydrogen bonding of N-H and $\mathrm{C}=\mathrm{O}$ groups on the backbone of adjacent polypeptide chains. Comparing the direction of polypeptide chains, $\beta$-sheets are divided into anti-parallel $\beta$-sheets and parallel $\beta$-sheets.

The tertiary structure of a protein describes the folding of the entire polypeptide chain including the side chains, driven by hydrophobic force. Non-polar side chains are folded inside the hydrophobic core and the polar residues are exposed to the protein surface. In biological systems, water-soluble proteins are folded in such a way that the hydrophobic side chains are buried inside the protein and the hydrophilic side chains are exposed at the surface.

The quaternary structure is the arrangement of two or more polypeptides in a protein. The quaternary structure is stabilized by noncovalent interactions between polypeptide chains.

\subsubsection{Cytochrome c (cyt c)}

Cyt $\mathrm{c}$ is a small hemoprotein attached to a mitochondrial membrane. It serves as an electron transfer protein by transporting electrons from one complex to another complex embedded inside the membrane. During electron transfer, cyt $\mathrm{c}$ is either 
oxidized or reduced. Therefore, cyt c plays an important role in the processes that involve energy production and electron transfer reactions in cells such as mitochondrial respiration.

Horse heart cyt $\mathrm{c}$ is a well-characterized protein due to its small size (M.W. $12386 \mathrm{Da})$ and high solubility in water. The heme is the prosthetic group of cyt c, consisting of an iron atom and a porphyrin, a highly conjugated organic molecule coordinated to the iron atom. During electron transfer, cyt $\mathrm{c}$ is oxidized by converting $\mathrm{Fe}$ (II) to $\mathrm{Fe}$ (III), and vice versa in the reduction of cyt $\mathrm{c}$.

The three dimensional (3-D) structure of horse heart cyt $\mathrm{c}$ and the structure of the heme are shown in Figure 1.3. ${ }^{10}$. The heme is covalently linked to cyt $\mathrm{c}$ by formation of two thioether bonds between two vinyl groups on porphyrin and the side chains of two cysteine residues (Cys14 and Cys17) on cyt c. The formed thioether covalent bonds stabilize the heme group at the protein surface for electron transfer. The central iron atom in the heme group coordinates to six ligands, among which four are the nitrogen atoms on the porphyrin ring and two are amino acid residues from cyt c at the axial position including one immidazole nitrogen of His18 and one sulfur atom of Met80. 

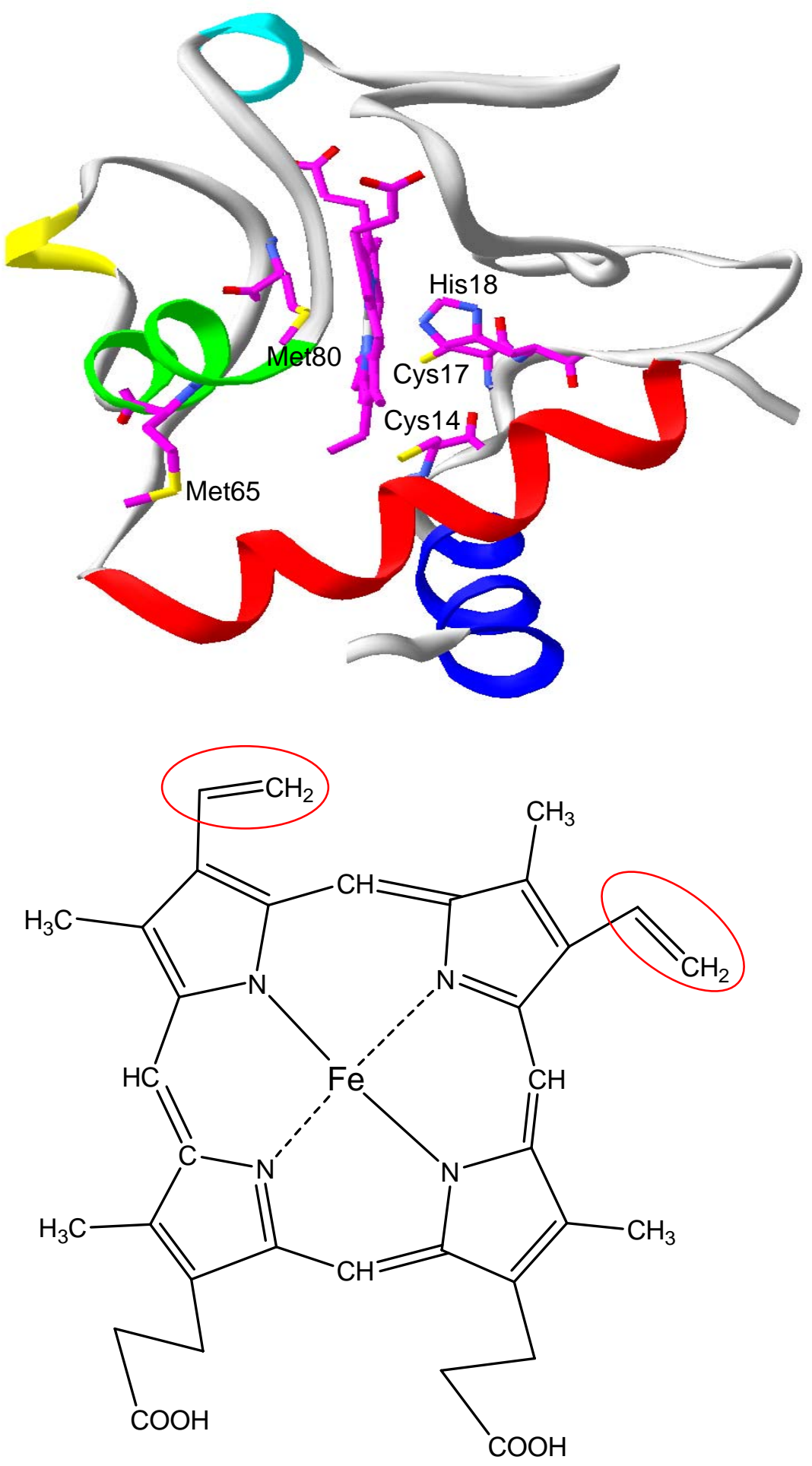

Figure 1.3. The 3-D structure of cyt $c$ and the structure of the heme group ${ }^{10} 11$ 


\subsubsection{Myoglobin (Mb)}

$\mathrm{Mb}$ is ared hemoprotein in muscle cells and serves as an $\mathrm{O}_{2}$ reservoir by reversibly binding to $\mathrm{O}_{2}$ and facilitating $\mathrm{O}_{2}$ transportation to mitochondria under anoxic conditions ${ }^{12,13}$. It is a small globular protein and contains a single polypeptide of 153 amino acids and a heme group as the prosthetic group. The Mb backbone is folded into $8 \alpha$-helices labeled A-H and several short loops. The entire polypeptide chain is further folded into a tight globular structure, leaving a pocket at helix C, E and $\mathrm{F}$ for the heme group. The heme group is located between His64 and His93 and held in the pocket by the covalent interaction between His93 and Fe.

In deoxymyoglobin, the iron atom in the heme group only coordinates to 5 ligands, 4 nitrogen atoms on the porphyrin, and 1 nitrogen atom from imidazole of His93 in the axial position. The coordination to His93 pulls the iron atom slightly out of the the porphyrin plane. The other coordination site at the axial position is the potential binding site for $\mathrm{O}_{2}, \mathrm{CO}$, or $\mathrm{NO}$. When $\mathrm{CO}\left(\mathrm{O}_{2}\right.$ or $\left.\mathrm{NO}\right)$ binds $\mathrm{Fe}$, it pulls $\mathrm{Fe}$ back into the porphyrin plane and forms a hydrogen bond with distal His64, shown in Figure 1.4. The change of the Fe position relative to the porphyrin plane suggests the binding of $\mathrm{O}_{2}$ involves a conformational change of $\mathrm{Mb}$. 

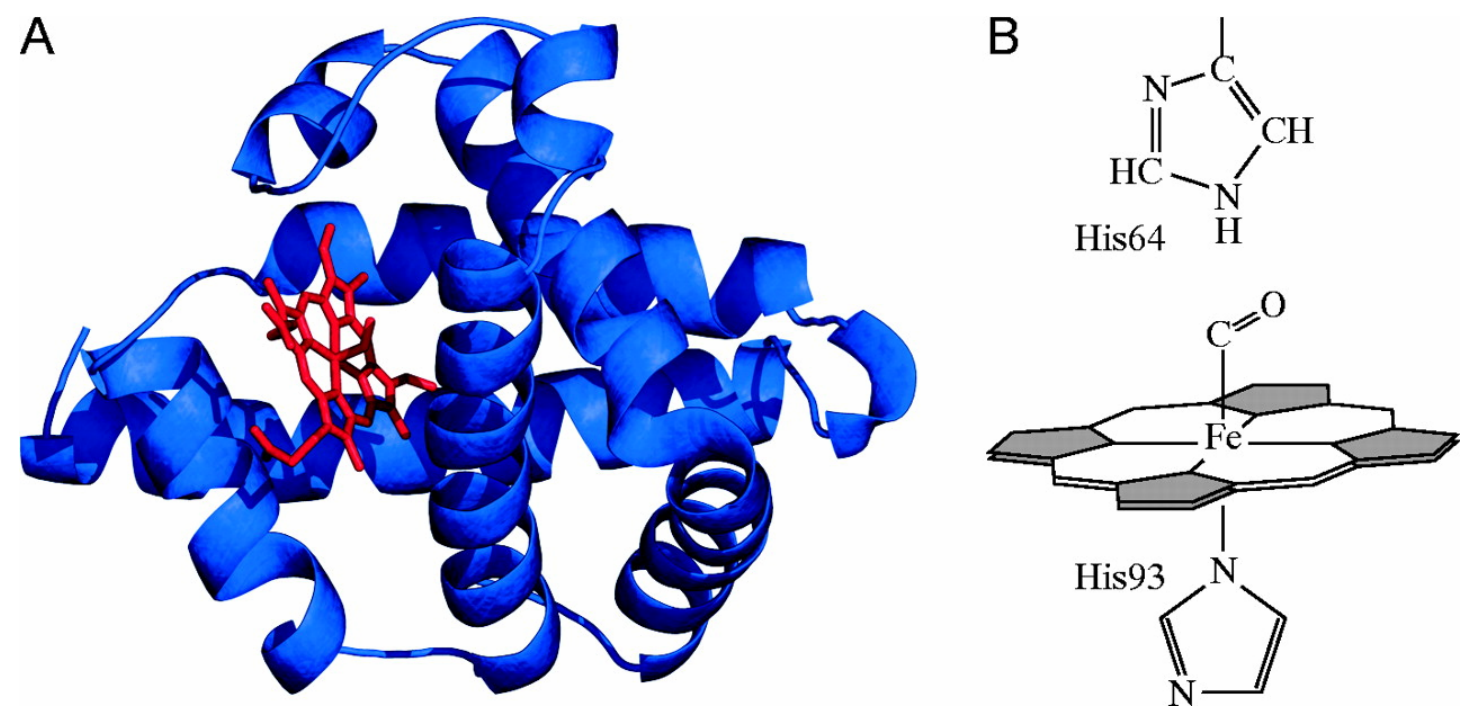

Figure 1.4. The Mb structure $(A)$ The 3-D structure of $M b$ in which the polypeptide is blue and the heme group is red. (B) The structure of the active site when $\mathrm{CO}$ binds to $\mathrm{Fe}$ in the heme group. Adapted from reference 12.

\subsubsection{Ubiquitin (Ub)}

$\mathrm{Ub}{ }^{14,15}$ is a small protein with a molecular weight of $8565 \mathrm{Da}$. It is ubiquitous in eukaryotic cells and can be isolated from a variety of sources. The sequences of ubiquitins from different sources are highly indistinguishable. Humans, bovines, and insects have identical sequences from the first amino acid at the $\mathrm{N}$ terminus to the 74th amino acid residue. Ub carries out many functions within the cell by covalently interacting with target proteins. For example, ubiqutin performs an important role in regulating protein degradation. $\mathrm{Ub}$ can recognize old proteins, selectively bind to them, and form protein-ubiquitin complexes through covalent interactions between the carboxylic group at the $\mathrm{C}$ terminus of ubiquitin and the amino group of the lysine residue in the target protein. The formation of these complexes indicates that the cell 
is ready to degrade.

$\mathrm{Ub}$ is a small protein of a single polypeptide with 76 amino acids. The polypeptide backbone is folded into $2 \alpha$-helices and $5 \beta$-strands, and a few turns and coils, which are shown in Figure 1.5. The entire polypeptide chain is tightly folded by hydrogen bonding. Ub is very stable and resistant to proteolysis under extreme conditions.

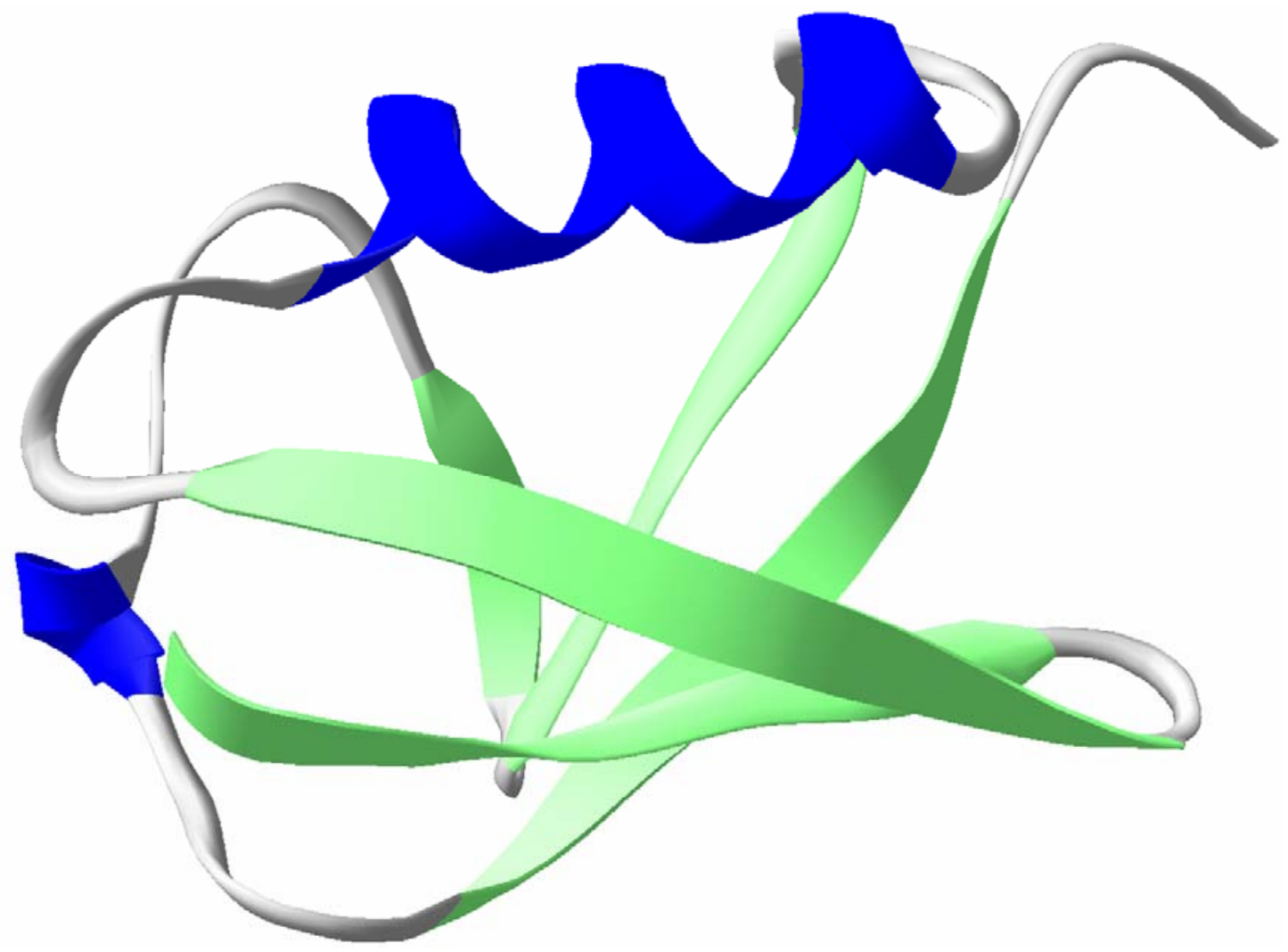

Figure 1.5. The 3-D structure of ubiquitin ${ }^{16}$ 


\subsection{Mass spectrometry}

A mass spectrometer primarily includes three parts: an ionization source to produce ions in the gas phase, a mass analyzer to separate the ions by their mass to charge ratio $(\mathrm{m} / \mathrm{z})$, and a detector to measure the abundance of the separated ions. The features of a mass spectrometer are always described by its ionization source and mass analyzer. In this dissertation, electrospray ionization is used as the ionization source to ionize proteins, peptides, and protein-Pt metallodrug adducts. The resultant ions undergo mass analysis in either quadrupole ion trap or Fourier transform mass spectrometry systems.

\subsubsection{Electrospary ionization (ESI)}

ESI is an ionization technique used to transfer ions directly from aqueous solution into the gas phase. Since its introduction by Yamashita and Fenn in $1984^{17,18}$, it has become the most important technique in biological mass spectrometry because of its ability to ionize thermally labile molecules. A high voltage $(2-5 \mathrm{kV})$ is applied to a metal capillary, which is placed 1-3 $\mathrm{cm}$ away from the grounded ion sampling orifice of a mass spectrometer. Because the tip of the metal capillary is very thin, an extremely strong electric field is created at the capillary tip when the high voltage is applied. This electric field $\left(\mathrm{E}_{\mathrm{c}}\right)$ can be estimated by Equation (1) 


$$
E_{c}=\frac{2 V_{c}}{r_{c} \ln \left(4 d / r_{c}\right)} \quad \text { Equation (1) }
$$

Where $\mathrm{V}_{\mathrm{c}}$ is the applied voltage, $\mathrm{r}_{\mathrm{c}}$ is the radius of the metal capillary, and $\mathrm{d}$ is the distance of the tip to the orifice of the mass spectrometer. If a voltage of $4 \mathrm{kV}$ is applied to a metal capillary $\left(r_{c}=10^{-4} \mathrm{~m}\right)$ and there is a distance of $0.03 \mathrm{~m}$ from the capillary tip to the counter electrode, an electric field of $10^{7}$ volts $/ \mathrm{m}$ is generated according to Equation 1.

Either positive or negative voltages can be applied to the capillary; the polarity is determined by the nature of the analyte. Because proteins and peptides are analyzed under the positive mode in this dissertation, the positive mode is used to describe the mechanism of ESI for this work ${ }^{19}$.

Figure 1.6. shows the schematic of the ESI process. An analyte solution is pumped through a silica capillary, which is in contact with the metal capillary, at a flow rate of $(0.1-10 \mathrm{uL} / \mathrm{min})$. When the positive voltage $(2-5 \mathrm{kV})$ is applied to the metal capillary, the electric field will penetrate into the solution. Under the influence of the electric field, positively charged ions in the solution will drift down the field and toward the meniscus of the solution at the capillary tip. Negatively charged ions will drift away from the capillary tip. Because of the accumulation of the positive ions at the capillary tip, the coulombic repulsion between the positively charged ions will force the liquid surface of the meniscus to expand and form a "Taylor cone" ${ }^{20}$. If the electric field is high enough, the surface tension is overcome and a fine jet with small 
charged droplets will emerge as the cone breaks down. In commercial instruments, droplet formation is assisted by using a sheath gas around the capillary tip. The sheath gas also aids in solvent evaporation and droplet shrinkage. As the droplets shrink by evaporation, the coulombic repulsion overcomes the surface tension, leading to the droplets' fission into smaller droplets. This repeated evaporation and fission process produces very small charged droplets $(<10 \mathrm{~nm}$ in diameter). The origin of gas phase ions from the small droplets is still in debate. Two mechanisms, ion evaporation mechanism (IEM) and charged residue mechanism (CRM), are used to describe the process.

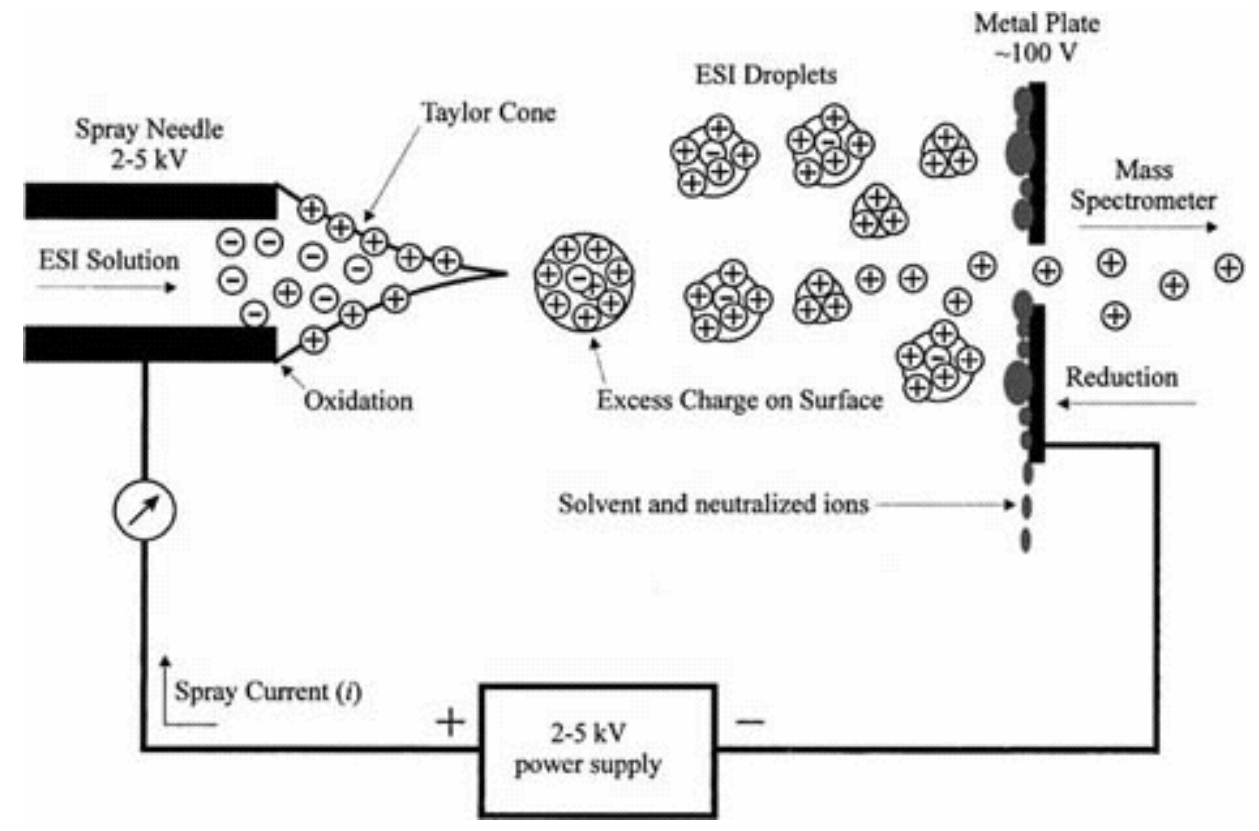

Figure 1.6. Schematic of the ESI processes, adapted from reference 19

IEM was formulated by Iribarne and Thomson ${ }^{21,22}$ based on transition state 
theory. In a droplet, the coulombic repulsion of the other ions to the escaping ion and the attraction of the polar solvent to the escaping ion are opposed to each other at the transition state. Once the coulombic repulsion can overcome the attraction, the ions can be directly emitted from very small droplets with radii less than $10 \mathrm{~nm}$. Dole and his coworkers ${ }^{23}$ proposed CRM, which states that the gas phase ion is yielded by continuous droplet shrinkage and fission due to coulombic repulsion. These two mechanisms are useful to explain some results but the mechanism of ESI of is still under investigation.

\subsubsection{Quadrupole ion trap (QIT)}

The quadrupole ion trap (QIT) was introduced by Paul and Steinwedel in $1960^{24}$, but it did not find widespread use until the 1980s. QIT is considered the workhorse of biochemical research because of its mechanical and operational simplicity, simple vacuum requirement, ruggedness, high sensitivity, and compatibility with different ionization sources ${ }^{25}$.

A schematic representation of QIT is displayed in Figure 1.7. As shown in Figure 1.7, the QIT consists of two hyperbolic endcaps and one donut-shaped ring electrode. $r$ is the radial direction of the QIT and is defined as the distance from the center of the ion trap to the closest point on the ring electrode. $\mathrm{z}$ represents the axial direction and is the distance from the center of the QIT to the endcaps. Both endcaps have one hole in the center. One is for ion injection and the other is for ion ejection ${ }^{26}$. 


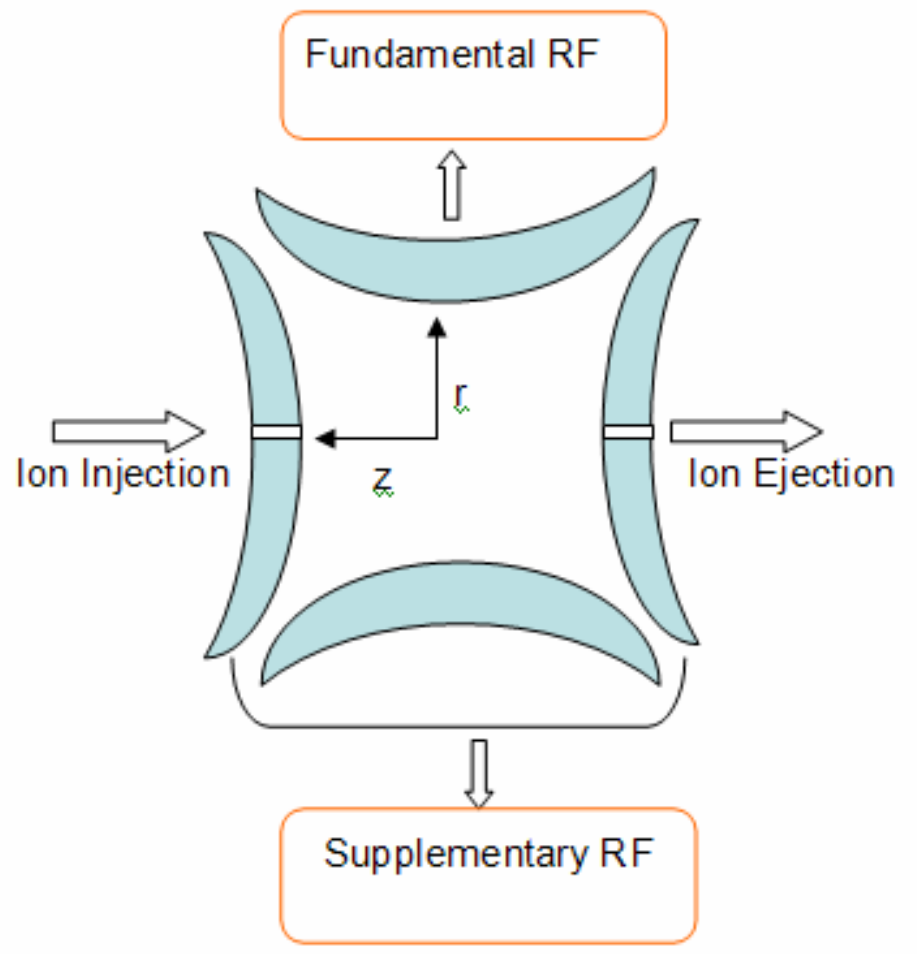

Figure 1.7. Schematic of a quadrupole ion trap

In the application of a QIT as a mass analyzer, a fundamental RF with a fixed frequency is applied to the ring electrode and an electric field that traps the ions is generated. The strength of the electric field is linearly related to the distance to the center of the QIT, i.e. the center has the weakest electric field but the electric field increases in strength toward the edges of the QIT. For this reason, ions at the center experience a weak electric field, but ions at the edges experience a much stronger force which drives the ions toward the center.

The motion of an ion in the QIT is described by the Mathieu equation. From the 
Mathieu equation, two parameters $\left(\mathrm{a}_{\mathrm{u}}\right.$ and $\mathrm{q}_{\mathrm{u}}$ ) are obtained and used to describe the stability of the ion in both $\mathrm{z}$ and $\mathrm{r}$ directions. Because only an RF potential is applied to the ring electrode in commercial instruments, the stability of the ion is described by $\mathrm{q}_{\mathrm{z}}$, which is shown in Equation $2^{26}$. Ions with $\mathrm{q}_{\mathrm{z}}<0.908$ can be trapped.

$$
q_{z}=-2 q_{r}=\frac{8 e V}{m\left(r^{2}+2 z^{2}\right) \Omega^{2}} \quad \text { Equation (2) }
$$

In equation $2, \mathrm{~m}$ is the mass of the ion; $\mathrm{e}$ is the charge of the ion; $\mathrm{r}$ and $\mathrm{z}$ refer to the distance from the center to the ring electrode and to the endcaps along the radial and axial direction, respectively; $\Omega$ and $\mathrm{V}$ are the frequency and the amplitude of the fundamental RF voltage. In reality, $r, z$, and $\Omega$ are fixed. The stability of the ion is determined by $\mathrm{V}$ and $\mathrm{m} / \mathrm{z}$ of the ions. the mass range of the trapped ions is determined by the RF amplitude in Equation 2.

During ion injection, the high kinetic energy of the injected ions leads to ion spread and even direct ejection of the ions. $1 \mathrm{mTorr}$ He is used in the QIT to dampen the kinetic energy of the injected ions by collisional cooling ${ }^{27}$, thereby improving the injection efficiency and the resolution of the QIT. Meanwhile, the number of ions that can be placed in the trap is limited because of space-charge effects. If the trap is over-filled, the ions will repel each other, which will spread out the ion cloud and destroy the resolution of the QIT. On the other hand, insufficient ion loads will result in weak signals. Ion accumulation for low abundance ions is performed over a longer time period in the ion trap in order to increase the number of ions in the QIT and improve detection signals before ion ejection. 
The ions are ejected by mass selective instability ${ }^{28}$ and resonance ejection ${ }^{29}$ for mass analysis. In mass selective instability, the ions are sequentially ejected out of the trap from low to high mass by ramping the RF amplitude. The ions with a large $\mathrm{m} / \mathrm{z}$ require a large RF voltage to be destabilized. In reality, there is an upper limit to the $\mathrm{RF}$ amplitude such that only ions $<\mathrm{m} / \mathrm{z} 650$ can be ejected, otherwise electric breakdown occurs in the trap.

Ions $>\mathrm{m} / \mathrm{z} 650$ are ejected by resonance ejection. In the QIT, each ion has a unique secular frequency, which describes the periodicity of its motion inside the trap. The secular frequency of each ion will change as the RF amplitude changes. If the secular frequency of an ion is in resonance with the amplitude of the supplementary $\mathrm{RF}$, the ion will gain kinetic energy and exit the trap. Thus, resonance ejection is performed by ramping the RF amplitude of the supplementary RF voltage to eject ions. The employment of resonance ejection significantly increases the mass range of the QIT.

\subsubsection{Tandem mass spectrometry (MS/MS) and multiple stages of mass spectrometry $\left(\mathrm{MS}^{\mathrm{n}}\right)$ in an ion trap}

MS/MS and $\mathrm{MS}^{\mathrm{n}}$ provide structural information for a parent ion ${ }^{30}$. Two stages of mass analysis are involved in MS/MS in an ion trap. The first stage isolates the parent ion and the second stage analyzes the product ions after ion activation. In the ion trap, the ions are often activated by collision induced dissociation (CID) ${ }^{31}$, in which ions 
are forced to collide with neutral gas atoms or molecules, frequently the damping gas He, by applying a supplemental potential to the ion trap. The kinetic energy of the parent ion is converted into internal energy during CID, leading to ion fragmentation in the gas phase. If this process is repeated to provide more structural information of a product ion, it is called $\mathrm{MS}^{3} \cdot \mathrm{MS}^{\mathrm{n}}$ is to repeat ion isolation, ion activation, and mass analysis for multiple times.

$\mathrm{MS} / \mathrm{MS}$ and $\mathrm{MS}^{\mathrm{n}}$ analysis is performed in the ion trap by carrying out each stage of mass analysis sequentially in time ${ }^{26}$. The parent ions are isolated by the combination of mass selective instability and resonance ejection. Once isolated within the ion trap, the parent ion is activated by CID. In CID, a supplementary RF voltage is applied to the endcaps in order to increase the kinetic energy of the parent ion. The applied amplitude of the supplementary RF voltage is smaller than that used to eject the ions out of the trap. Multiple collisions between the accelerated ions with the target gas $(\mathrm{He})$ lead to dissociation of the parent ion and production of fragment ions. The obtained fragment ions are ejected by mass selective instability and resonance ejection for mass analysis. The processes of ion isolation, ion activation, and ion detection can be repeated for the product ions to obtain more structural information. 


\subsubsection{Linear trap quadrupole (LTQ)}

In a LTQ, ions is confined in the axial position by applying stopping potentials at the entrance and the exit of the LTQ ${ }^{32}$. A two dimensional (2-D) electric field is applied to a square array of quarupole rods to confine the ions in the radial direction. Because of the application of the 2-D electric field, the ion motions inside the LTQ are so complex that the motions in the $\mathrm{x}$ and $\mathrm{y}$ directions cannot be described separately. Because there is no sharp boundary between stability and instability, no stability diagram can be used to describe the stability of ions in the LTQ. The ion trajectories and its oscillation frequency strongly depend on the initial conditions of each ion.

The basis for ion trapping, collision cooling, ion excitation, and ion detection in the LTQ is similar to QIT ${ }^{33}$. Ions are trapped at low amplitude of the fundamental RF potential. Helium is used as damping gas to reduce the kinetic energies of the ions and confine the ions in the center of the LTQ. The fundamental RF potential applied to the quadrupoles is ramped to eject ions for ion detection and a supplementary RF potential is applied at the same time to accelerate the ion ejection. In MS/MS, the ions are forced to collide with the target gas He by applying a smaller supplementary RF voltage to induce ion dissociation.

Ion isolation in the LTQ is different from that in QIT. Three voltages including ion isolation waveform voltage, resonance excitation voltage, and resonance ejection voltage are applied to the ejection electrodes to eject all unwanted ions. Because the LTQ has a larger dimension than a QIT, the LTQ 
provides higher ion injection efficiency and storage capacity, and is less affected by space charge effects than QIT. Moreover, the LTQ is compatible with other mass analyzers such as FT-MS to form hybrid instruments. Collision cooling of the ions in the LTQ before entering FT-MS stabilizes the motion of the ions to provide a more coherent ion packet for injection ${ }^{34}$.

\subsubsection{Identification of covalent modification sites of a protein or peptide by MS/MS and MS ${ }^{\mathrm{n}}$ analyses}

Product-ion spectra obtained from MS/MS analysis of peptides in an ion trap enable peptide sequencing, protein identification, and protein covalent modification site assignment ${ }^{35}$. To acquire the product-ion spectra, proteins are first digested into peptides by site specific enzymes. Trypsin, used most often for such digestion, is an endoproteinase that specifically cleaves the peptide bonds containing lysine (Lys) or arginine (Arg) residues at the $\mathrm{C}$ terminus. Because the average percentage of Lys and Arg in a protein sequence is about $5 \%$ and $6 \%$ respectively, a reasonable amount of peptide fragments can be produced by trypsin digestion. Some of the obtained peptides are multiply charged due to the presence of basic residues Lys and Arg.

The peptide digest is separated by liquid chromatography to increase the resolution of MS and concentrate the analytes before MS/MS analysis of the peptides. If the peptides can be resolved by mass analysis and the sample is sufficient for the entire analysis, the peptide mixture can be introduced by direct infusion and the peptides of interest are isolated and analyzed. 
In QIT, the peptide of interest is isolated by the first stage of mass analysis, followed by CID to fragment the peptide. The obtained product ions are sequentially scanned out and the product-ion spectrum is generated by recording the $\mathrm{m} / \mathrm{z}$ of each fragment ion relative to its intensity in the full mass range.

Figure 1.8. shows six possible types of fragment ions obtained from dissociation at three different positions along the backbone during CID. The sequence obtained from $\mathrm{b}$ ion-series is from the $\mathrm{N}$ terminus to the $\mathrm{C}$ terminus and vice versa for the sequence obtained from the $y$-ion series. Therefore, $b$ ions and y ions obtained from CID are able to provide important sequence information of a peptide. In addition, some fragments caused by the neutral loss of water or ammonia from side chains are often observed in the product-ion spectrum of the peptide. But these ions from neutral losses cannot provide information regarding the peptide sequence.

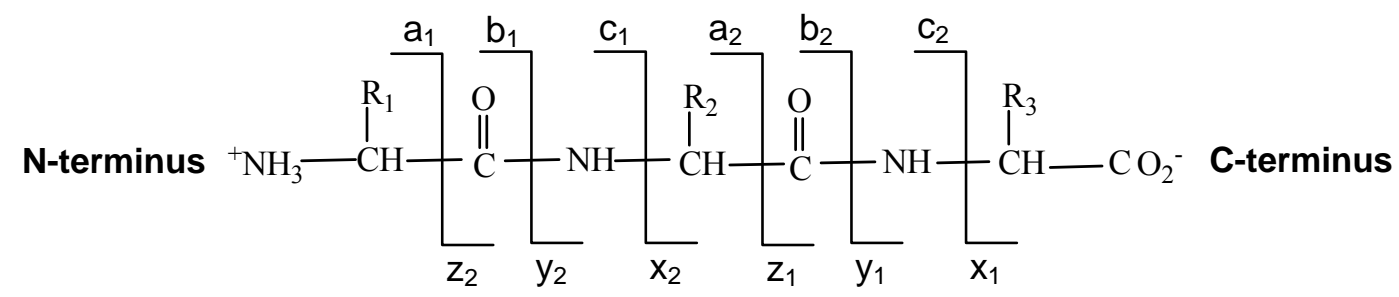

Figure 1.8. The types of the product ions generated by MS/MS

MS/MS and $\mathrm{MS}^{\mathrm{n}}$ analyses of a modified peptide in the ion trap allow for determination of covalent modification to the peptide ${ }^{36}$. The sequence ions containing the covalently modified moieties can be inferred by their mass shift because the modified residues have a common mass shift corresponding to their theoretical mass. 
The exact modified site of the moieties can be determined by characterizing the modified sequence ions of the peptide in $\mathrm{MS}^{\mathrm{n}}$ analysis. In this dissertation, the binding sites of cisplatin on cyt $\mathrm{c}, \mathrm{Mb}$, and $\mathrm{Ub}$ are determined by MS/MS and $\mathrm{MS}^{3}$ analyses.

\subsubsection{Fourier transform mass spectrometry (FT-MS)}

FT-MS was introduced in 1974 by Marshall and Comisarow ${ }^{37}$. The technique provides unparalleled mass accuracy and resolution in mass spectrometry. Its mass accuracy can reach 2 ppm and its resolution can reach $1 \mathrm{e}^{6}$ for ions below $500 \mathrm{~m} / \mathrm{z}$. Its high mass accuracy and high resolution arise from the fundamental basis of FT-MS.

An ion in a magnetic field will take a circular trajectory, perpendicular to the magnetic field. The circular motion of the ion is balanced by centrifugal force and centripetal force. The balance of the two forces is described by Equation 3. The rearrangement of Equation 3 gives Equation $4^{38,39}$ :

$$
\begin{aligned}
& \quad \frac{m v^{2}}{r}=B z v \quad \text { Equation (3) } \\
& \begin{array}{l}
\text { Centrifugal } \\
\text { Centripetal } \\
\text { force }
\end{array}
\end{aligned}
$$

In these two equations, $\mathrm{m}$ and $\mathrm{z}$ is the mass and charge of the ion respectively, $v$ is the ion velocity, $\mathrm{B}$ is the magnetic field strength, $\mathrm{r}$ is the radius of the circular trajectory, and $\omega$ is the angular velocity of the ion motion. According to Equation 4, the angular frequency $\omega$ of each ion is reversely related to the $\mathrm{m} / \mathrm{z}$ of the ion in a fixed magnetic field. Therefore, the $\mathrm{m} / \mathrm{z}$ of the ion can be measured by measuring $\omega$, 
cyclotron frequency, for that $\mathrm{m} / \mathrm{z}$ value.

An ion can be excited by an external electric field of the same cyclotron frequency $\omega$ of the ion. After such excitation, the kinetic energy of the ion increases, thereby increasing the radius of its cyclotron trajectory. This phenomenon is called ion cyclotron resonance (ICR). Because ions with the same $\mathrm{m} / \mathrm{z}$ will be excited by the same frequency, the ions with the same $\mathrm{m} / \mathrm{z}$ will circulate on the same trajectory with the same frequency in a packet. Therefore, ICR is used to excite ions. The first application of ICR theory was by Hipple et al. in $1949{ }^{40}$.

Ion detection in FT-MS primarily involves two steps: ion excitation and detection of the image current ${ }^{38,39}$. Figure 1.9. displays a schematic of a cylindrical ICR cell. The top and bottom sections on the cylinder are the two sections for ion detection. The side sections are the two sections used to excite the ions by an RF potential with a broad range of frequencies.

All the ions in the ICR are excited simultaneously for detection by applying a RF potential with constant amplitude and a broad range of frequencies to the excitation plates for about 1 us. The application of the RF potential enables all the ions to simultaneously gain kinetic energy and enlarge their radius of trajectory while in an ion packet. When the ion packet is very close to one detection plate, their charge causes electrons in the detection circuit to flow to that plate. When the packet approaches the other plate, the electrons flow back through the detection circuit to that plate. The continuously circular motion of the ions along their trajectory will generate image current, oscillating at the same frequency as their cyclotron frequency. The generated image current is detected by monitoring the current flow that is then recorded as a function of time. The current signal at each specific time arises from the 
sum of image currents for all the ion packets with a broad range of cyclotron frequencies. A Fourier transform is used to convert the time-domain signal into a frequency-domain signal to assign the intensity and the cyclotron frequency for each individual ion packet to a specific m/z value based on Equation 4 .

The repeated measurement of image current contributes to the high mass precision of the technique. The narrower the peak is, i.e., the higher the resolution is. However, the resolution of FT-MS is affected by the pressure in the cell, thus a high vacuum (less than $10^{-9}$ ) is required.

The tremendous pressure difference between the ESI source and FT-MS makes it difficult to use ESI as the ionization source for this technique. The coupling of the ESI source with FT-MS is achieved by using several stages of differential pumping ${ }^{41}$. The performance is improved by coupling FT-MS with other mass analyzers (such as LTQ). The coupling of the LTQ and FT-MS enables accumulation and collision cooling of ions in the LTQ before entering FT-MS ${ }^{32}$. 


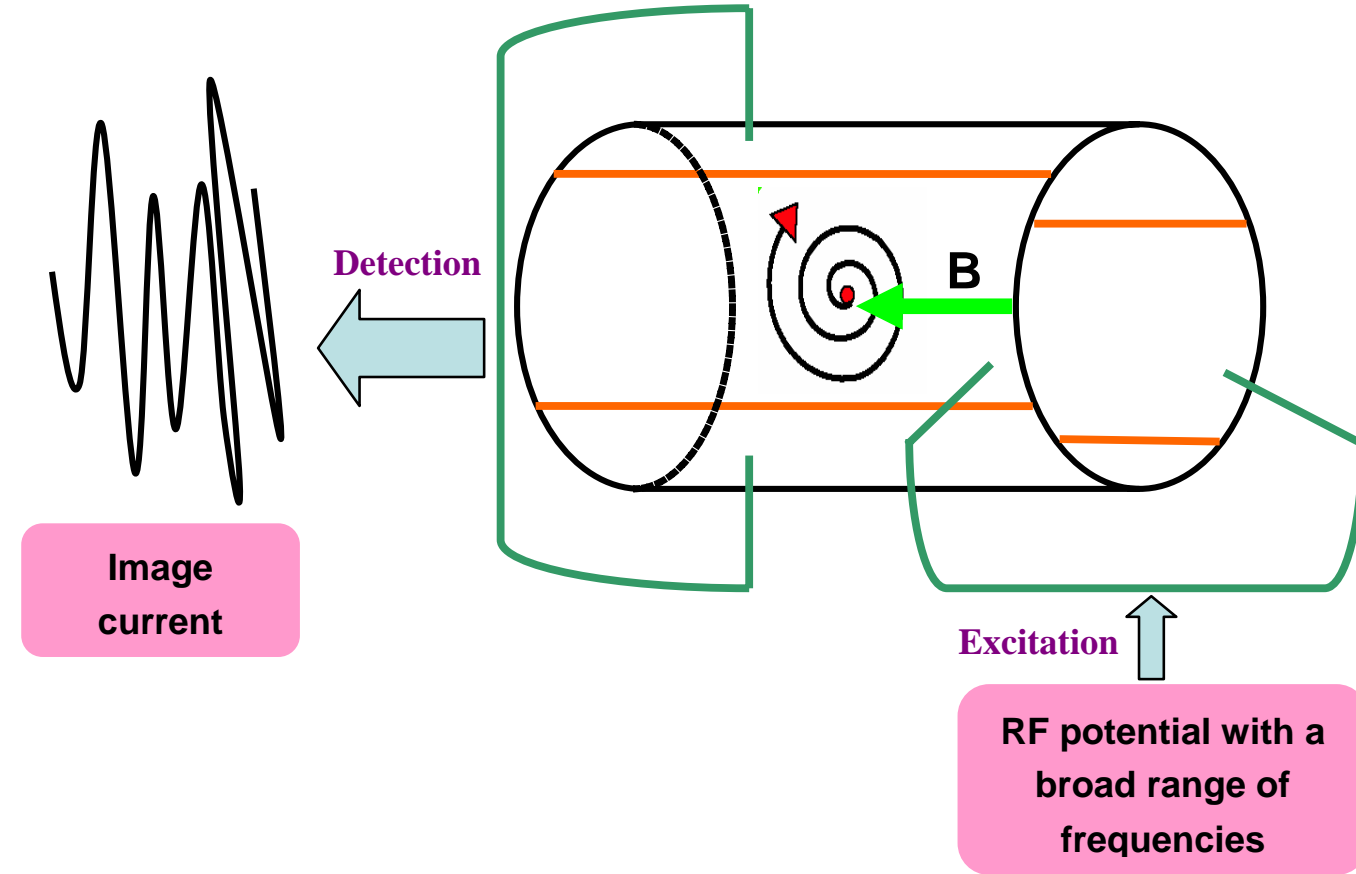

Figure 1.9. Schematic of a FT-MS instrument 


\subsection{References}

(1) Rosenberg, B.; Van Camp, L.; Krigas, T. Nature. 1965, 205, 698-699.

(2) Najajreh, Y.; Gibson, D. Metal Compounds in Cancer Chemotherapy. 2005, 285-320.

(3) Alderden R.A., H. M. D., and Hambley T. W. J. Chem. Educ. 2006, 83, 732-734.

(4) Ishida, S.; Lee, J.; Thiele, D. J.; Herskowitz, I. PNAS. 2002, 99, 14298-14302.

(5) DeConti, R. C.; Toftness, B. R.; Lange, R. C.; Creasey, W. A. Cancer Res. 1973, 33, 1310-5.

(6) Reedijk, J. Chem. Rev. 1999, 99, 2499-2510.

(7) Lippert, B. Metal Ions in Biological Systems. 1996, 33, 105-141.

(8) Voet, D., Voet J.G. Biochemistry. 2 ed.; John Wiley \& Sons, Inc., 1995.

(9) Branden, C., Tooze, J. Introduction to Protein Structure. 2 ed.; Garland Publishing, Inc., 1999.

(10) Gordon W. Bushnell, G. V. L., Gary D. Brayer J. Mol. Biol. 1990, 214, 585-595.

(11) Caughey W. S., S. G. A., O'Keeffe D. H., Maskasky, J. E., Smith $\quad$ M. I. J. Biol. Chem. 1975, 250, 7602-7622.

(12) Ordway, G. A.; Garry, D. J. Exp. Biol. 2004, 207, 3441-3446.

(13) Collman, J. P.; Boulatov, R.; Sunderland, C. J.; Fu, L. Chem. Rev. 2004, 104, 561-588.

(14) Vijay-Kumar, S.; Bugg, C. E.; Wilkinson, K. D.; Cook, W. J. PNAS. 1985, 82, 3582-3585.

(15) Goldstein, G.; Scheid, M.; Hammerling, U.; Schlesinger, D. H.; Niall, H. D.; Boyse, E. A. PNAS. 1975, 72, 11-15.

(16) Vijay-Kumar, S., Bugg, C.E., Cook, W.J. J. Mol. Biol. 1987, 194, 531-544.

(17) Yamashita, M.; Fenn, J. B. J. Phys. Chem. 1984, 88, 4671-4675.

(18) Yamashita, M.; Fenn, J. B. J. Phys. Chem. 1984, 88, 4451-4459.

(19) Nadja B. Cech, C. G. E. Mass Spectrom. Rev. 2001, 20, 362-387.

(20) Taflin, D. C.; Ward, T. L.; Davis, E. J. Langmuir. 1989, 5, 376-384.

(21) Iribarne, J. V.; Thomson, B. A. J. Chem. Phys. 1976, 64, 2287-2294.

(22) Thomson, B. A.; Iribarne, J. V. J. Chem. Phys. 1979, 71, 4451-4463.

(23) Dole, M.; Mack, L. L.; Hines, R. L.; Mobley, R. C.; Ferguson, L. D.; Alice, M. B. J. Chem. Phys. 1968, 49, 2240-2249.

(24) Paul, W., Steinwedel, H.S. United States Patent. 1960, US 2,939,952.

(25) Cooks, R. G., Gilish, G.L., Mcluckey, S.A., and Kaiser, R.E. C\& EN. 1991, 69, $26-41$.

(26) Raymond, E. M. J. Mass Spectrom. 1997, 32, 351-369.

(27) Quarmby, S. T.; Yost, R. A. Int. J. Mass Spectrom. 1999, 190-191, 81-102.

(28) Stafford, G. C., Jr.; Kelley, P. E.; Syka, J. E. P.; Reynolds, W. E.; Todd, J. F. J. Int. J. Mass Spectrom. Ion Process. 1984, 60, 85-98.

(29) Kaiser, R. E., Jr.; Louris, J. N.; Amy, J. W.; Cooks, R. G. Rapid Commun. Mass Spectrom. 1989, 3, 225-229.

(30) McLafferty, F. W. Science 1981, 214, 280-287.

(31) Shukla, A.K.; Futrell, J. H. J. Mass Spectrom. 2000, 35, 1069-1090.

(32) Douglas, D.J.; Frank, A. J.; Mao, D. Mass Spectrom. Rev. 2005, 24, 1-29.

(33) Finnigan LTQ hardware manual; B ed.; Cooperation, Thermo Electron, San Jose, 2005, 97055-97013.

(34) Senko, M. W.; Hendrickson, C. L.; Emmett, M. R.; Shi, S. D. H.; Marshall, A. G. J. Am. Soc. 
Mass Spectrom.1997, 8, 970-976.

(35) Kinter, M.; Sherman, N. E Protein Sequencing and Identification Using Tandem Mass Spectrometry. 1 ed.; Wiley-Interscience, 2000.

(36) Medzihradszky, K. F. Methods Enzymol. 2005, 402, 209-244.

(37) Comisarow, M. B.; Marshall, A. G. Chem. Phys. Lett. 1974, 25, 282-283.

(38) Marshall, A.G.; Hendrickson, C. L.; Jackson, G. S. Mass Spectrom. Rev. 1998, 17, 1-35.

(39) Hoffmann, E. D.; Stroobant, V. Mass Spectrometry: Principles and Applications; 2nd ed.; John Wiley \& Sons, Inc.: New York, 2002.

(40) Hipple, J. A.; Sommer, H.; Thomas, H. A. Phys. Rev. 1949, 76, 1877.

(41) Henry, K. D.; Williams, E. R.; Wang, B. H.; McLafferty, F. W.; Shabanowitz, J.; Hunt, D. F. PNAS. 1989, 86, 9075-9078. 


\section{Chapter 2. Direct Determination of the Primary Binding Site of Cisplatin on Cytochrome c by Mass Spectrometry}

\subsection{Introduction}

Cisplatin is effective in the treatment of various cancers, particularly testicular and ovarian cancers ${ }^{1,2}$. In the body, cisplatin interacts with DNA and thereby induces apoptosis in tumor cells ${ }^{3,4}$. Because blood plasma proteins are good nucleophiles for cisplatin, they play an important role in transporting cisplatin to the tumor cells ${ }^{5}$. Unfortunately, some blood plasma protein-cisplatin binding is irreversible, which not only renders cisplatin inactive but also allows it to accumulate in tissues and induce side effects ${ }^{6,7}$. Exploration of protein-platinum metallodrug interactions provides insight into both the transportation role of the blood plasma proteins that enables therapeutic use and the irreversible binding that induces side effects. This knowledge can be employed in the design of new therapeutic agents with increased effectiveness and reduced side effects.

Pioneering work by Ivanov et al. ${ }^{8}$ employed nuclear magnetic resonance spectroscopy (NMR) to locate the binding sites of cisplatin on human serum albumin. Recently, X-ray crystallography elucidated the crystal structures of superoxide 
dismutase-cisplatin adducts ${ }^{9}$ and lysozyme-cisplatin adducts ${ }^{10}$. Electrospray ionization mass spectrometry (ESI-MS) ${ }^{11,12}$ coupled with the development of technologies for determining protein post-translational modifications ${ }^{13}$ enabled characterization of protein-Pt metallodrug interactions.

Gibson's group first reported the studies of the ubiquitin-cisplatin interactions using ESI-MS ${ }^{14,15}$. Subsequently, the binding site of cisplatin on transferrin was determined by liquid chromatography tandem mass spectrometry (LC-MS/MS), providing the basis for molecular modeling of the transferrin-cisplatin interactions ${ }^{16,17}$. In addition, the performances of matrix-assisted laser desorption/ionization mass spectrometry (MALDI-MS) and ESI-MS were compared for the study of the ubiquitin-Pt metallodrug interactions ${ }^{18}$. More recently, Dyson and his coworkers ${ }^{19}$ reported a rapid top-down approach to determine the binding sites of Pt metallodrugs on ubiquitin. Clearly, mass spectrometry has proven to be a powerful technique for the study of the protein-Pt metallodrug interactions.

Cytochrome c (cyt c) is a small, well-characterized protein containing several potential binding sites for Pt metallodrugs including methionines and histidines. Like ubiquitin, cyt $\mathrm{c}$ is a common model protein that has been used to study the protein-Pt metallodrug interactions by ESI-MS and MS/MS ${ }^{20-22}$. LC-MS/MS experiments, described in the literature ${ }^{20}$, enabled the determination of the binding sites of carboplatin on cyt c. Although Casini et al. ${ }^{21}$ reported the formation of the cyt c-cisplatin adducts using ESI-MS, they did not determine the binding site of cisplatin 
on cyt c. Recently, Casini et al. ${ }^{22}$ reported a comprehensive study of the interactions of Pt (II) iminoethers with cyt $\mathrm{c}$ including the determination of the primary binding site of Pt (II) iminoethers on cyt c based on ESI-MS and NMR.

Assigning the location of a protein's binding site(s) for Pt metallodrugs is essential to better understanding the protein-Pt metallodrug interactions. This research describes direct determination of the binding site(s) of cisplatin on cyt c via Fourier transform mass spectrometry (FT-MS) ${ }^{23}$ and tandem mass spectrometry $\left(\mathrm{MS}^{\mathrm{n}}\right)$. The high resolution and high mass accuracy of FT-MS enable identification of different fragments in the adduct digest from those in the free cyt $\mathrm{c}$ digest without need for a sample purification step. $\mathrm{MS}^{\mathrm{n}}$ analyses of the unique fragments in the adduct digest provide their structural information and enable the determination of the binding site(s) of cisplatin based on the mass shift of $\mathrm{b}$ ions or $\mathrm{y}$ ions of the peptides in the Pt-compound containing fragments ${ }^{24}$, revealed by broader isotope distributions of some product ions in their product-ion spectra ${ }^{17}$.

\subsection{Experimental}

\subsubsection{Materials}

Horse heart cyt c, cisplatin, ammonium acetate $\left(\mathrm{NH}_{4} \mathrm{OAc}\right)$, and ammonium bicarbonate were purchased from Sigma (St, Louis, MO). Sequencing grade modified trypsin, methanol (HPLC grade), and acetic acid (HAc) (analytical grade) were 
obtained from Fisher Scientific (Pittsburgh, PA). All chemicals were used directly without further purification. Deionized water was used throughout the experiments. The cyt c sequence is displayed in Figure 2.1.

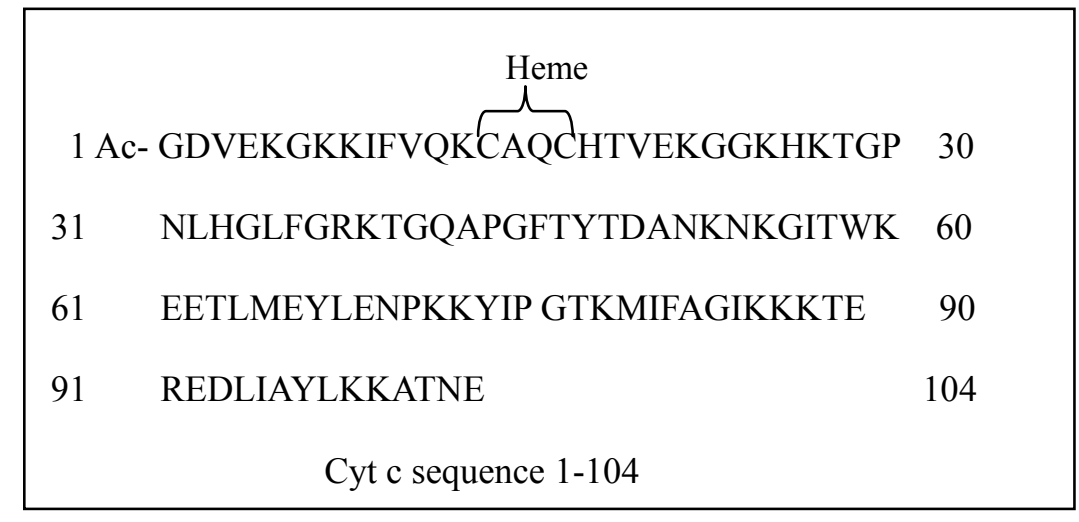

Figure 2.1. The cyt c sequence

\subsubsection{Preparation of the cyt c-cisplatin adducts}

$100 \mu \mathrm{M}$ cyt $\mathrm{c}$ was reacted with cisplatin at different molar ratios (cyt c:cisplatin $1: 4,1: 8,1: 12$, and $1: 16)$ under native conditions in $5 \mathrm{mM} \mathrm{NH}_{4} \mathrm{OAc}$ aqueous solution (pH 6.8) at $37{ }^{\circ} \mathrm{C}$ for different time in order to investigate the formation of the cyt c-cislatin adducts by ESI-MS. The cyt c-cisplatin adducts used in protein digestion were prepared by reacting $100 \mu \mathrm{M}$ cyt $\mathrm{c}$ with cisplatin at $1: 16$ cyt $\mathrm{c}$ :cisplatin molar ratio at $\mathrm{pH} 6.8,37{ }^{\circ} \mathrm{C}$ for $24 \mathrm{~h}$. Prior to ESI-MS, the cyt c solutions were diluted to $100 \mathrm{nM}$ with a $30 \% \mathrm{MeOH}-5 \mathrm{mM} \mathrm{NH}_{4} \mathrm{OAc}$ solution. 


\subsubsection{Protein digestion}

The cyt c-cisplatin adducts in the 1:16 cyt c:cisplatin mixture were diluted to 20 $\mu \mathrm{M}$ with $50 \mathrm{mM} \mathrm{NH} \mathrm{HCO}_{3}(\mathrm{pH}$ 7.8) and then subjected to trypsin digestion at a protein to enzyme ratio of $50: 1(\mathrm{w} / \mathrm{w})$ at $37{ }^{\circ} \mathrm{C}$ for $70 \mathrm{~min}$. As a control, $20 \mu \mathrm{M}$ free cyt c was digested under the same conditions. Before ESI-MS analysis, the digest solution was diluted to $5 \mu \mathrm{M}$ with a $50 \% \mathrm{MeOH}-0.1 \%$ HAc buffer.

\subsubsection{ESI-MS analyses of the cyt c adducts}

ESI-MS analyses of free cyt $\mathrm{c}$ and the cyt c-cisplatin adducts were carried out on a quadrupole ion trap mass spectrometer coupled with a standard electrospray ionization source (Finnigan $\mathrm{LCQ}^{\mathrm{TM}}$, San Jose, CA). The heated metal capillary was maintained at $200{ }^{\circ} \mathrm{C}$. The spray voltage was set to $4.5 \mathrm{kV}$. Nitrogen was used as the sheath gas and its flow rate was 30 units/min. The capillary voltage and the tube lens voltage were held at $35 \mathrm{~V}$ and $10 \mathrm{~V}$, respectively. The cyt c solutions were introduced by direct infusion with a flow rate of $3 \mu \mathrm{L} / \mathrm{min}$. Ion optics were tuned at $1766 \mathrm{~m} / \mathrm{z}$. A mass range of $1500-2000 \mathrm{~m} / \mathrm{z}$ was used to collect ESI-MS spectra. The ESI-MS spectra were deconvoluted using MagTran software ${ }^{25}$. OriginPro8 (OriginLab Corporation, Northampton, MA) was used to plot the data obtained in preparation of the cyt c-cisplatin adducts. 


\subsubsection{FT-MS, MS/MS and $M S^{3}$ analyses}

FT-MS, MS/MS, and $\mathrm{MS}^{3}$ analyses of the cyt $\mathrm{c}$ digests were carried out on a Thermo Finnigan LTQ-FT system equipped with an Ion Max ion source (San Jose, CA). The operating conditions of the ESI source were mentioned above. The digests were introduced by direct infusion at $3 \mu \mathrm{L} / \mathrm{min}$. Ion optics were tuned for the ions of interest. FT-MS analyses of the free cyt $\mathrm{c}$ digest and the adduct digest in a mass range of $500-2000 \mathrm{~m} / \mathrm{z}$ were performed to identify unique fragments in the adduct digest. Those fragments appearing uniquely in the FT-MS spectrum of the adduct digest were subjected to MS/MS and $\mathrm{MS}^{3}$ in the linear ion trap. The isolation width was set to 5 $\mathrm{m} / \mathrm{z}$. Before collision induced dissociation (CID), the ions of interest were accumulated for 150 to $500 \mathrm{~ms}$ to increase ion intensity. A normalized collision energy (NCE\%) of 30\% was employed in MS/MS and $\mathrm{MS}^{3}$. The isotope distributions of product ions were obtained by zoom scan. All product spectra were recorded in a full mass range during the MS/MS and $\mathrm{MS}^{3}$ analyses of the digests. The product spectra were replotted and labeled in Origin 6.0 (OriginLab Corporation, Northampton, MA). ExPASy Proteomics Server was used to search the cyt c sequence and to calculate the theoretical mass of the fragments in the adduct digest and the product ions of the peptides involved. 


\subsection{Results and Discussion}

\subsubsection{Preparation of the cyt c-cisplatin adducts}

The formation of the cyt $\mathrm{c}$ adducts in three solutions, containing cyt $\mathrm{c}$ and cisplatin at molar ratios of 1:4, 1:8 and 1:12 respectively, was examined at different time intervals over $30 \mathrm{~h}$ in order to monitor the adduct formation. Throughout these studies, 12604.3 Da is the primary adduct ion observed in the deconvoluted ESI-MS spectra. This signal is assigned as monoadduct cyt c-Pt $\left(\mathrm{NH}_{3}\right)_{2}\left(\mathrm{H}_{2} \mathrm{O}\right)$ because the formation of the adduct results in a mass shift of 245.9 Da from free cyt c (measured mass $12358.4 \mathrm{Da})$, which is close to the theoretical mass of $\mathrm{Pt}\left(\mathrm{NH}_{3}\right)_{2}\left(\mathrm{H}_{2} \mathrm{O}\right)(246.026$ Da). No cyt c- $\mathrm{Pt}\left(\mathrm{NH}_{3}\right)_{2} \mathrm{Cl}$ is detected, indicating that the side chains of cyt c replace one water in hydrolyzed cisplatin $\mathrm{Pt}\left(\mathrm{NH}_{3}\right)_{2}\left(\mathrm{H}_{2} \mathrm{O}\right)_{2}$ yielding cyt c-Pt $\left(\mathrm{NH}_{3}\right)_{2}\left(\mathrm{H}_{2} \mathrm{O}\right)^{18}$. For clarity, the charge states of the Pt compounds are omitted in this paper. The formation of cyt c- $\mathrm{Pt}\left(\mathrm{NH}_{3}\right)_{2}\left(\mathrm{H}_{2} \mathrm{O}\right)$ is described by Equation 1:

$$
\text { cytc }+\mathrm{Pt}\left(\mathrm{NH}_{3}\right)_{2}\left(\mathrm{H}_{2} \mathrm{O}\right)_{2} \rightleftarrows \text { cytc }-\mathrm{Pt}\left(\mathrm{NH}_{3}\right)_{2}\left(\mathrm{H}_{2} \mathrm{O}\right)+\mathrm{H}_{2} \mathrm{O} \quad \text { Equation (1) }
$$

Because the signal of cyt c-Pt $\left(\mathrm{NH}_{3}\right)_{2}\left(\mathrm{H}_{2} \mathrm{O}\right)$ covers over $90 \%$ of the signals of the adducts in the three solutions, the percentage of cyt c- $\mathrm{Pt}\left(\mathrm{NH}_{3}\right)_{2}\left(\mathrm{H}_{2} \mathrm{O}\right)$ in the total cyt c of each solution is used to represent the formed adducts. Figure 2.2. shows the changes of the percentage of cyt c-Pt( $\left(\mathrm{NH}_{3}\right)_{2}\left(\mathrm{H}_{2} \mathrm{O}\right)$ in three solutions over $30 \mathrm{~h}$. Although more cyt c-Pt $\left(\mathrm{NH}_{3}\right)_{2}\left(\mathrm{H}_{2} \mathrm{O}\right)$ appears in the solution with a higher cisplatin concentration, the trends of the formation of cyt c- $\mathrm{Pt}\left(\mathrm{NH}_{3}\right)_{2}\left(\mathrm{H}_{2} \mathrm{O}\right)$ are similar in the 
three solutions. The percentage of cyt c- $\mathrm{Pt}\left(\mathrm{NH}_{3}\right)_{2}\left(\mathrm{H}_{2} \mathrm{O}\right)$ in all three solutions increases sharply during the first 5 hours, and then increases gradually until 21 hours, after which it remains constant indicating the attainment of equilibrium. In this research, $24 \mathrm{~h}$ is used as the reaction time to prepare the cyt c-cisplatin adducts for protein digestion.

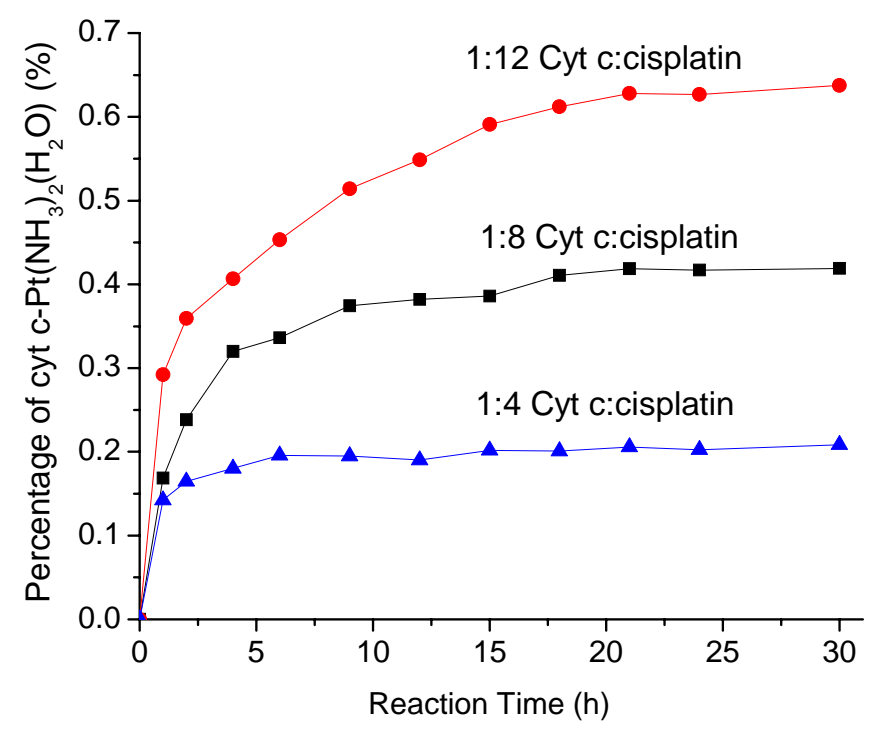

Figure 2.2. The percentage of cyt c-Pt( $\left(\mathrm{NH}_{3}\right)_{2}\left(\mathrm{H}_{2} \mathrm{O}\right)$ in three cyt c-cisplatin solutions: ( $\boldsymbol{\Delta}$ ) 1:4 cyt c:cisplatin; $(\square)$ 1:8 cyt c: cisplatin; $(\bullet)$ 1:12 cyt c:cisplatin at different time intervals over 30 hours

Figure 2.3. shows the deconvoluted ESI-MS spectra of free cyt $\mathrm{c}$ and the cyt c-cisplatin adducts prepared by reacting $100 \mu \mathrm{M}$ of cyt c with cisplatin at different cyt c:cisplatin molar ratios $(1: 8,1: 12$ and 1:16) under native conditions for $24 \mathrm{~h}$. Three 
groups of peaks are observed, arising from free cyt $\mathrm{c}$, the 1:1 cyt c:cisplatin adducts (monoadducts), and the 1:2 cyt c:cisplatin adducts (diadducts), respectively. In all of these spectra, the diadduct signal is extremely low, indicating that monoadducts are the major adducts. Besides the primary monoadduct cyt c- $\mathrm{Pt}\left(\mathrm{NH}_{3}\right)_{2}\left(\mathrm{H}_{2} \mathrm{O}\right)$, the other monoadducts are assigned as cyt c-Pt $\left(\mathrm{NH}_{3}\right)$, cyt c-Pt $\left(\mathrm{NH}_{3}\right)_{2}$, cyt c-Na-Pt( $\left(\mathrm{NH}_{3}\right)_{2}\left(\mathrm{H}_{2} \mathrm{O}\right)$, and cyt c- $\mathrm{H}_{2} \mathrm{O}-\mathrm{Na}-\mathrm{Pt}\left(\mathrm{NH}_{3}\right)_{2}\left(\mathrm{H}_{2} \mathrm{O}\right)$ corresponding to the small peaks at 12569.0, 12586.2, 12626.7, and 12644.3 Da. Because these spectra also indicate that the largest amount of adducts are produced in the 1:16 cyt c-cisplatin solution, this solution is selected for the preparation of the cyt c-cisplatin adducts for trypsin digestion in the following studies.

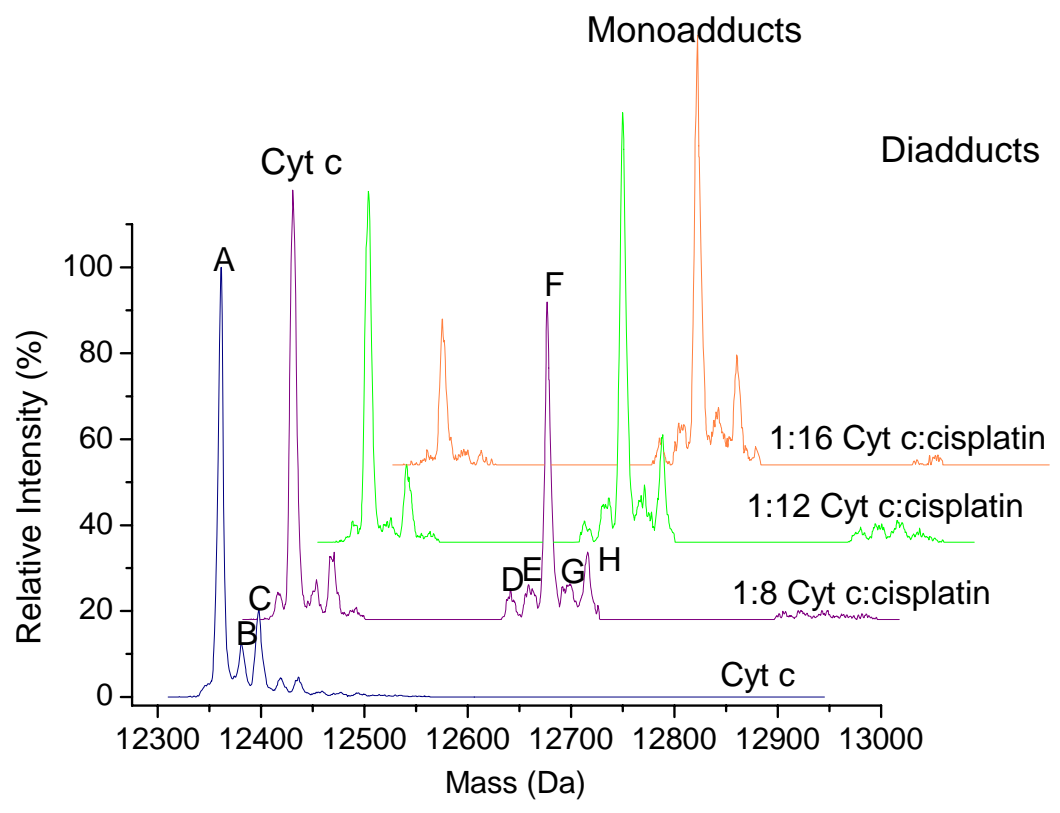

Figure 2.3. Deconvoluted ESI-MS spectra of free cyt $\mathrm{c}$ and the cyt c-cisplatin adducts obtained by incubating cyt $\mathrm{c}$ and cisplatin at different molar ratios for $24 \mathrm{~h}$ under native conditions. The assignment of individual peaks: A) cyt c; B) cyt c- $\mathrm{H}_{2} \mathrm{O}$; C) cyt c- $\left(\mathrm{H}_{2} \mathrm{O}\right)_{2}$; D) cyt c-Pt $\left(\mathrm{NH}_{3}\right)$;

E) cyt c-Pt $\left(\mathrm{NH}_{3}\right)_{2}$; F) cyt c-Pt $\left(\mathrm{NH}_{3}\right)_{2}\left(\mathrm{H}_{2} \mathrm{O}\right)$; G) cyt c-Na-Pt $\left(\mathrm{NH}_{3}\right)_{2}\left(\mathrm{H}_{2} \mathrm{O}\right)$;

H) cyt c- $\mathrm{H}_{2} \mathrm{O}-\mathrm{Na}-\mathrm{Pt}\left(\mathrm{NH}_{3}\right)_{2}\left(\mathrm{H}_{2} \mathrm{O}\right)$ 


\subsubsection{Determination of the primary binding site of cisplatin on cyt c}

\subsubsection{Protein digestion}

$\mathrm{MS}^{\mathrm{n}}$ analyses of smaller fragments arising from trypsin digestion of the cyt c-cisplatin adducts provide information regarding the adduct structure. Because the stable cyt c-cisplatin adducts were obtained under native conditions, trypsin digestion was performed under native conditions in order to prevent dissociation of the Pt-compounds from cyt c and cyt c fragments. A $50 \mathrm{mM} \mathrm{NH}_{4} \mathrm{HCO}_{3}$ aqueous solution $\left(\mathrm{pH} 7.8\right.$ ) held at $37^{\circ} \mathrm{C}$ was used for optimal conditions in trypsin digestion ${ }^{26}$. Initially, free cyt $\mathrm{c}$ was digested under the above conditions for $70 \mathrm{~min}$ to serve as the experimental control. Figure 2.4. shows the FT-MS spectrum of the free cyt c digest, which indicates a complete digestion of free cyt c. Small peptides with low charge states from 1 to 3 , located within $500-1200 \mathrm{~m} / \mathrm{z}$, give rise to the most abundant signals.

Under the same conditions, the adduct solution prepared from 1:16 cyt c:cisplatin mixture was digested. The FT-MS spectrum of the adduct digest is displayed in Figure 2.5. Figure 2.5. is compared with Figure 2.4. in detail in order to identify the new digest fragments in the adduct digest. As indicated in Figure 2.5., the new fragments in the mass range over $1000 \mathrm{~m} / \mathrm{z}$ with high charges $(+4$ to +6$)$ suggest partial digestion of the adducts. Such partial digestion of the adducts likely arises because the 
cisplatin binding to cyt $\mathrm{c}$ results in a tighter folding of the cyt c. Although extension of the digestion time permits a more complete digestion, it also results in the production of additional fragments that increase the complexity of the resulting FT-MS and $\mathrm{MS}^{\mathrm{n}}$ spectra. Therefore, the digestion time of the cyt c adducts was $70 \mathrm{~min}$, the same as the digestion time of free cyt c.

Further $\mathrm{MS}^{\mathrm{n}}$ analyses of the new fragments observed in the adduct digest indicate that these fragments correspond to four multiply charged fragments listed in Table 2.1, obtained by trypsin cleavage at two peptide bonds in the adducts. Of the four fragments, two are $\mathrm{Pt}\left(\mathrm{NH}_{3}\right)_{2}\left(\mathrm{H}_{2} \mathrm{O}\right)$-containing peptides and the other two are heme-containing peptides. The product-ion spectra of these four fragments reveal the primary binding site of cisplatin. 


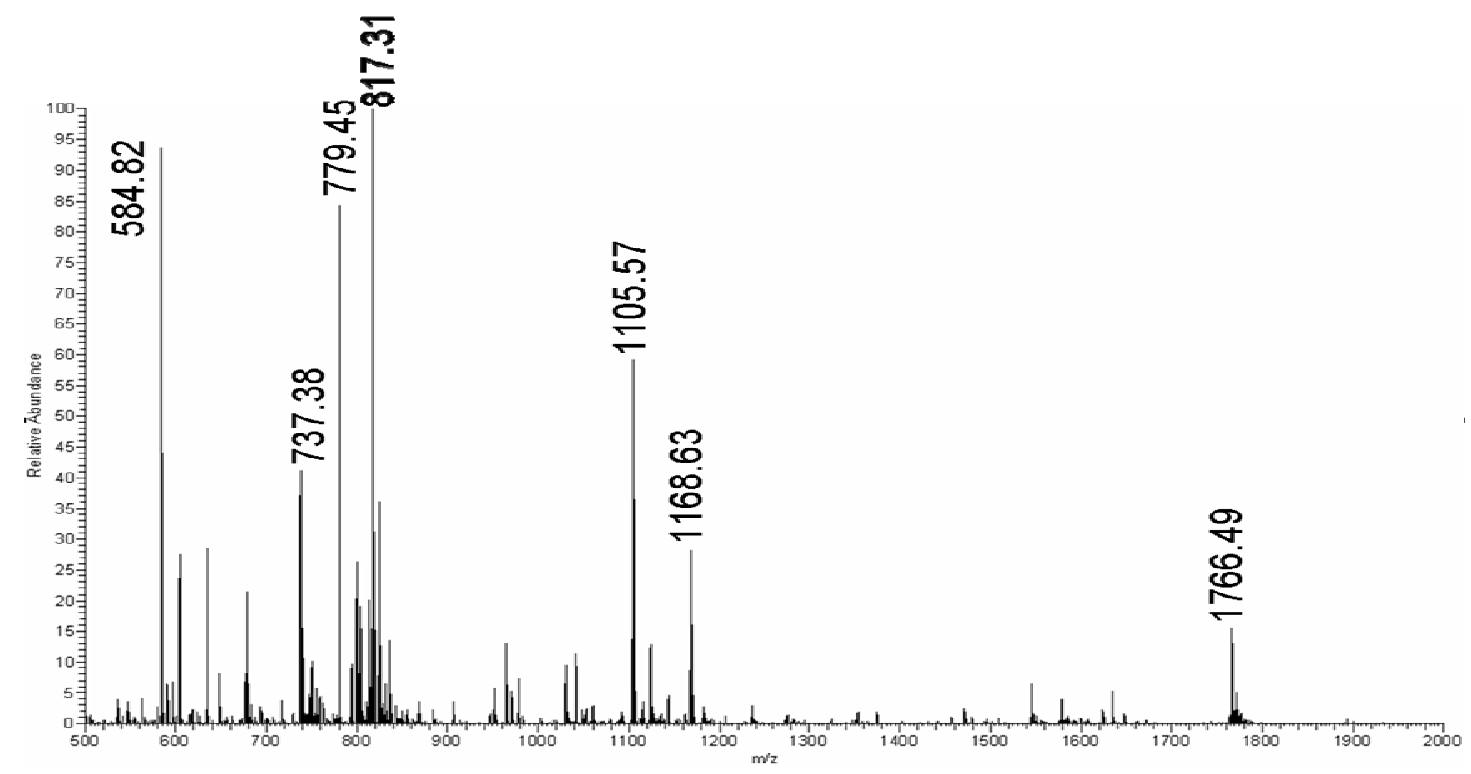

Figure 2.4. The FT-MS spectrum of the free cyt c digest

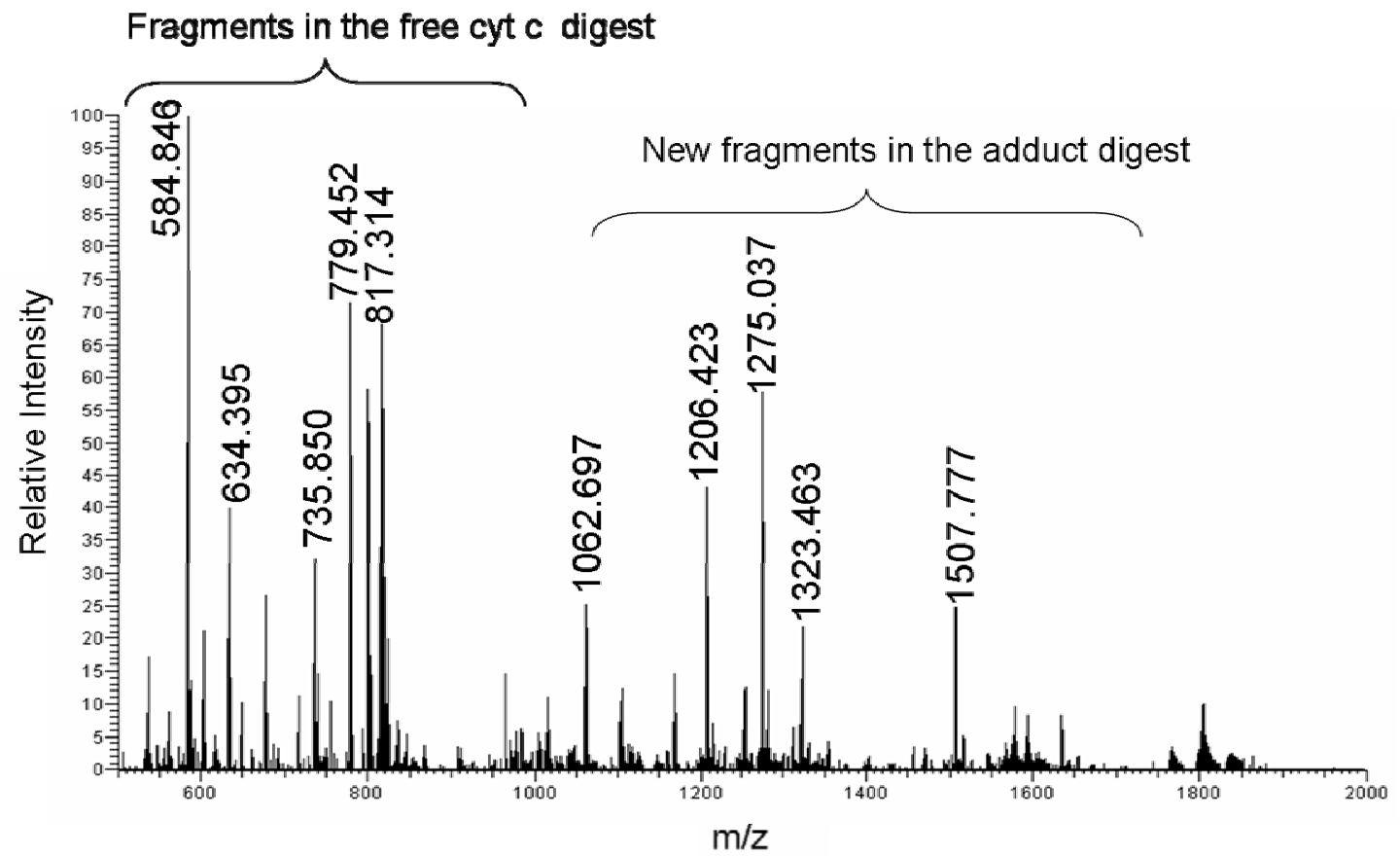

Figure 2.5. The FT-MS spectrum of the adduct digest 
Table 2.1. Four new fragments in the FT-MS spectrum of the adduct digest identified by $\mathrm{MS} / \mathrm{MS}$ and $\mathrm{MS}^{3}$ analyses

\begin{tabular}{|c|c|c|c|c|}
\hline Fragments & The fragments' & $m / z$ of the & Calculated & Measured \\
\hline & \multirow[t]{2}{*}{ composition } & \multirow[t]{2}{*}{ fragments } & mass & mass \\
\hline & & & (Da) & (Da) \\
\hline \multirow[t]{2}{*}{$\# 1$} & Gly56-Glu104+ $\mathrm{H}_{2} \mathrm{O}$ & $1507.777^{4+}$ & 6023.109 & 6027.112 \\
\hline & $+\mathrm{Pt}\left(\mathrm{NH}_{3}\right)_{2}\left(\mathrm{H}_{2} \mathrm{O}\right)$ & $1206.423^{5+}$ & & $\Delta \mathrm{m}^{*}=4.003$ \\
\hline \multirow[t]{2}{*}{$\# 2$} & Asn54-Glu104+ $\mathrm{H}_{2} \mathrm{O}$ & $1568.311^{4+}$ & 6265.247 & 6269.247 \\
\hline & $+\mathrm{Pt}\left(\mathrm{NH}_{3}\right)_{2}\left(\mathrm{H}_{2} \mathrm{O}\right)$ & $1254.850^{5+}$ & & $\Delta \mathrm{m}=4.000$ \\
\hline \multirow[t]{3}{*}{$\# 3$} & Acety1-Gly1-Lys53+Heme & $1593.546^{4+}$ & 6369.124 & 6370.184 \\
\hline & & $1275.037^{5+}$ & & $\Delta \mathrm{m}=1.060$ \\
\hline & & $1062.697^{6+}$ & & \\
\hline \multirow[t]{3}{*}{$\# 4$} & Acetyl-Gly1-Lys55+Heme & $1654.077^{4+}$ & 6611.262 & 6611.982 \\
\hline & & $1323.463^{5+}$ & & $\Delta \mathrm{m}=0.720$ \\
\hline & & $1102.887^{6+}$ & & \\
\hline
\end{tabular}

${ }^{*} \Delta \mathrm{m}$ is mass deviation of measured mass from calculated mass. 


\subsubsection{Determination of the primary binding site from Fragment \#1 and Fragment \#2}

MS/MS and $\mathrm{MS}^{3}$ analyses indicate both $1507.777^{4+}$ and $1206.423^{5+}$ ions arise from Fragment \#1. Figure 2.6. shows the product-ion spectrum from MS/MS of the $1507.777^{4+}$ ion, in which two abundant doubly charged fragment ions 1456.27 and 1558.18 appear. The total mass of the $1456.27^{2+}$ and $1558.18^{2+}$ ions is $6024.90 \mathrm{Da}$, which has -2.21 Da mass difference from the mass of the parent ion $1507.777^{4+}$ (6027.11 Da), suggesting that $1507.777^{4+}$ primarily fragments at one position during CID to produce the $1456.27^{2+}$ and $1558.18^{2+}$ fragment ions. $\mathrm{MS}^{3}$ analyses of both fragment ions provide additional structural information. $\mathrm{MS}^{3}$ analysis of the $1456.27^{2+}$ ion from the $1507.777^{4+}$ ion, Figure 2.7., indicates that the $1456.27^{2+}$ ion corresponds to a peptide with the sequence Met80-Glu104 (theoretical mass 2909.60 Da). The $1456.27^{2+}$ ion has a mass deviation of $0.93 \mathrm{Da}$ from the theoretical mass of Met80-Glu104. Met80-Glu104 is at the C terminus of the cyt c sequence, suggesting that the $1456.27^{2+}$ and $1558.18^{2+}$ ions arise from the cleavage of the Lys79 Met80 peptide bond. 


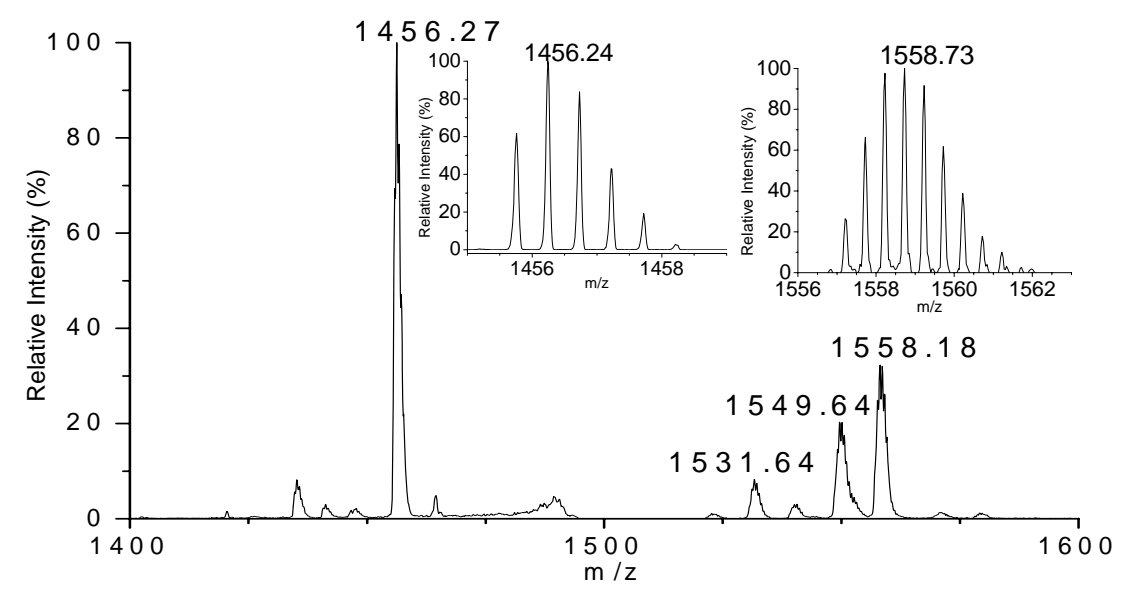

Figure 2.6. The product-ion spectrum of the MS/MS analysis of the $1507.777^{4+}$ ion and zoom scans of the product ions $1456.27^{2+}$ and $1558.18^{2+}$

The broader isotope distribution of the ion envelope at $1558.18^{2+}$ compared with that at $1456.27^{2+}$ in Figure 2.6. suggests $1558.18^{2+}$ corresponds to a Pt-compound containing fragment. Because $\mathrm{Pt}\left(\mathrm{NH}_{3}\right)_{2}\left(\mathrm{H}_{2} \mathrm{O}\right)$ is the primary Pt-compound bound to cyt $\mathrm{c}$, the peptide mass of $1558.18^{2+}$ is estimated by subtracting the mass of $\operatorname{Pt}\left(\mathrm{NH}_{3}\right)_{2}\left(\mathrm{H}_{2} \mathrm{O}\right)(246.03 \mathrm{Da})$ from the mass of $1558.18^{2+}(2868.33 \mathrm{Da})$. The estimated mass is very close to the mass of the peptide Gly56-Lys79 (theoretical mass 2867.48 Da) with a mass difference of $0.85 \mathrm{Da}$. The peptide sequence of $1558.18^{2+}$ as Gly56-Lys79 is consistent with the above result that $1558.18^{2+}$ is produced by cleaving the peptide bond Lys79 Met80 in Fragment \#1. Some sequence ions of 
peptide Lys56-Met79 are also observed in the $\mathrm{MS}^{3}$ analysis of $1507.777^{4+}$ at $1558.18^{2+}$, displayed in Figure 2.8. Consequently, the fragmentation of Fragment \#1 produces two peptide fragments, the $\mathrm{Pt}\left(\mathrm{NH}_{3}\right)_{2}\left(\mathrm{H}_{2} \mathrm{O}\right)$ bound peptide Gly56-Lys79 and the peptide Met80-Glu104. The formation of two peptide fragments in gas phase from Fragment \#1 suggests that one water molecule is associated with the peptide bond Lys79 Met80. The peptide bond Lys79 Met80 is not cleaved in trypsin digestion even after it is associated with one water molecule, suggesting the interactions $\operatorname{Pt}\left(\mathrm{NH}_{3}\right)_{2}\left(\mathrm{H}_{2} \mathrm{O}\right)$ with the peptide Gly56-Glu104 results in a more stable Lys79 Met80 peptide bond.

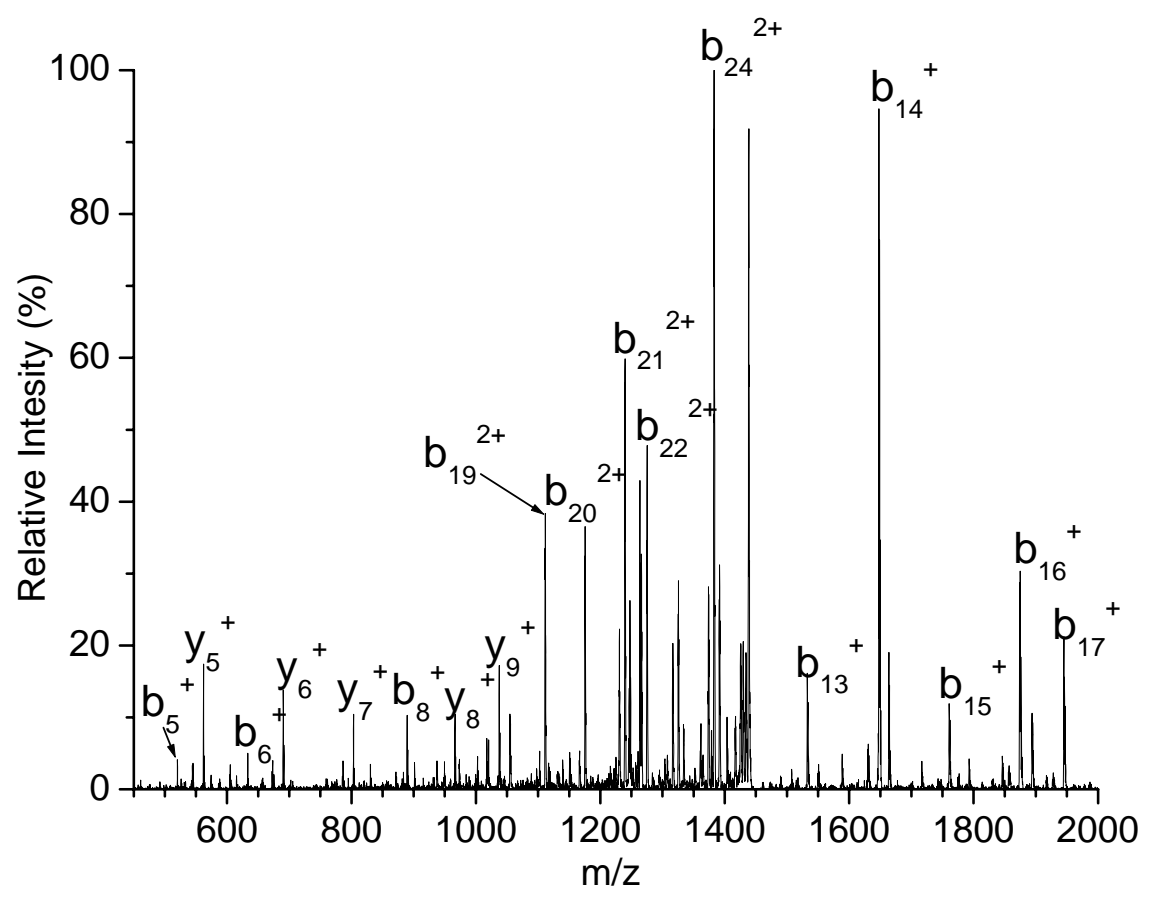

Figure 2.7. The product-ion spectrum of the $\mathrm{MS}^{3}$ analysis of the $1507.777^{4+}$ ion at $\mathrm{m} / \mathrm{z} 1456.27$. The peptide sequence of the $1456.27^{2+}$ ion : (Met80-Glu104) MIFAGIKKKTEREDLIAYLKKA TNE 
In Figure 2.8., the $1531.64^{2+}$ ion is the primary product ion produced by neutral loss of two $\mathrm{H}_{2} \mathrm{O}$ and one $\mathrm{NH}_{3}$ from the $1558.18^{2+}$ ion, indicating the peptide bonds in the $1558.18^{2+}$ ion are hard to break due to the $\mathrm{Pt}\left(\mathrm{NH}_{3}\right)_{2}\left(\mathrm{H}_{2} \mathrm{O}\right)$ binding. Most peaks are enlarged 20 times in Figure 2.8. in order to display the sequence ions for the peptide Gly56-Lys79 and the Pt-compound containing fragment ions $\left(1383.45^{+}, 1419.36^{+}\right.$, and $\left.1952.82^{+}\right)$. The strong intensity of $\mathrm{y}_{14}{ }^{+}\left(1679.82^{+}\right)$suggests that the peptide bond Met65 Glu66 readily fragments. The calculated mass of the complementary ion of $\mathrm{y}_{14}{ }^{+}$is $1436.54 \mathrm{Da}$, which is close to the molecular mass of $\left[\mathrm{b}_{10}+\mathrm{Pt}\left(\mathrm{NH}_{3}\right)_{2}\left(\mathrm{H}_{2} \mathrm{O}\right)\right]^{+}$ (theoretical mass1435.62 Da). However, the $1383.45^{+}$and $1419.36^{+}$ions are observed and assigned as the Pt-compound containing $\mathrm{b}_{10}{ }^{+}$ions because neutral loss dominates during fragmenting the $1558.18^{2+}$ ion, indicated by the primary fragment ion $1531.64^{2+}$ in Figure 2.8. Based on the assignments of the Pt-compound containing fragment ions, the Pt compounds bind to one of the amino acid residues of the $\mathrm{b}_{10}{ }^{+}$ ion (Gly56-Met65), in which Met65 has highest affinity for the Pt(II) compounds. Therefore, Met65 is the most probable binding site for $\mathrm{Pt}\left(\mathrm{NH}_{3}\right)_{2}\left(\mathrm{H}_{2} \mathrm{O}\right)$. Met65 is located in the middle of the fragment Gly56-Lys79 and the tight interaction between $\mathrm{Pt}\left(\mathrm{NH}_{3}\right)_{2}\left(\mathrm{H}_{2} \mathrm{O}\right)$ and Met65, contributes to strong peptide bonds in the $\mathrm{MS}^{3}$ analysis of $1507.777^{4+}$ at $1558.18^{2+}$. 


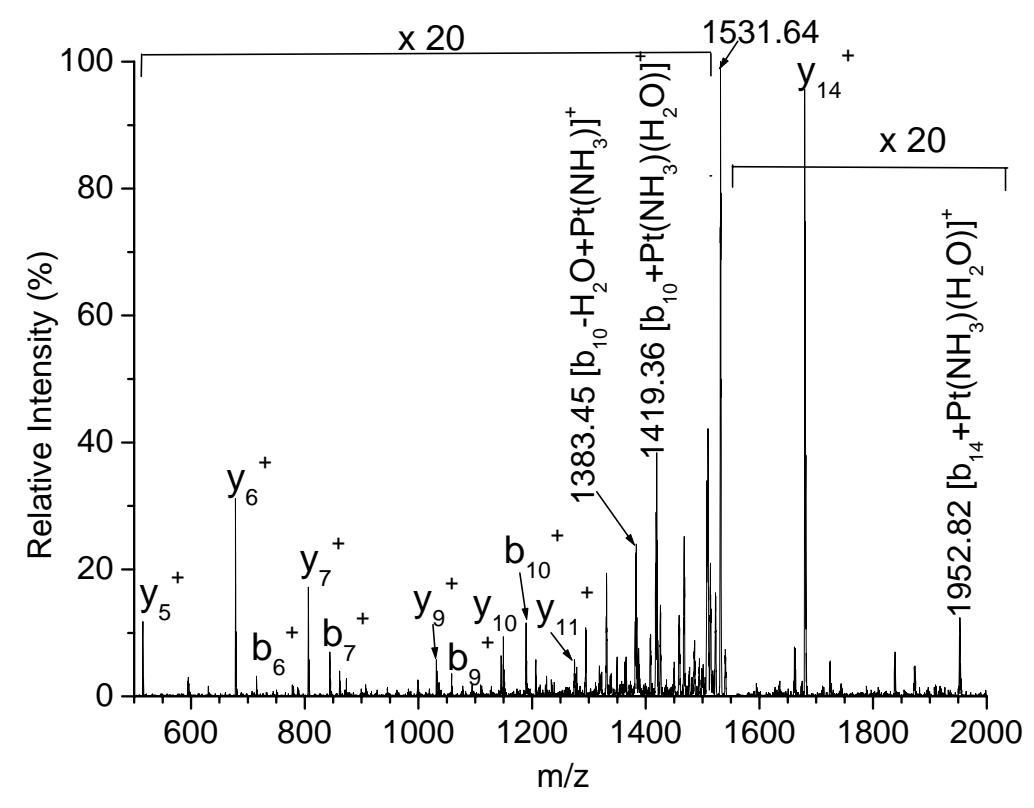

Figure 2.8. The product-ion spectrum of the $\mathrm{MS}^{3}$ analysis of the $1507.777^{4+}$ ion at $\mathrm{m} / \mathrm{z}$ 1558.18. The peptide sequence of the $1558.18^{2+}$ ion: (Gly56-Lys79) GITWKEETLMEYLENPK KYI PGTK

The MS/MS and $\mathrm{MS}^{3}$ analyses of Fragment \#2 also suggest Met65 is the $\operatorname{Pt}\left(\mathrm{NH}_{3}\right)_{2}\left(\mathrm{H}_{2} \mathrm{O}\right)$ binding site. The mass difference between Fragment \#1 and Fragment \#2 is $242.135 \mathrm{Da}$, which is the mass of amino acid residues NK (theoretical mass 242.137 Da), suggesting that Fragment \#2 is a $\mathrm{Pt}\left(\mathrm{NH}_{3}\right)_{2}\left(\mathrm{H}_{2} \mathrm{O}\right)$ bound peptide with a sequence of Asn54-Glu104. The structure of Fragment \#2 as the $\mathrm{Pt}\left(\mathrm{NH}_{3}\right)_{2}\left(\mathrm{H}_{2} \mathrm{O}\right)$ bound Asn54-Glu104 is confirmed by the MS/MS analysis of the $1568.311^{4+}$ ion for Fragment \#2, which is shown in Figure 2.9. Similar to Figure 2.6., two complementary fragment ions, $1456.36^{2+}$ and $1679.27^{2+}$, are observed in the MS/MS analysis of the $1568.311^{4+}$ ion. Identical to Fragment \#1, the $1456.36^{2+}$ ion arises from the peptide fragment Met80-Glu104. Figure 2.9. indicates that the $1679.27^{2+}$ ion is a 
$\operatorname{Pt}\left(\mathrm{NH}_{3}\right)_{2}\left(\mathrm{H}_{2} \mathrm{O}\right)$ containing peptide fragment. Therefore, the appearance of the $1456.36^{2+}$ and $1679.27^{2+}$ ions confirms that Fragment \#2 is a $\operatorname{Pt}\left(\mathrm{NH}_{3}\right)_{2}\left(\mathrm{H}_{2} \mathrm{O}\right)$ bound peptide with a sequence of Asn54-Glu104. The binding site of $\mathrm{Pt}\left(\mathrm{NH}_{3}\right)_{2}\left(\mathrm{H}_{2} \mathrm{O}\right)$ is at the peptide fragment Asn54-Lys79. In the residues from Asn54 to Lys79, Met65 is still the most probable binding site for $\mathrm{Pt}\left(\mathrm{NH}_{3}\right)_{2}\left(\mathrm{H}_{2} \mathrm{O}\right)$.

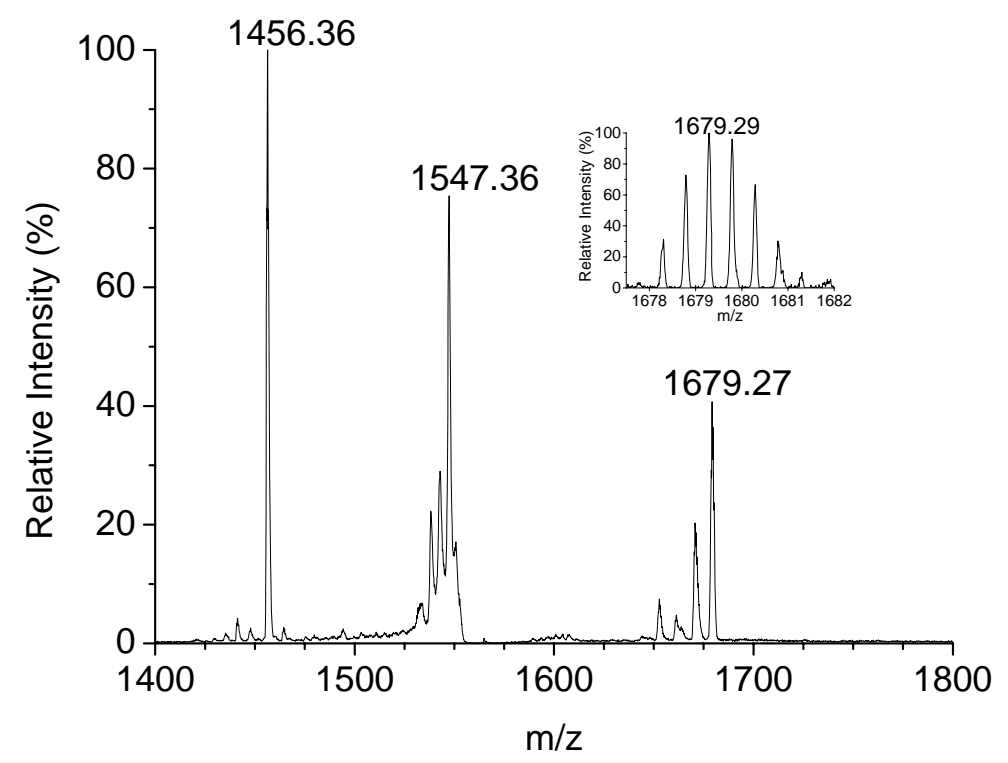

Figure 2.9. The product-ion spectrum of the MS/MS analysis of the $1568.311^{4+}$ ion and zoom scan of the product ion $1679.27^{2+}$

\subsubsection{Identification of Fragment \#3 and Fragment \#4}

Fragment \#3 is represented by three ions $1593.546^{4+}, 1275.037^{5+}, 1062.697^{6+}$ and Fragment \#4 is also observed as three ions $1654.077^{4+}, 1323.463^{5+}, 1102.887^{6+}$ in Figure 2.5. Figure 2.10. and 2.11. are the product-ion spectrum of the $1275.037^{5+}$ ion 
at Fragment \#3 and the product-ion spectrum of the $1323.463^{5+}$ ion at Fragment $\# 4$, respectively. Figure 2.10. and 2.11. have several common fragment ions, suggesting that Fragment \#3 and Fragment \#4 have similar structures. The heme group is present in both fragments according to the peak at $\mathrm{m} / \mathrm{z} 617.27$ in both spectra. Spectral analyses of Figure 2.10. and 2.11. indicate that Fragment \#3 is identified as a heme containing peptide, the sequence of which is Acetyl-Glyl-Lys53, produced by cleaving Lys53 Asn54 in trypsin digestion. Fragment \#4 is identified as a heme bound peptide, Acetyl-Gly1-Lys55, produced by cleaving the peptide bond at Lys55 Gly56 in trypsin digestion. Therefore, Fragment \#3 is complementary to Fragment \#2 and Fragment \#4 is complementary to Fragment \#1 according to the cyt c sequence, suggesting the cleavage mainly occurred at two positions (Lys53 Asn54 and Lys55 Gly56 ) in trypsin digestion of the cyt c adduct. The results of the $\mathrm{MS}^{\mathrm{n}}$ analyses of the four fragments indicate that Met65 is the primary binding site of cisplatin on cyt c. 


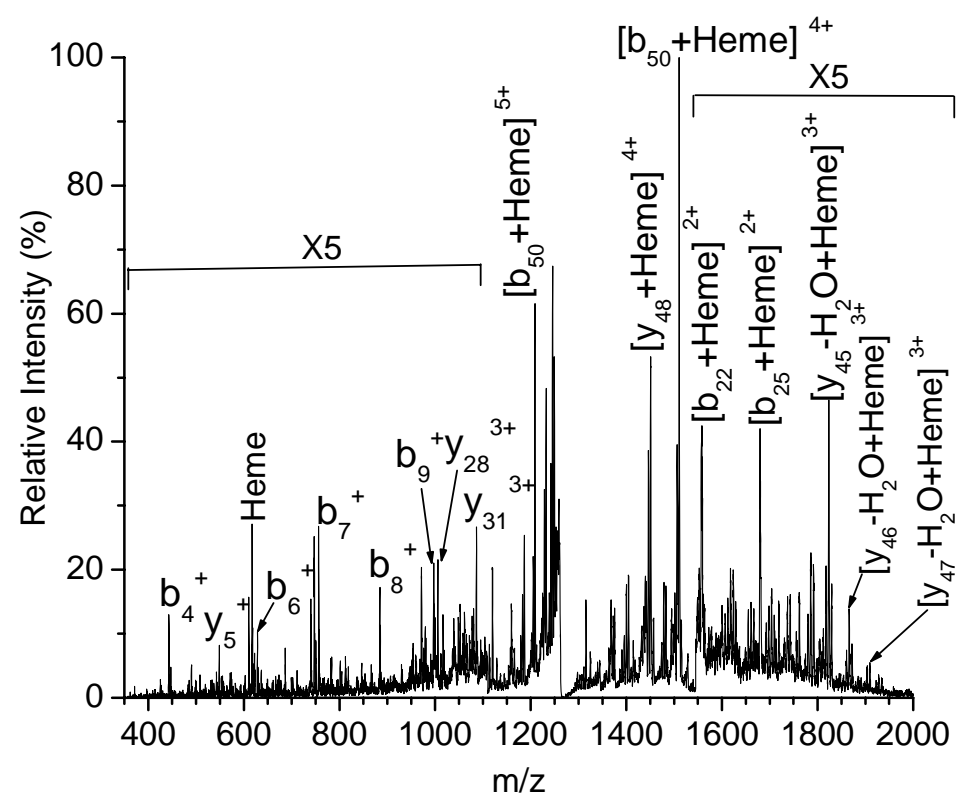

Figure 2.10. The product-ion spectrum of the MS/MS analysis of the $1275.037^{5+}$ ion. The peptide sequence of the $1275.037^{5+}$ ion: (Acetyl-Gly1-Lys53) Acetyl-GDVEKGKKIFVQKCA QCHTVEKGGKHKTGPNLHGLFGRKTGQAPGFTYTDANK

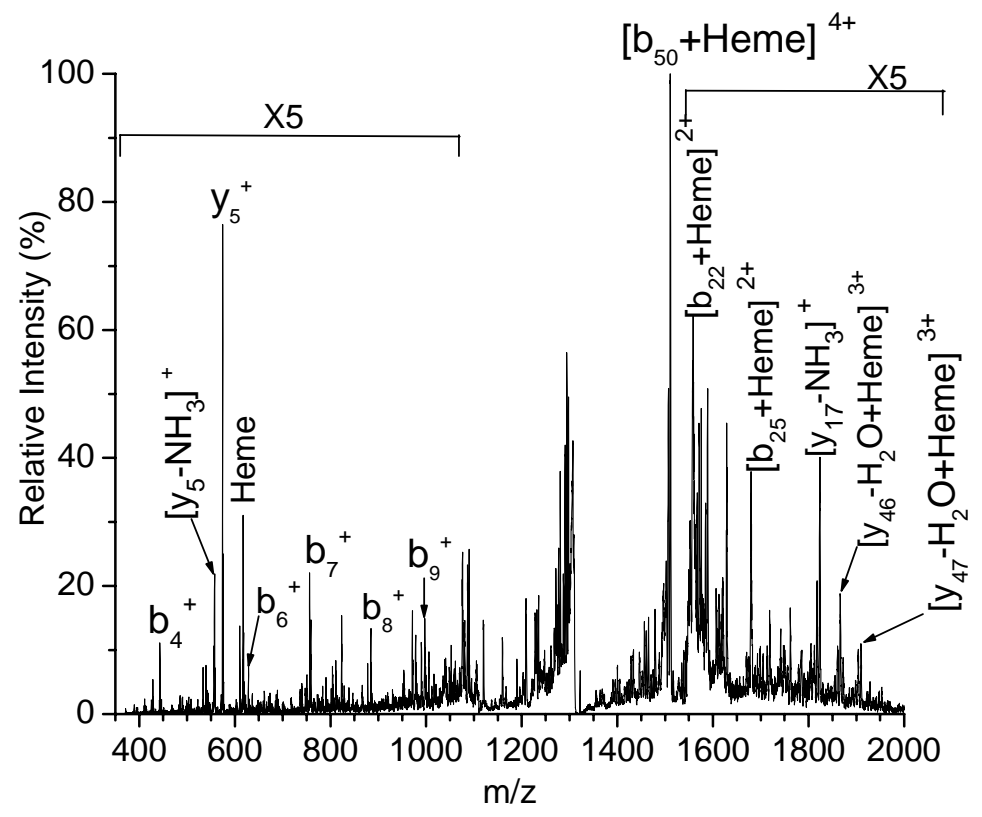

Figure 2.11. The product-ion spectrum of the MS/MS analysis of the $1323.463^{5+}$ ion. The peptide sequence of the $1323.463^{5+}$ ion: (Acetyl-Gly1-Lys55) Acetyl-GDVEKGKKIFVQKCAQ CHTV EKGGKHKTGPNLHGLFGRKTGQAPGFTYTDANKNK 


\subsection{Conclusions}

This research illustrates a mass spectrometric method for the direct determination of the primary binding site of cisplatin on cyt c. ESI-MS data reveal that the cyt c- $\mathrm{Pt}\left(\mathrm{NH}_{3}\right)_{2}\left(\mathrm{H}_{2} \mathrm{O}\right)$ monoadduct is the primary adduct produced by the cyt c-cisplatin interactions under native conditions in $30 \mathrm{~h}$. Four new fragments appear in the adduct digest compared with the free cyt $\mathrm{c}$ digest. The complete identification of these four fragments suggests that the cyt $\mathrm{c}$ adducts are cleaved mainly at two positions Lys53 Asn54 and Lys55 Gly56 by trypsin. These data support the assignment of Met65 as the primary binding site of cisplatin on cyt c. Therefore, the monoadduct cyt c- $\mathrm{Pt}\left(\mathrm{NH}_{3}\right)_{2}\left(\mathrm{H}_{2} \mathrm{O}\right)$ arises from covalent interactions between $\mathrm{Pt}\left(\mathrm{NH}_{3}\right)_{2}\left(\mathrm{H}_{2} \mathrm{O}\right)$ and Met65 in cyt c. The high specificity of this MS method enables direct determination of the primary cisplatin binding site without need for additional sample purification. The successful identification implies that this mass spectrometric approach based on FT-MS and $\mathrm{MS}^{\mathrm{n}}$ can be useful in the exploration of the binding site(s) of the Pt metallodrugs on other proteins. 


\subsection{References}

(1) Jamieson, E. R.; Lippard, S. J. Chem. Rev. 1999, 99, 2467-2498.

(2) Lippert, B. Cisplatin: Chemistry and Biochemistry of a Leading Anticancer Drug, 1999.

(3) Hickman, J. A. Cancer Metastasis Rev. 1992, 11, 121-139.

(4) Hurley, L. H.; Boyd, F. L. Trends Pharmacol. Sci. 1988, 9, 402-7.

(5) DeConti, R. C.; Toftness, B. R.; Lange, R. C.; Creasey, W. A. Cancer Res. 1973, 33, 1310-1315.

(6) Timerbaev, A.R.; Hartinger C.G.; Aleksenko, S. S.; Keppler B.K. Chem. Rev. 2006, 106, 2224-2248.

(7) Appleton, T. G. Coord. Chem. Rev. 1997, 166, 313-359.

(8) Ivanov, A. I.; Christodoulou, J.; Parkinson, J. A.; Barnham, K. J.; Tucker, A.; Woodrow, J.; Sadler, P. J. J. Biol.Chem. 1998, 273, 14721-14730.

(9) Calderone, V.; Casini, A.; Mangani, S.; Messori, L.; Orioli, P. L. Angew. Chem. Int. Ed. 2006, 45, 1267-1269.

(10) Casini, A.; Mastrobuoni, G.; Temperini, C.; Gabbiani, C.; Francese, S.; Moneti, G.; Supuran, C. T.; Scozzafava, A.; Messori, L. Chem. Commun. 2007, 156-158.

(11) Heck Albert, J. R.; Van Den Heuvel Robert, H. H. Mass Spectrom. Rev. 2004, 23, 368-389.

(12) Loo, J. A. Mass Spectrom. Rev. 1997, 16, 1-23.

(13) Carr, S. A.; Annan, R. S.; Huddleston, M. J. Methods Enzymol. 2005, 405, 82-115.

(14) Gibson, D.; Costello, C. E. Eur. Mass Spectrom. 1999, 5, 501-510.

(15) Peleg-Shulman, T.; Gibson, D. JACS. 2001, 123, 3171-3172.

(16) Allardyce, C. S.; Dyson, P. J.; Coffey, J.; Johnson, N. Rapid Commun. Mass Spectrom. 2002, 16, 933-935.

(17) Khalaila,I.; Allardyce, C. S.; Verma, C. S.; Dyson, P. J. ChemBioChem. 2005, 6, 1788-1795.

(18) Hartinger, C. G.; Ang, W. H.; Casini, A.; Messori, L.; Keppler, B. K.; Dyson, P. J. J. Anal. At. Spectrom. 2007, 22, 960-967.

(19) Hartinger, C. G.; Tsybin, Y. O.; Fuchser, J.; Dyson, P. J. Inorg. Chem. 2008, 47, 17-19.

(20) Yang, G.; Miao, R.; Jin, C.; Mei, Y.; Tang, H.; Hong, J.; Guo, Z.; Zhu, L. J. Mass Spectrom. 2005, 40, 1005-1016.

(21) Casini, A.; Gabbiani, C.; Mastrobuoni, G.; Messori, L.; Moneti, G.; Pieraccini, G. ChemMedChem. 2006, 1, 413-417.

(22) Casini, A.; Gabbiani, C.; Mastrobuoni, G.; Pellicani, R. Z.; Intini, F. P.; Arnesano, F.; Natile, G.; Moneti, G.; Francese, S.; Messori, L. Biochemistry. 2007, 46, 12220-12230.

(23) Marshall, A. G.; Hendrickson, C. L.; Jackson, G. S. Mass Spectrom. Rev. 1998, 17, 1-35.

(24) Medzihradszky, K. F. Methods Enzymol. 2005, 402, 209-244.

(25) Zhang, Z.; Marshall, A. G. J. Am. Soc. Mass Spectrom. 1998, 9, 225-233.

(26) Medzihradszky, K. F. Methods Enzymol. 2005, 405, 50-65. 


\section{Chapter 3. Myoglobin Denaturation}

\subsection{Introduction}

Cisplatin is an effective anti-tumor drug, which can disrupt DNA replication and stop cell division by binding to DNA ${ }^{1}$. Because platinum (II) is a soft metal ion, cisplatin also interacts with blood plasma proteins especially those sulfur-containing proteins. On the one hand, the blood plasma protein-cisplatin interactions are believed to contribute to drug efficacy because the formed adducts might serve as a Pt reservoir for $\mathrm{DNA}^{2}$. On the other hand, irreversible interactions between blood plasma proteins and cisplatin not only decrease drug efficacy but also lead to side effects ${ }^{3}$. Therefore, it is important to determine the cisplatin binding sites on proteins in order to understand the principles that govern adduct formation and the roles that proteins play in the therapeutic profile of cisplatin.

Myoglobin $(\mathrm{Mb})$ is used as a model protein to study such protein interactions with cisplatin. $\mathrm{Mb}$ has a molecular weight of 17, $567 \mathrm{Da}$ and contains a polypeptide chain of 153 amino acids and a heme prosthetic group. Under native conditions, the secondary structures of $\mathrm{Mb}$ including eight helices (A-H), turns, and loops are tightly

packed, leaving a hydrophobic cleft at helices C, E, and F for the heme moiety ${ }^{4}$. The 
entire polypeptide is folded into a globular structure with all the hydrophobic residues buried inside and most of the polar residues exposed to the environment ${ }^{5}$.

Electrospray ionization mass spectrometry (ESI-MS) and tandem mass spectrometry (MS/MS) are utilized to determine the binding sites of cisplatin on $\mathrm{Mb}$. Because peptides are more suitable for MS/MS than proteins, Mb adducts are digested into peptides prior to MS/MS. Proteins are often digested by fast and simple in-solution protein digestion. However, $\mathrm{Mb}$ can not be digested by this approach because $\mathrm{Mb}$ is a globular protein and the cleavable sites of $\mathrm{Mb}$ are buried inside the $\mathrm{Mb}$ structure. Therefore, $\mathrm{Mb}$ denaturation is required to disrupt the secondary and tertiary structures in order to expose the potential cleavage sites to the digestion agent 6.

This chapter describes the selection and optimization of an approach used to denature the tightly folded $\mathrm{Mb}$. Thermal denaturation and organic-aqueous solvent denaturation are used with apo-Mb and the Mb-cisplatin adducts. The conditions of the selected approach are optimized in order to enable efficient protein digestion.

\subsection{Experimental}

Mb-cisplatin adducts were prepared by incubating $100 \mu \mathrm{M} \mathrm{Mb}$ with $600 \mu \mathrm{M}$ cisplatin under $37^{\circ} \mathrm{C}$ at $\mathrm{pH} 6.8$ for 24 hour. In all the experiments, free $\mathrm{Mb}$ and the Mb-cisplatin adducts were digested by trypsin at a protein/enzyme (w/w) ratio of 50:1. 
The protein denaturation method was preliminarily investigated with free Mb. After preliminary investigation, the method was applied to the Mb-cisplatin adducts.

A $25 \mathrm{mM} \mathrm{NH}_{4} \mathrm{HCO}_{3}$ aqueous solution was used as the buffer for protein digestion under native conditions and thermal denaturation of proteins. In protein denaturation by mixed-organic solvents, mixtures of different percentages $(50 \%, 60 \%$, and $70 \%$ ) of methanol and $25 \mathrm{mM} \mathrm{NH} \mathrm{HCO}_{3}$ were used as the denaturation solutions. $\mathrm{Mb}$ and $\mathrm{Mb}$ adducts are denatured by a 4-fold volume of the denaturing solutions. After $\mathrm{Mb}$ denaturation, the denatured $\mathrm{Mb}$ solutions were subjected to trypsin digestion. The obtained digests were diluted to $5 \mu \mathrm{M}$ of the total $\mathrm{Mb}$ concentration with $50 \%$ $\mathrm{MeOH}-0.3 \%$ HAc solution for ESI-MS analysis on a quadrupole ion trap mass spectrometer (Finnigan LCQ ${ }^{\mathrm{TM}}$, San Jose, CA).

\subsection{Results and Discussion}

\subsubsection{Tryptic digestion of free $\mathrm{Mb}$ under native conditions}

Free $\mathrm{Mb}$ was digested by trypsin under native conditions as a control to compare with the results of trypsin digestion after $\mathrm{Mb}$ denaturation. Figure 3.1. shows the ESI-MS spectrum of the Mb digest obtained by incubating free Mb with trypsin for 21 $\mathrm{h}$ under native conditions at $37^{\circ} \mathrm{C}$. In Figure 3.1, the peak at $\mathrm{m} / \mathrm{z} 616.2$ corresponds to the heme group. The peaks from $\mathrm{m} / \mathrm{z} 848.6$ to $\mathrm{m} / \mathrm{z} 1883.8$ arise from free Mb without the heme group with the charge states from 20 to 9 , suggesting $\mathrm{Mb}$ is resistant to 
trypsin digestion under native conditions. This is because the structure of $\mathrm{Mb}$ is very compact under native conditions and the cleavage sites are shielded inside the hydrophobic core. Thus, protein denaturation was performed to disrupt the 3-D structure of $\mathrm{Mb}$ and expose the cleavage sites.

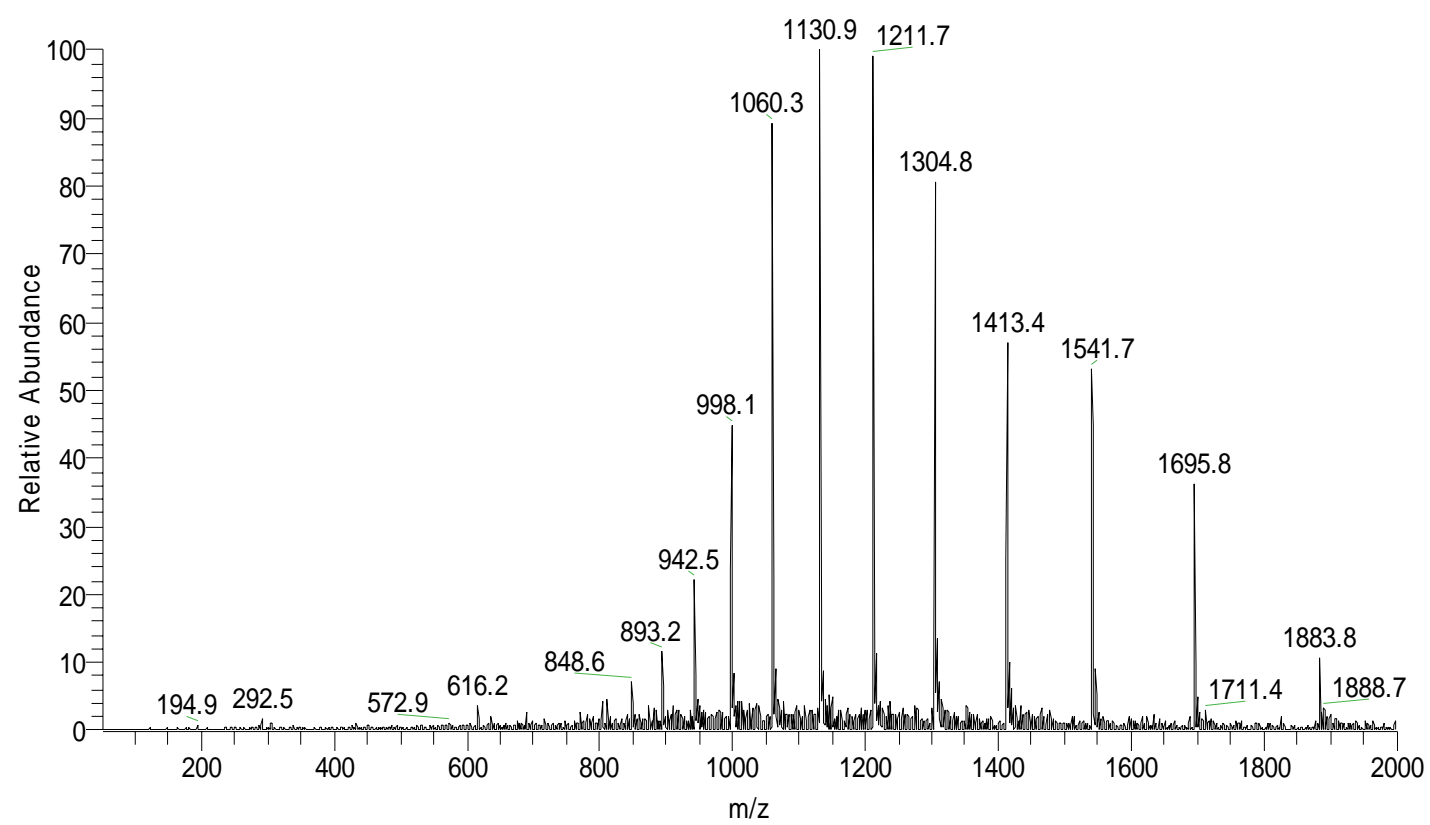

Figure 3.1. The native $\mathrm{Mb}$ digest after tryptic digestion for $21 \mathrm{~h}$

\subsubsection{Thermal denaturation}

Proteins can be denatured by thermal denaturation, which is performed simply by heating up the sample solution for a few minutes to increase the kinetic energy of the protein. At a higher temperature, the bond vibration inside the proteins becomes more rapid and violent, leading to disruption of high-order protein structures and protein 
denaturation ${ }^{7}$. Free $\mathrm{Mb}$ and Mb-cisplatin adducts were denatured under $90^{\circ} \mathrm{C}$, according to Park et al. $^{7}$ During thermal denaturation, protein aggregation was observed in both free $\mathrm{Mb}$ and the $\mathrm{Mb}$-cisplatin adduct solutions. The longer the incubation time was, more aggregates were observed. Because there was little protein aggregation observed within the first $20 \mathrm{~min}, 20 \mathrm{~min}$ was selected as the incubation time for thermal denaturation to prevent protein aggregation.

After thermal denaturation for $20 \mathrm{~min}$, both free $\mathrm{Mb}$ and the Mb-cisplatin adducts were subjected to trypsin digestion. Figure 3.2. and Figure 3.3. show the ESI-MS spectra of the digests of thermally denatured free $\mathrm{Mb}$ and the Mb-cisplatin adducts after $17 \mathrm{~h}$ of trypsin digestion, respectively. In the ESI-MS spectra, the peaks at different $\mathrm{m} / \mathrm{z}$ ratios arise from the components in the solutions and the intensity of each peak indicates the abundance of the corresponding component in the solutions. The abundant free $\mathrm{Mb}$ peaks in Figure 3.2. indicate that most $\mathrm{Mb}$ were not digested. Although there were more peptide peaks observed in the adduct digest in Figure 3.3., the peak envelopes arising from free $\mathrm{Mb}$ and the $\mathrm{Mb}$-cisplatin adducts were still abundant. It was decided that thermal denaturation under the conditions used in this research was unable to denature the Mb-cisplatin adducts sufficiently for protein digestion. 


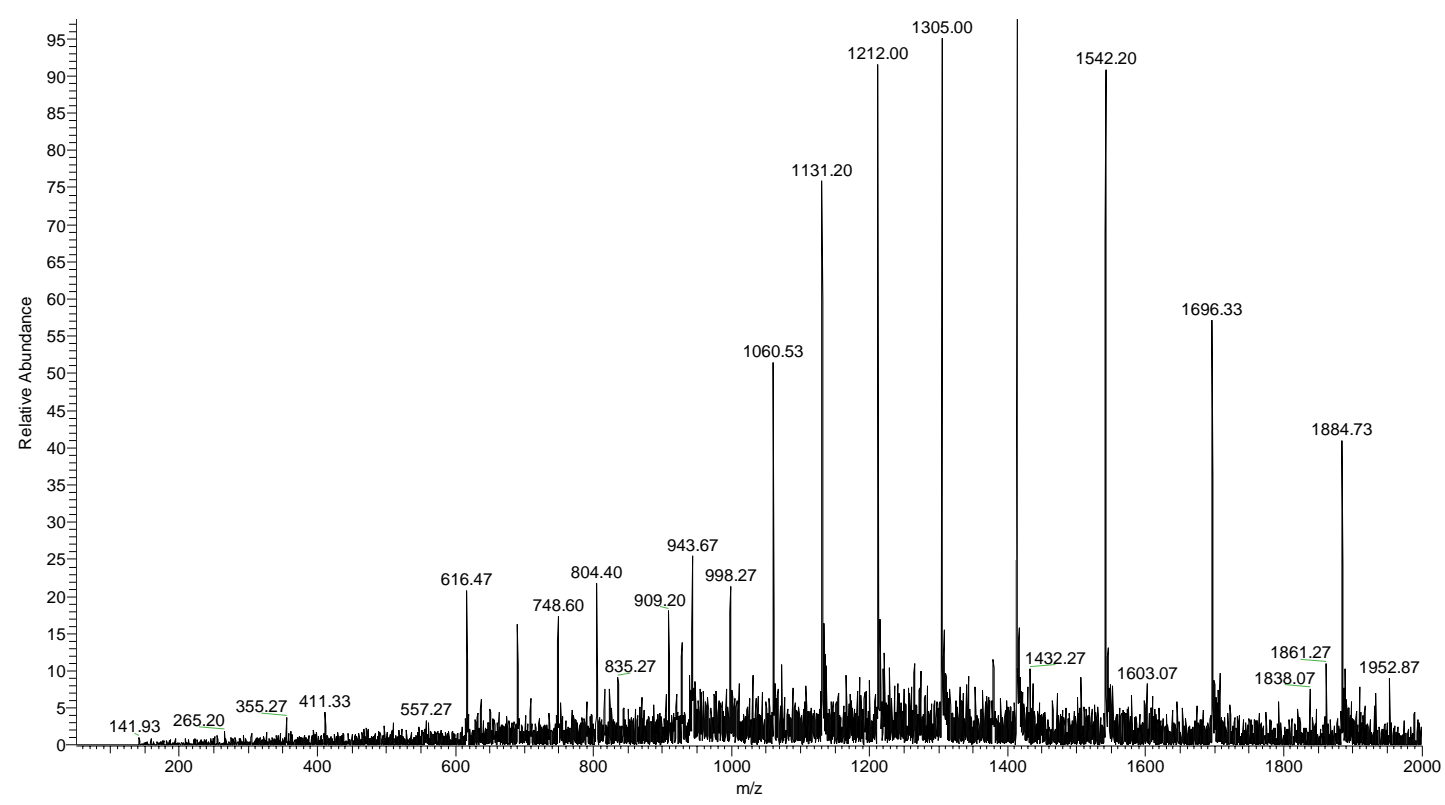

Figure 3.2. The free Mb digest obtained by trypsin digestion for $17 \mathrm{~h}$ after thermal denaturation

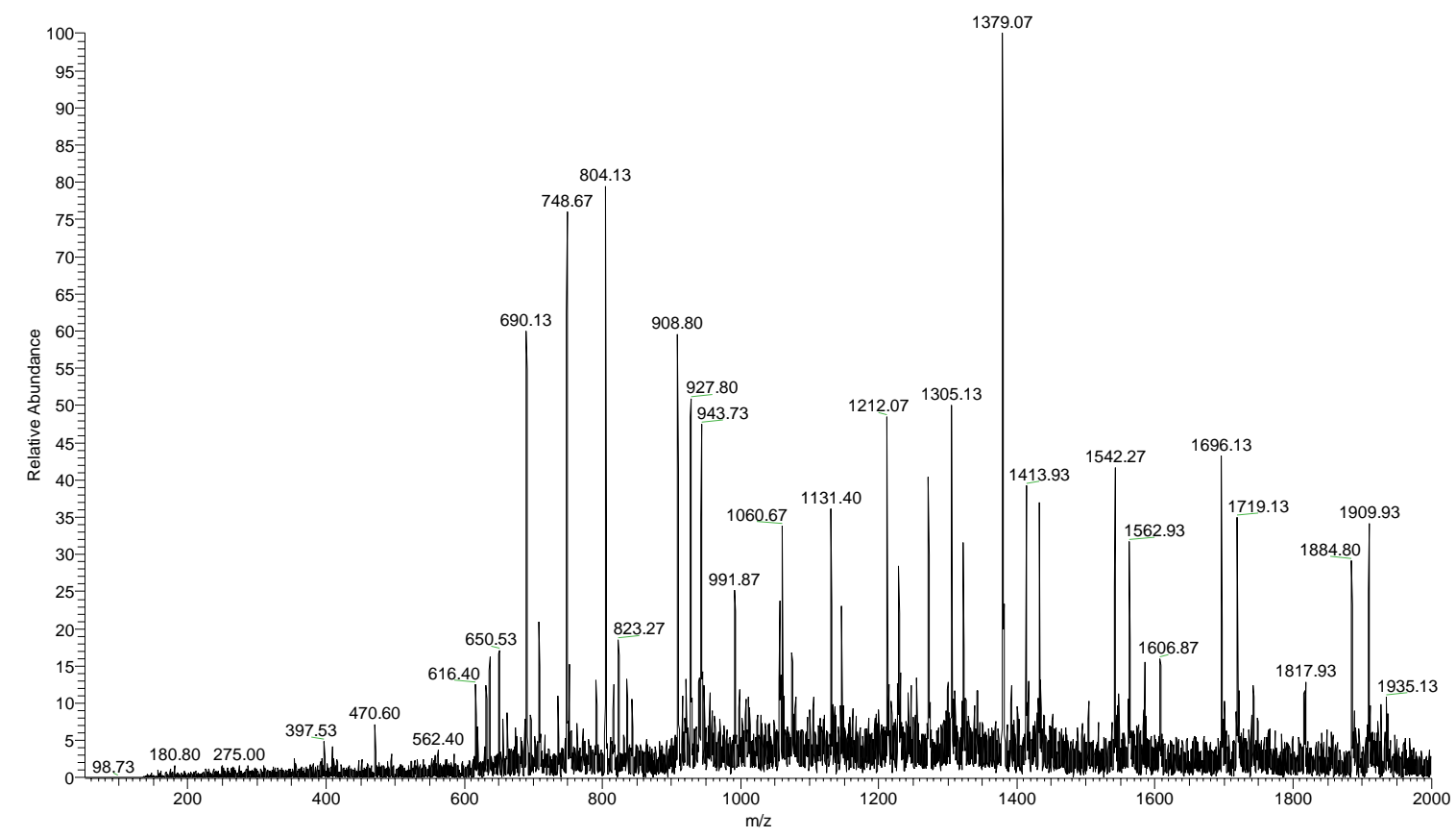

Figure 3.3. The Mb-cisplatin adduct digest obtained by trypsin digestion for $17 \mathrm{~h}$ after thermal denaturation 


\subsubsection{Protein denaturation by a mixed methanol-aqueous solvent}

Chemical denaturation enables a complete protein denaturation using $8 \mathrm{M}$ urea or $6 \mathrm{M}$ guanidine $\mathrm{HCl}$ as denaturing reagents ${ }^{6}$. However, the reagents used not only increase the complexity of the sample but also are incompatible with ESI-MS. Sample purification is often required to remove the added chemicals before ESI-MS.

Russell's group demonstrated successful protein denaturation using a mixed organic-aqueous solvent ${ }^{8}$. Methanol and acetonitrile are often used in the mixed solvent system for protein denaturation and the solvents for ESI-MS. Because the nitrile group in acetonitrile can displace Pt moieties on the Mb-cisplatin adducts and the hydroxy group in methanol does not interrupt the Mb-cisplatin interactions, methanol is used as the organic solvent to denature $\mathrm{Mb}$.

It was reported by Kamatari et al. ${ }^{9}$ that the tertiary structure of free $\mathrm{Mb}$ was destroyed when the methanol concentration was above $30 \%$. When $\mathrm{Mb}$ was in $50 \%$ $\mathrm{MeOH}$ solvent, more than one denatured state was present besides the intermediate state $\left(\mathrm{I}_{\mathrm{M}}\right)$, which has similar helical content to the native $\mathrm{Mb}$. The existence of other states than the $\mathrm{I}_{\mathrm{M}}$ state suggests the change in the secondary structure of free $\mathrm{Mb}$. Therefore, $50 \% \mathrm{MeOH}, 60 \% \mathrm{MeOH}$, and $70 \% \mathrm{MeOH}$ were used to denature $\mathrm{Mb}$ before trypsin digestion. In these three mixed organic-aqueous solvents, $25 \mathrm{mM}$ $\mathrm{NH}_{4} \mathrm{HCO}_{3}$ was added in order to control ionic strength of the solutions.

Three $\mathrm{Mb}$ solutions were denatured by $50 \% \mathrm{MeOH}, 60 \% \mathrm{MeOH}$, and $70 \%$ 
$\mathrm{MeOH}$, respectively, followed by trypsin digestion for 75 min. Figures 3.4., 3.5., and 3.6. show the mass spectra obtained for the $\mathrm{Mb}$ digests of these three solutions. Comparing these three spectra with Figures 3.1. and 3.2., it is obvious that no free $\mathrm{Mb}$ peaks were observed. All the peaks arise from peptides, suggesting the Mb solutions were effectively denatured by the $\mathrm{MeOH}$-aqueous solvents prior to trypsin digestion. Only 75 min was needed to fully digest $\mathrm{Mb}$ in each solvent $(50 \% \mathrm{MeOH}, 60 \% \mathrm{MeOH}$ and $70 \% \mathrm{MeOH}$ ), indicating the activity of trypsin was not significantly influenced by a high organic content ${ }^{8}$. More abundant peptide fragments are observed in the two spectra, Figure 3.5. and Figure 3.6., than in Figure 3.4., indicating that $60 \% \mathrm{MeOH}$ and $70 \% \mathrm{MeOH}$ are more effective than $50 \% \mathrm{MeOH}$ for the denaturation of $\mathrm{Mb}$.

In order to fully denature the Mb-cisplatin adducts, $70 \% \mathrm{MeOH}$ with $25 \mathrm{mM}$ $\mathrm{NH}_{4} \mathrm{HCO}_{3}$ is used as the buffered denaturation system. After denaturation, the adducts are digested by trypsin for $75 \mathrm{~min}$. The digest was analyzed by ESI-MS, yielding the mass spectrum shown in Figure 3.7. All the peaks correspond to peptides, demonstrating the effectiveness of the $70 \% \mathrm{MeOH}-25 \mathrm{mM} \mathrm{NH}_{4} \mathrm{HCO}_{3}$ solvent system for the denaturarion of $\mathrm{Mb}$. Therefore, the $70 \% \mathrm{MeOH}-25 \mathrm{mM} \mathrm{NH}_{4} \mathrm{HCO}_{3}$ solvent is selected and used as the denaturation buffer to denature the globular protein $\mathrm{Mb}$ and the $\mathrm{Mb}$ adducts in subsequent studies. 


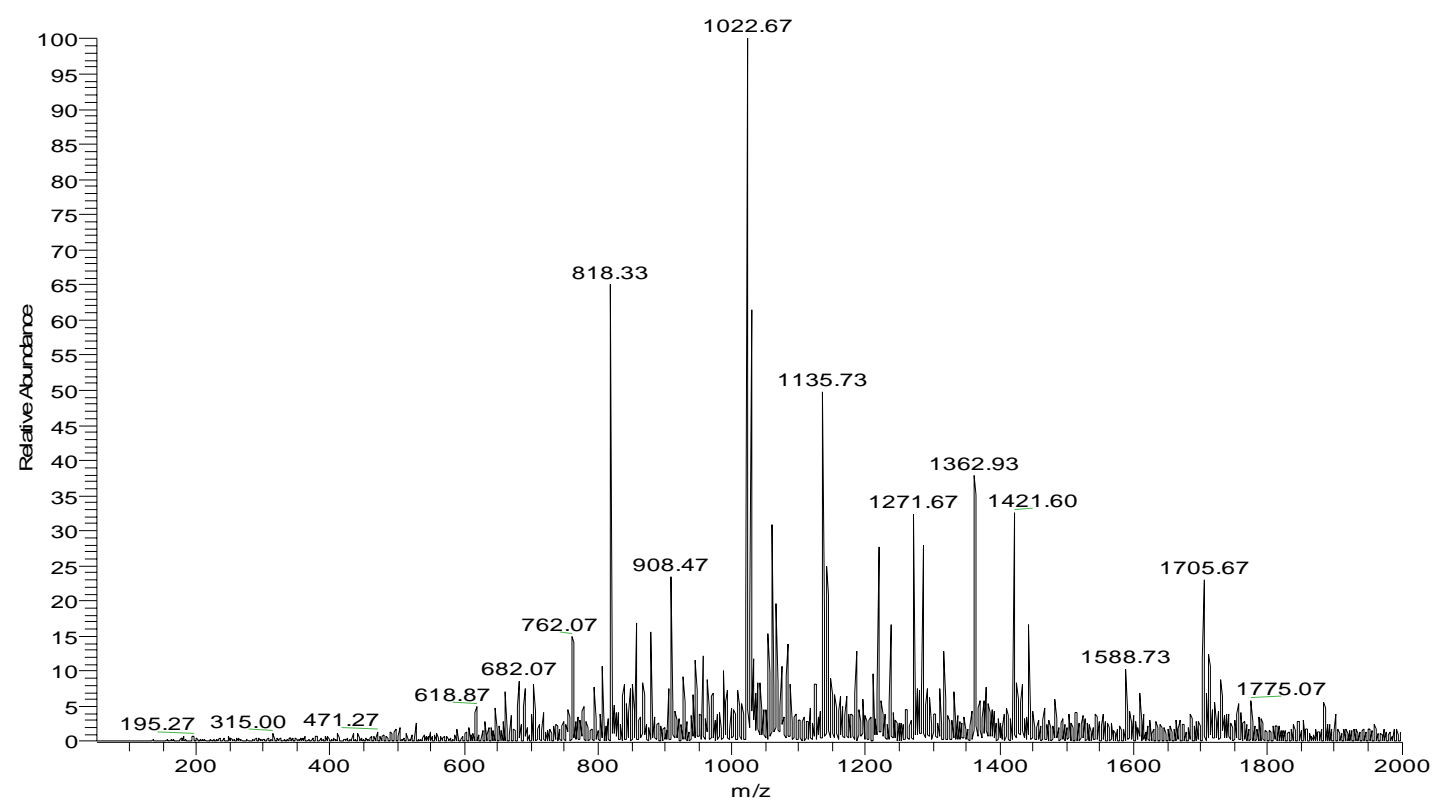

Figure 3.4. The $\mathrm{Mb}$ digest obtained by trypsin digestion after denaturation in a $50 \%$ $\mathrm{MeOH}-25 \mathrm{mM} \mathrm{NH}_{4} \mathrm{HCO}_{3}$ solvent

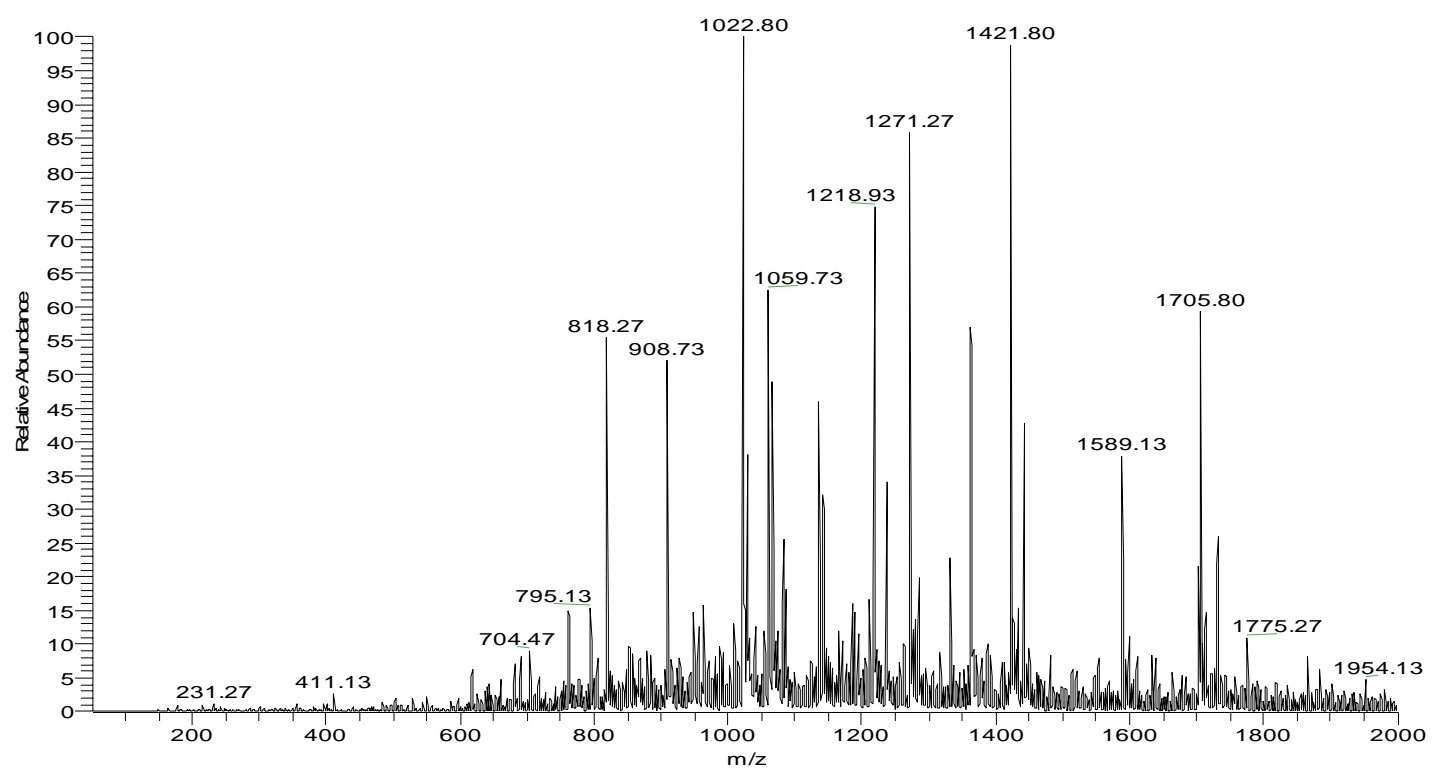

Figure 3.5. The $\mathrm{Mb}$ digest obtained by trypsin digestion after denaturation in a $60 \%$ $\mathrm{MeOH}-25 \mathrm{mM} \mathrm{NH}_{4} \mathrm{HCO}_{3}$ solvent 


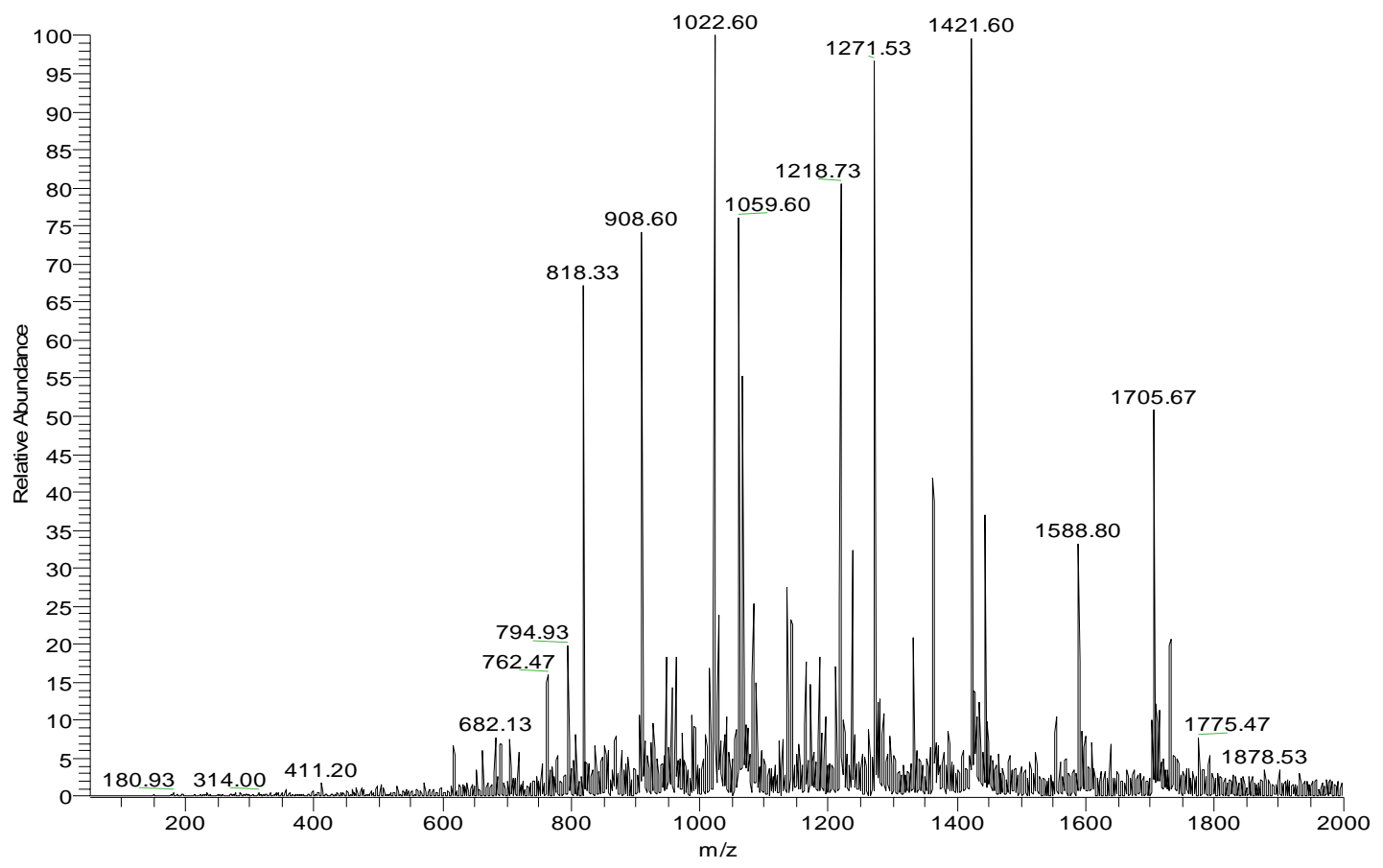

Figure 3.6. The $\mathrm{Mb}$ digest obtained by trypsin digestion after denaturation in a $70 \%$ $\mathrm{MeOH}-25 \mathrm{mM} \mathrm{NH}_{4} \mathrm{HCO}_{3}$ solvent

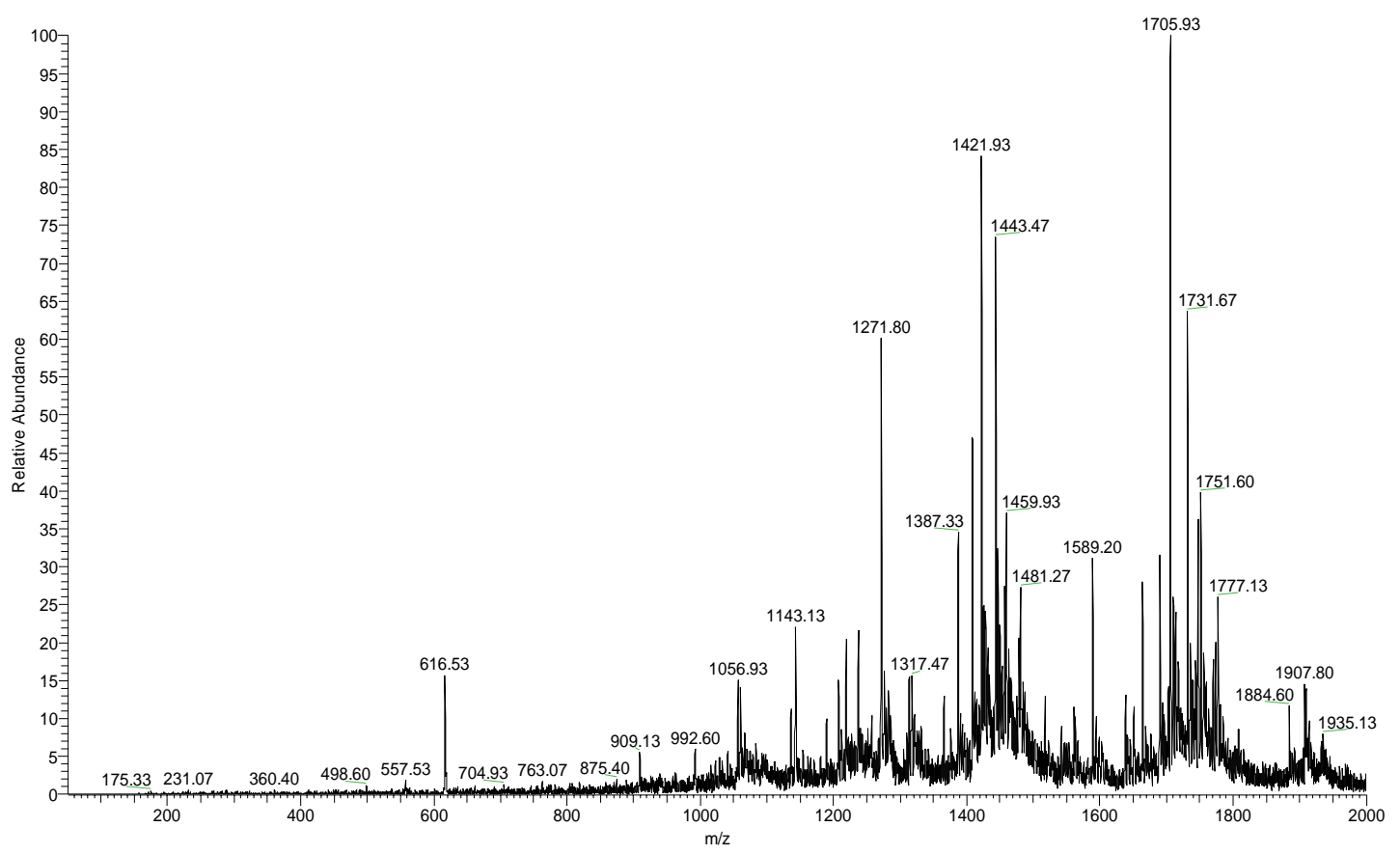

Figure 3.7. The $\mathrm{Mb}$ adduct digest obstained by trypsin digestion after solvent denaturation with a $70 \% \mathrm{MeOH}-25 \mathrm{mM} \mathrm{NH}_{4} \mathrm{HCO}_{3}$ solvent 


\subsection{Conclusions}

Both thermal denaturation and the methanol-aqueous solvent denaturation were tested for their suitability to the denaturation of $\mathrm{Mb}$ for trypsin digestion. Thermal denaturation is inapplicable because it is not sufficient for the subsequent digestion. Protein aggregation is also a problem in thermal denaturation. By contrast, the methanol-aqueous solvent approach efficiently denatures $\mathrm{Mb}$. The Mb solutions denatured by $50 \% \mathrm{MeOH}, 60 \% \mathrm{MeOH}$, and $70 \% \mathrm{MeOH}$, all can be digested in only 75 min with trypsin. According to the ESI-MS spectra, there were more peptides in the solutions denatured by $60 \% \mathrm{MeOH}$ and $70 \% \mathrm{MeOH}$ than the solution denatured by $50 \% \mathrm{MeOH}$. In subsequent work in this lab, the $70 \% \mathrm{MeOH}-25 \mathrm{mM} \mathrm{NH} \mathrm{NCO}_{3}$ solvent was used to denature the Mb-cisplatin adducts for trypsin digestion and satisfactory results were obtained. The $70 \% \mathrm{MeOH}--25 \mathrm{mM} \mathrm{NH} \mathrm{NHCO}_{3}$ aqueous solvent is used to denature $\mathrm{Mb}$, the $\mathrm{Mb}$ adduct, ubiquitin $(\mathrm{Ub})$, and the Ub adducts in this dissertation. 


\subsection{References}

(1) Najajreh, Y.; Gibson, D. Metal Compounds in Cancer Chemotherapy. 2005, 285-320.

(2) Reedijk, J. Chem. Rev. 1999, 99, 2499-2510.

(3) Appleton, T. G. Coord. Chem. Rev. 1997, 166, 313-359.

(4) Everse, J. Encyclopedia of Biological Chemistry. 2004, 2, 354-361.

(5) Berg, J.M.; Tymoczko, J.L.; Stryer, L. Biochemistry. 5th ed.; W.H. Freeman and Company.

(6) Wilkinson, J.M. Pratical Protein Chemistry. John Wiley \& Sons Ltd.: 1986, p 121-148.

(7) Park, Z.Y.; Russell, D. H. Anal. Chem. 2000, 72, 2667-2670.

(8) Russell, W. K.; Park, Z.Y.; Russell, D. H. Anal. Chem. 2001, 73, 2682-2685.

(9) Kamatari, Y. O.; Ohji, S.; Konno, T.; Seki, Y.; Soda, K.; Kataoka, M.; Akasaka, K. Protein Sci. 1999, 8, 873-882. 


\section{Chapter 4. A Mass Spectrometric Comparison of the Interactions of Cisplatin and Transplatin with Myoglobin}

\subsection{Introduction}

Cisplatin [cis-diamminedichloroplatinum (II)] is a successful anticancer drug, able to form intrastrand crosslinks with adjacent guanine residues in DNA and induce apoptosis of cancer cells ${ }^{1}$. In contrast, transplatin [trans-diamminedichloroplatinum (II)], the geometric isomer of cisplatin, has no anticancer activity because it is unable to form the intrastrand crosslinks with DNA ${ }^{2}$. Although the cytotoxicity of cisplatin arises from the DNA-cisplatin interactions, blood plasma protein-cisplatin interactions are believed to play important roles in the efficacy of cisplatin as an anticancer drug. A higher level of human serum albumin (HSA) enabled better treatment of patients ${ }^{3,4}$ because the formation of HSA-cisplatin adducts might be responsible for the transportation of cisplatin to DNA, suggested by model studies with small molecules ${ }^{5}$. Unfortunately, the irreversible binding of cisplatin to the blood plasma proteins induces side effects ${ }^{6}$.

Because blood plasma protein-Pt metallodrug interactions contribute to both 
drug efficacy and toxicity, nuclear magnetic resonance spectroscopy (NMR) ${ }^{7}, \mathrm{X}$-ray crystallography ${ }^{8}$, and mass spectrometry (MS) ${ }^{9,10}$ have been employed to enhance our understanding of the protein-Pt metallodrug interactions. Although such studies have improved our knowledge regarding the protein-Pt metallodrug interactions, little is known about the similarities and differences between the interactions of cisplatin and transplatin with proteins. Previous studies focused on the interactions of cisplatin and transplatin with ubiquitin indicated that cisplatin and transplatin have distinctly different interactions with ubiquitin ${ }^{11}$. That report also provided preliminary information on the kinetics of cisplatin and transplatin interactions with $\mathrm{Mb}^{11}$.

Myoglobin $(\mathrm{Mb})$ is a globular protein, consisting of a heme and a polypeptide of 153 amino acid residues. Under physiological conditions, over $70 \%$ of the polypeptide backbone is folded into alpha helices and the folding of the entire $\mathrm{Mb}$ polypeptide leads to a tight globular structure with the interior almost filled with nonpolar residues. There are several potential binding sites for Pt metallodrugs on $\mathrm{Mb}$ including 2 Met and 11 His ${ }^{12}$. In order to gain insights into the interactions of cisplatin and transplatin with such globular proteins in biological fluids, the interactions of cisplatin and transplatin with myoglobin are compared in detail in this research. First, the kinetics of the Mb-cisplatin and Mb-transplatin interactions is studied by monitoring the interactions over $30 \mathrm{~h}$ by electrospray ionization mass spectrometry (ESI-MS). Subsequently, the formed Mb-cisplatin and Mb-transplatin adducts are compared. Furthermore, the binding sites of cisplatin and transplatin are determined based on the previously reported approach ${ }^{13}$ to elucidate the binding 
mode of $\mathrm{Mb}$ with cisplatin and transplatin. Finally, the stability of the Mb-cisplatin and Mb-transplatin adducts are evaluated by reacting the Mb-cisplatin and Mb-transplatin adducts with 5'-guanosine monophosphate (GMP), respectively.

\subsection{Experimental}

\subsubsection{Materials}

Cisplatin, transplatin, horse heart myoglobin, ammonium acetate $\left(\mathrm{NH}_{4} \mathrm{OAc}\right)$, ammonium bicarbonate, and guanosine 5'-monophosphate (GMP) disodium salt were purchased from Sigma (St. Louis, MO). Sequencing grade modified trypsin, methanol (HPLC grade), and acetic acid (analytical grade) were obtained from Fisher Scientific (Pittsburgh, PA). All reagents were used as purchased. Figure 4.1. shows the structure of cisplatin, transplatin, guanosine 5'-monophosphate, and the Mb sequence ${ }^{12}$.

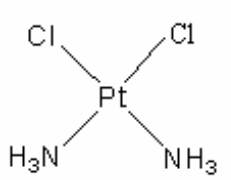

Cisplatin

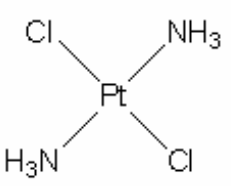

Transplatin

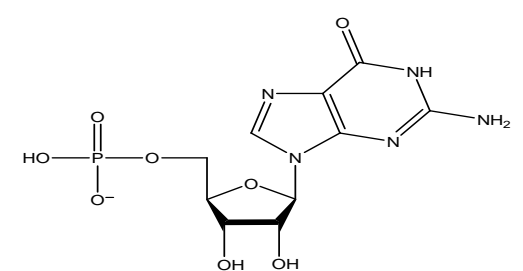

Guanosine 5'-monophosphate (GMP) 


\begin{tabular}{|clr|}
\hline 1 & GLS (DGEWQQVLNVWGKVEA) D (IAGHGQEVLI & 30 \\
31 & RLFTG) HP (ETLE) KFDKFKHLKT (EAEMK) AS (ED & 60 \\
61 & LKKHGTVVTALGGIL) KKKGHH (EAELKPLA & 90 \\
91 & QSHAT) KHKIP (IKYLEFISDAIIHVLHSK) HP & 120 \\
121 & GDFG (ADAQGAMTKALELFRNDIAAKYKEL) G & 150 \\
151 & FQG & 153 \\
& \multirow{2}{*}{ The Mb sequence } & \\
\hline
\end{tabular}

Figure 4.1. The structures of cisplatin, transplatin, and guanosine 5'-monophosphate and the $\mathrm{Mb}$ sequence. The residues in the same helices are underlined and given in the same parentheses.

\subsubsection{The kinetics studies of Mb-cisplatin and Mb-transplatin interactions}

$100 \mu \mathrm{M} \mathrm{Mb}$ was reacted with cisplatin (or transplatin) at a Mb:cisplatin (or Mb:transplatin) molar ratio of $1: 6$ in a $5 \mathrm{mM} \mathrm{NH}_{4} \mathrm{OAc}$ solution $\left(\mathrm{pH}\right.$ 6.8) at $37^{\circ} \mathrm{C}$. Aliquots of the Mb-cisplatin and Mb-transplatin solutions were withdrawn and examined by ESI-QITMS (LCQ ${ }^{\mathrm{TM}}$, Thermo Finnigan, San Jose, CA), described below, at selected times over a $30 \mathrm{~h}$ period. Prior to ESI-QITMS, each solution was diluted to $500 \mathrm{nM}$ with a $50 \% \mathrm{MeOH}-0.3 \%$ HAc solution in order to denature $\mathrm{Mb}$ and adjust charges on the $\mathrm{Mb}$ species so that mass to charge ratios $(\mathrm{m} / \mathrm{z})$ of the $\mathrm{Mb}$ species were within the mass range of the ion trap. The percentage of each species in the solution was estimated by the ratio of the peak area of each species to the sum of the peak areas of all the species. The plot of the percentage of each Mb species in the solution versus the reaction time yielded the kinetics plot. 


\subsubsection{The digestion of Mb-cisplatin and Mb-transplatin adducts}

$\mathrm{Mb}$-cisplatin and Mb-transplatin adducts were prepared by allowing the reactions described above to proceed for $27 \mathrm{~h}$. The obtained $\mathrm{Mb}$ adducts and free $\mathrm{Mb}$ were digested under the same conditions. Prior to trypsin digestion, all the Mb solutions were denatured by mixing the $\mathrm{Mb}$ solutions with a 4-fold volume of a denaturing solution, consisting of $70 \% \mathrm{MeOH}$ and $25 \mathrm{mM} \mathrm{NH}_{4} \mathrm{HCO}_{3}$. After denaturation for 10 $\min$, free $\mathrm{Mb}$ and the $\mathrm{Mb}$ adducts were digested by trypsin at a protein to enzyme ratio of 50:1 (w/w) under $37^{\circ} \mathrm{C}$ for $75 \mathrm{~min}$. The obtained digests were diluted with the same volume of the $50 \%$ MeOH-0.3\% HAc solution before ESI-QITMS.

\subsubsection{Reactions of the Mb-cisplatin and Mb-transplatin adducts with 5'-GDP}

The Mb-cisplatin and Mb-transplatin adducts prepared under the same conditions as those used for protein digestion in 4.2.3. were thoroughly desalted by Microcon YM-3 centrifugal filter devices (Millipore, Billerica, MA). The desalted Mb-cisplatin and Mb-transplatin adducts were reacted with GMP $(5 \mathrm{mM})$ at molar ratio of 1:5 (the $\mathrm{Mb}$ adducts:GMP) under $\mathrm{pH}=6.8,37^{\circ} \mathrm{C}$. The formation of the Mb-GMP adducts was monitored over 3 days by ESI-QITMS. The percentage of each Mb species in the solution was estimated by the ratio of the peak area of each species to the total peak areas of all the $\mathrm{Mb}$ species. 


\subsubsection{ESI-MS and MS}

The reactions of cisplatin and transplatin with $\mathrm{Mb}$ and the reactions of the Mb-cisplatin and Mb-transplatin adducts with GMP were monitored on a quadrupole ion trap mass spectrometer equipped with a standard electrospray ionization source $\left(\mathrm{LCQ}^{\mathrm{TM}}\right.$, Finnigan, San Jose, CA). The spray voltage applied was $4.0 \mathrm{kV}$ and the temperature of the heated metal capillary was $200^{\circ} \mathrm{C}$. The sample was injected by direct infusion at a flow rate of $3 \mu \mathrm{L} / \mathrm{min}$ by a syringe pump. The flow rate of sheath gas (nitrogen) was 30 units/min. The capillary voltage and the tube lens voltage were held at $35 \mathrm{~V}$ and $10 \mathrm{~V}$, respectively. The ion injection time was $5 \mathrm{~ms}$. ESI-MS spectra were recorded in the range of $\mathrm{m} / \mathrm{z} 650-2000$.

The free $\mathrm{Mb}$ digest and the adduct digests were analyzed on a hybrid linear ion trap-Fourier transform mass spectrometer system equipped with an Ion Max ion source (LTQ-FT, Thermo Finnigan, San Jose, CA). The conditions of the ion source were described above. All the digests were analyzed by FT-MS identify ions characteristic of the adducts. The fragments observed only in the adduct digests were further analyzed by $\mathrm{MS} / \mathrm{MS}$ and $\mathrm{MS}^{3}$ on the linear ion trap to provide additional structural information. The isolation width was set at $5 \mathrm{~m} / \mathrm{z}$ and $35 \%$ of normalized collision energy (NCE\%) was applied during collision induced dissociation (CID). The isotope distributions of the product ions were acquired by zoom scan. All the product-ion spectra were recorded in a full mass range. In spectral analysis, ExPASy 
Proteomics Server was used to search the Mb sequence and calculate the theoretical mass of $b$ ions and $y$ ions for the peptides of interest. The data were plotted by OriginPro 8 software (OriginLab Corporation, Northampton, MA).

\subsection{Results and Discussion}

\subsubsection{The kinetics of the Mb-cisplatin and Mb-transplatin interactions}

The interactions of cisplatin and transplatin with $\mathrm{Mb}$ at $\mathrm{Mb}$ :cisplatin and $\mathrm{Mb}$ :transplatin molar ratio of 1:6 respectively were monitored by ESI-QITMS over 30 h. Monoadducts (1:1 Mb-cisplatin and 1:1 Mb-transplatin adducts) and diadducts (1:2 Mb-cisplatin and 1:2 Mb-transplatin adducts) are the primary adducts observed in the Mb-cisplatin and Mb-transplatin solutions. Figure 4.2a. and Figure 4.2b. show the percentage change of each $\mathrm{Mb}$ species in the Mb-cisplatin and Mb-transplatin solutions over $30 \mathrm{~h}$, respectively.

Comparison of Figure 4.2a. and Figure 4.2b. indicates that the adduct formation in the Mb-cisplatin interactions is faster than in the Mb-transplatin interactions. In Figure 4.2a., the percentage of the 1:1 Mb-cisplatin adducts increases steeply and reaches $40 \%$ in $6 \mathrm{~h}$. However, Figure $4.2 \mathrm{~b}$. shows $12 \mathrm{~h}$ was used to produce the similar amount of 1:1 Mb-transplatin adducts. For the diadducts, 1:2 Mb-cisplatin adducts are observed at $9 \mathrm{~h}$ in Figure 4.2a., while 1:2 Mb-transplatin adducts are 
observed at $12 \mathrm{~h}$ in Figure 4.2b. In addition, Figure 4.2b. shows that the $\mathrm{Mb}$-transplatin interactions attain equilibrium in 24h because both 1:1 Mb-transplatin adducts and 1:2 Mb-transplatin adducts remain constant after $24 \mathrm{~h}$. But this is not the case for the Mb-cisplatin interactions because the percentage of 1:2 Mb-cisplatin adducts continues to increase slowly after $30 \mathrm{~h}$. 1:3 Mb-cisplatin adducts will be observed after a longer reaction time. In this research, the Mb-cisplatin and Mb-transplatin interactions were allowed to proceed for $27 \mathrm{~h}$ to prepare the monoadducts and the diadducts. 

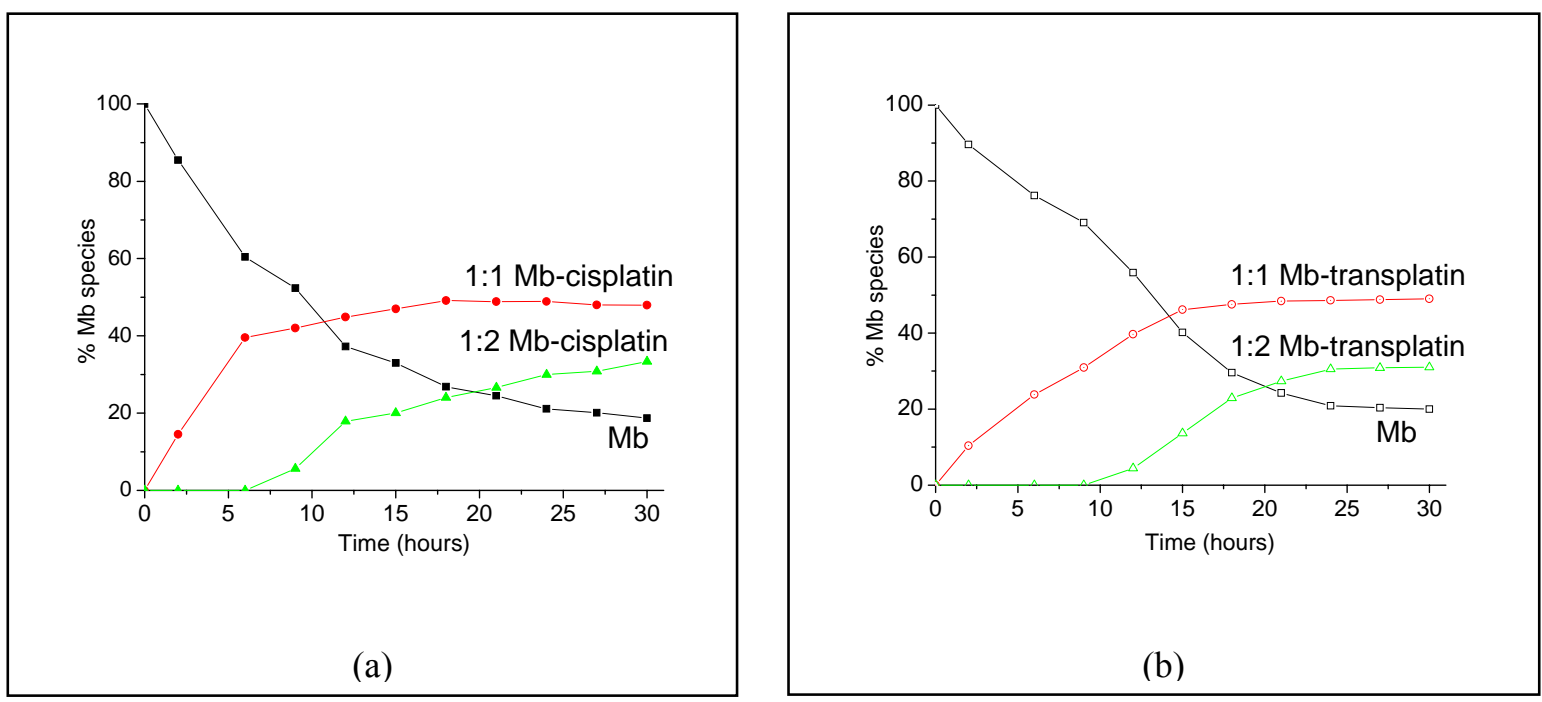

Figure 4.2. The kinetics plots for the Mb-cisplatin and Mb-transplatin solutions obtained by monitoring the percentages of the Mb species in the respective solutions as a function of time:(a) The Mb-cisplatin solution; (b) The Mb-transplatin solution

\subsubsection{The Mb-cisplatin and Mb-transplatin adducts}

Figure 4.3. shows the deconvoluted ESI-QITMS spectra of free Mb and the $\mathrm{Mb}$-cisplatin and Mb-transplatin adducts obtained by reacting $\mathrm{Mb}$ with cisplatin and transplatin for $27 \mathrm{~h}$. As shown in Figure 4.3, the formation of the monoadducts (measured mass 17, $182 \mathrm{Da}$ ) and the diadducts (measured mass 17, $409 \mathrm{Da}$ ) leads to 228 and $455 \mathrm{Da}$ of mass increase from free $\mathrm{Mb}$ (measured mass 16, $954 \mathrm{Da}$ ), suggesting $\mathrm{Pt}\left(\mathrm{NH}_{3}\right)_{2}$ (theoretical mass $228.016 \mathrm{Da}$ ) is the Pt compound that interacts with $\mathrm{Mb}$. For clarity, the charge states of the Pt compounds are not indicated. 
In the first $4 \mathrm{~h}$ of the Mb-transplatin interactions, the peak corresponding to monoadduct $\mathrm{Mb}-\mathrm{Pt}\left(\mathrm{NH}_{3}\right)_{2} \mathrm{Cl}$ is observed. However, the peak corresponding to the monoadduct $\mathrm{Mb}-\mathrm{Pt}\left(\mathrm{NH}_{3}\right)_{2}$ was the only peak observed in the first $4 \mathrm{~h}$ of the Mb-cisplatin interactions, indicating faster formation of $\mathrm{Mb}-\mathrm{Pt}\left(\mathrm{NH}_{3}\right)_{2}$ in the Mb-cisplatin interactions ${ }^{14}$. The different speed in the formation of the monoadducts $\mathrm{Mb}-\mathrm{Pt}\left(\mathrm{NH}_{3}\right)_{2}$ for the $\mathrm{Mb}$-cisplatin and $\mathrm{Mb}$-transplatin interactions might arise from the different arrangement of two chlorides for cisplatin and transplatin. Two chlorides in cisplatin are adjacent to each other and this arrangement is probably more favorable to the formation of the bidentate adducts $\mathrm{Mb}-\mathrm{Pt}\left(\mathrm{NH}_{3}\right)_{2}$.

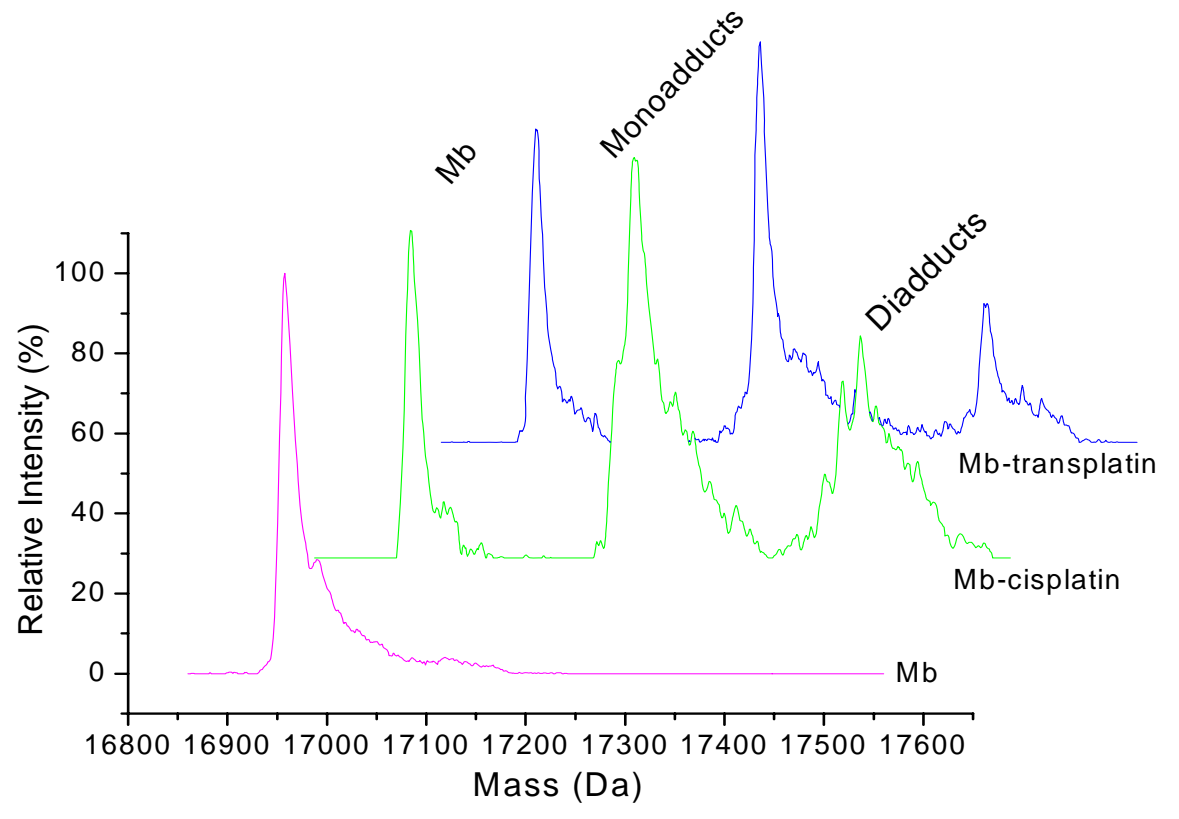

Figure 4.3. Deconvoluted ESI-QITMS spectra of free $\mathrm{Mb}$ and the Mb-cisplatin and Mb-transplatin adducts obtained by reacting $\mathrm{Mb}$ with cisplatin and transplatin for 27 hours 


\subsubsection{Determination of the cisplatin and transplatin binding sites on}

Mb

Determination of the binding sites of cisplatin and transplatin on Mb provides insights into the binding modes of $\mathrm{Pt}\left(\mathrm{NH}_{3}\right)_{2}$ with $\mathrm{Mb}$ for the Mb-cisplatin and Mb-transplatin interactions. In this research, the binding sites of cisplatin and transpaltin are determined using our previously reported mass spectrometric $\operatorname{approach}^{13}$

\subsubsection{The digestion of the Mb-cisplatin and Mb-transplatin adducts}

The Mb-cisplatin and Mb-transplatin adducts were subjected to trypsin digestion to obtain smaller fragments for $\mathrm{MS}^{\mathrm{n}}$ analyses. Free $\mathrm{Mb}$ was digested in parallel to serve as the control. According to the results of Chapter 3, the $70 \% \mathrm{MeOH}-25 \mathrm{mM}$ $\mathrm{NH}_{4} \mathrm{HCO}_{3}$ solvent is used to denature $\mathrm{Mb}$, the Mb-cisplatin adducts, and the Mb-transplatin adducts before trypsin digestion for $75 \mathrm{~min}$.

\subsubsection{FT-MS analyses of the digests}

FT-MS analyses were carried out to investigate the fragments in the digests of free $\mathrm{Mb}$, the Mb-cisplatin adducts, and the Mb-transplatin adducts. Figure 4.4., 4.5., and 4.6. are the FT-MS spectra of the digests of free Mb, the Mb-cisplatin adducts, and the Mb-transplatin adducts, respectively. From appearance, the three spectra are quite alike. Detailed examination of the three spectra indicates most fragments are observed at $\mathrm{m} / \mathrm{z}$ over 800 with high charge states ranging from $5+$ to $8+$, suggesting 
partial digestion of free $\mathrm{Mb}$ and the $\mathrm{Mb}$ adducts. The FT-MS spectra of the adduct digests were compared with that of the free $\mathrm{Mb}$ digest in order to identify the unique fragments in the adduct digests. The comparison indicates that most fragments in the three digests are common based on their $\mathrm{m} / \mathrm{z}$ and their charge state distributions.

The peaks corresponding to two fragments $1313.27^{5+}$ and $1316.68^{5+}$ are only observed in the FT-MS spectra of the adduct digests, indicated by the expanded FT-MS spectra of the free Mb digest, the Mb-cisplatin adduct digest, and the Mb-transplatin adduct digest in Figure 4.7., 4.8., and 4.9., respectively. Surprisingly, the peak envelops corresponding to the $1313.27^{5+}$ and $1316.68^{5+}$ ions are observed in both Figure 4.8. and Figure 4.9.

The MS/MS spectra of the $1313.27^{5+}$ and $1316.68^{5+}$ ions are displayed in Figure 4.10. and Figure 4.11., respectively. The $1313.27^{5+}$ and $1316.68^{5+}$ ions are of similar structure and have the identical peptide sequence because most peaks in the product-ion spectrum of the $1313.27^{5+}$ ion (Figure 4.10.) are also observed in the product-ion spectrum of the $1316.68^{5+}$ ion (Figure 4.11.). According to 17.05 Da mass difference between the $1313.27^{5+}$ and $1316.68^{5+}$ ions and the MS/MS and $\mathrm{MS}^{3}$ analyses of the $1313.27^{5+}$ and $1316.68^{5+}$ ions in the two adduct digests, the $1313.27^{5+}$ and $1316.68^{5+}$ ions are identified as $\mathrm{Pt}\left(\mathrm{NH}_{3}\right)$ and $\mathrm{Pt}\left(\mathrm{NH}_{3}\right)_{2}$ bound peptides His97-Gly153 respectively. Therefore, the characterization of the $1313.27^{5+}$ and $1316.68^{5+}$ ions in the adduct digests reveals one common binding site of cisplatin and transplatin on $\mathrm{Mb}$. Because the isotope distribution of the $1316.68^{5+}$ ion is overlapped 
with the isotope distribution of the peptide Leu32-Lys78 $\left(1317.48^{4+}\right)$ in the FT-MS spectra of both the adduct digests, the product-ion spectra of the MS/MS and $\mathrm{MS}^{3}$ analyses of the $1313.27^{5+}$ ion are displayed to show the results for the determination of the common binding site of cisplatin and transplatin on $\mathrm{Mb}$. 


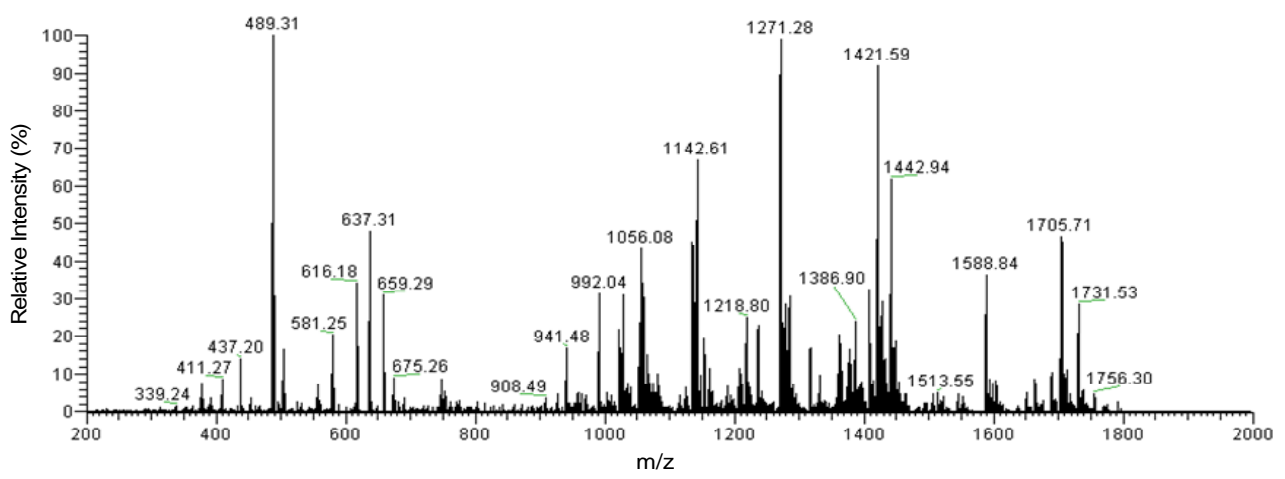

Figure 4.4. FT-MS spectrum of the free Mb digest

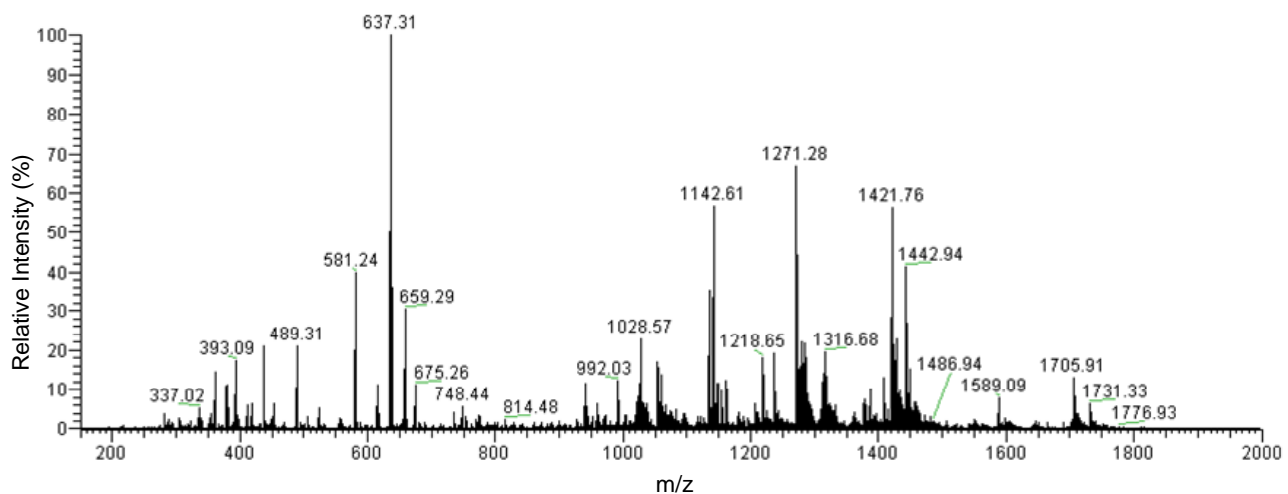

Figure 4.5. FT-MS spectrum of the Mb-cisplatin adduct digest

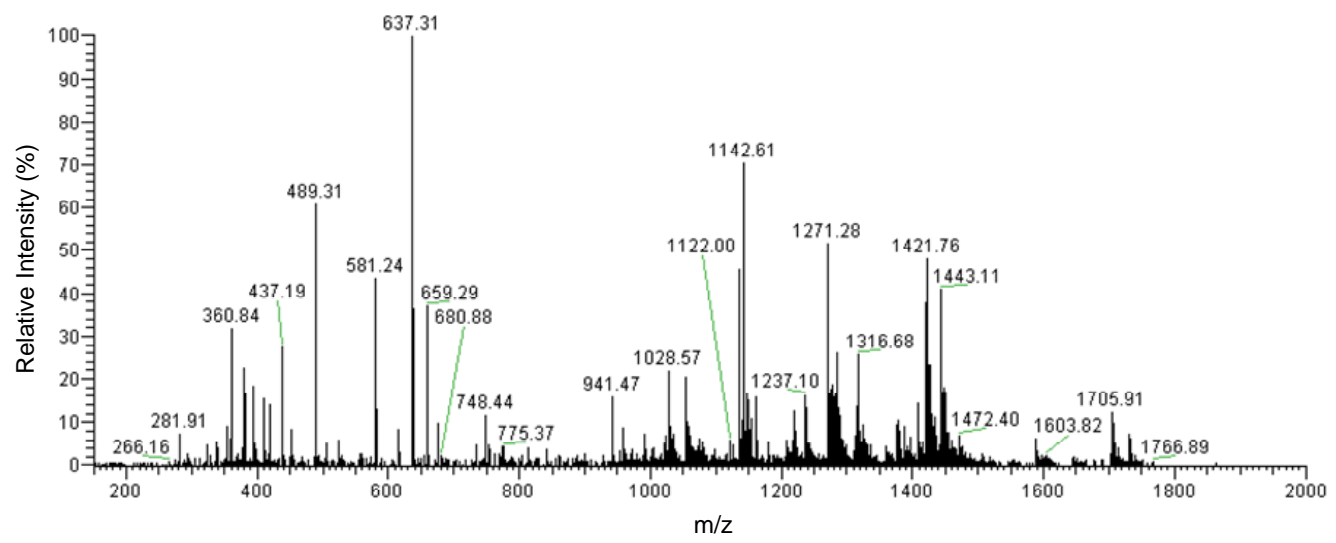

Figure 4.6. FT-MS spectrum of the Mb-transplatin adduct digest 


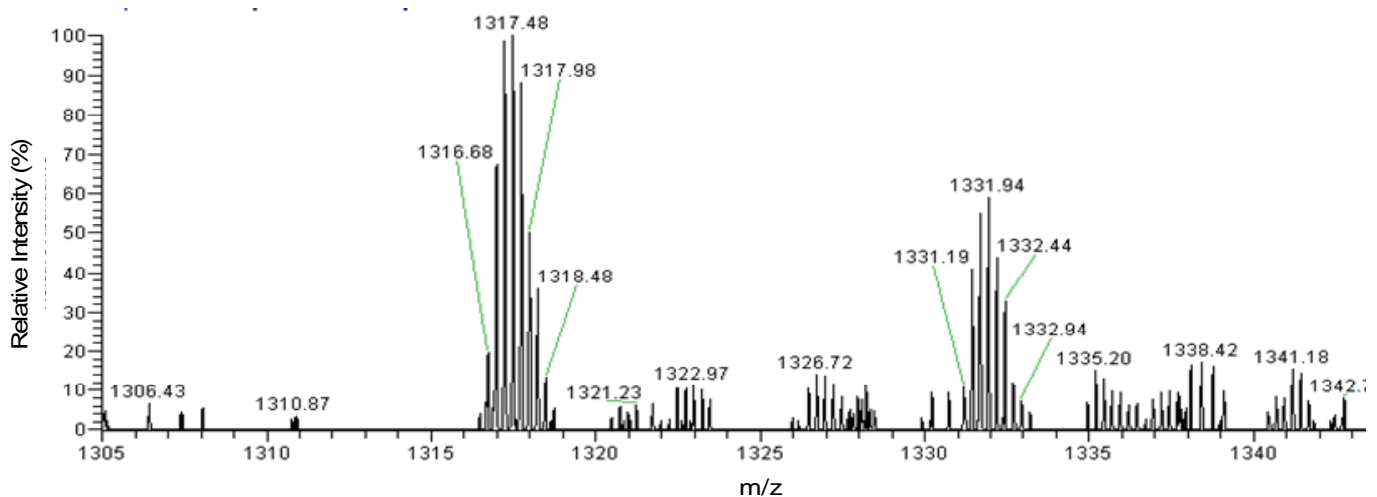

Figure 4.7. Expanded FT-MS spectrum of the free Mb digest

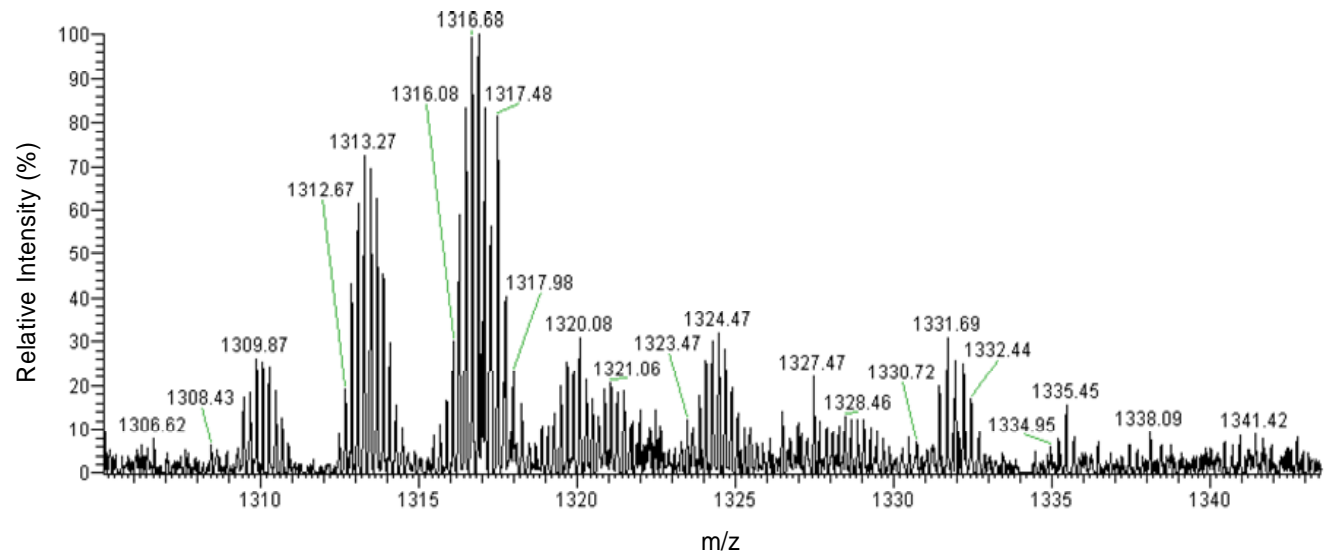

Figure 4.8. Expanded FT-MS spectra of the Mb-cisplatin digest

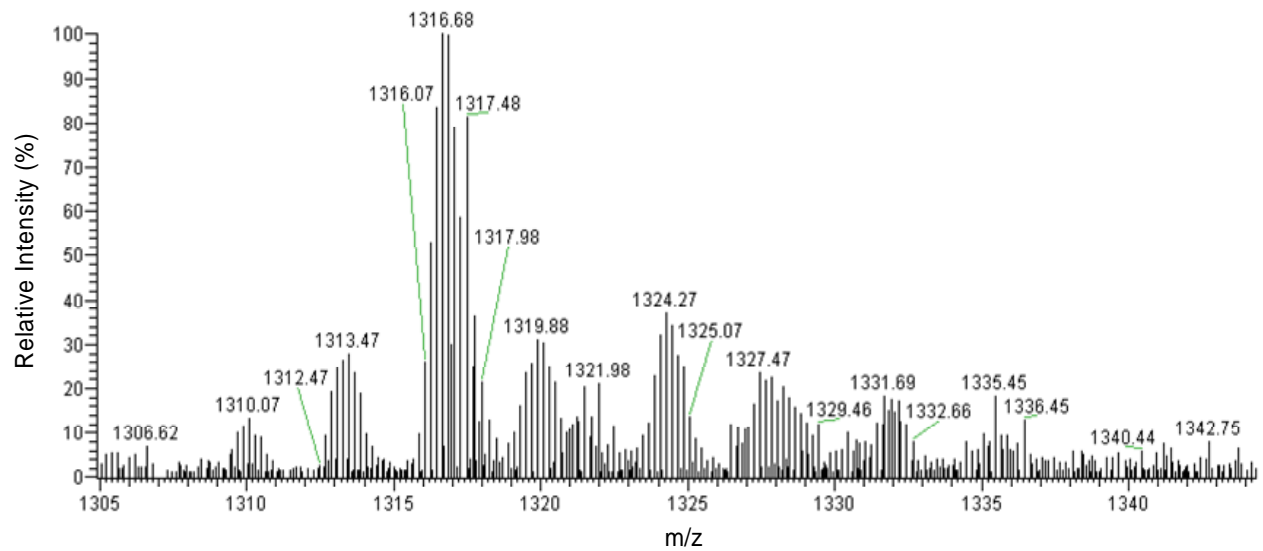

Figure 4.9. Expanded FT-MS spectra of the Mb-transplatin digest 


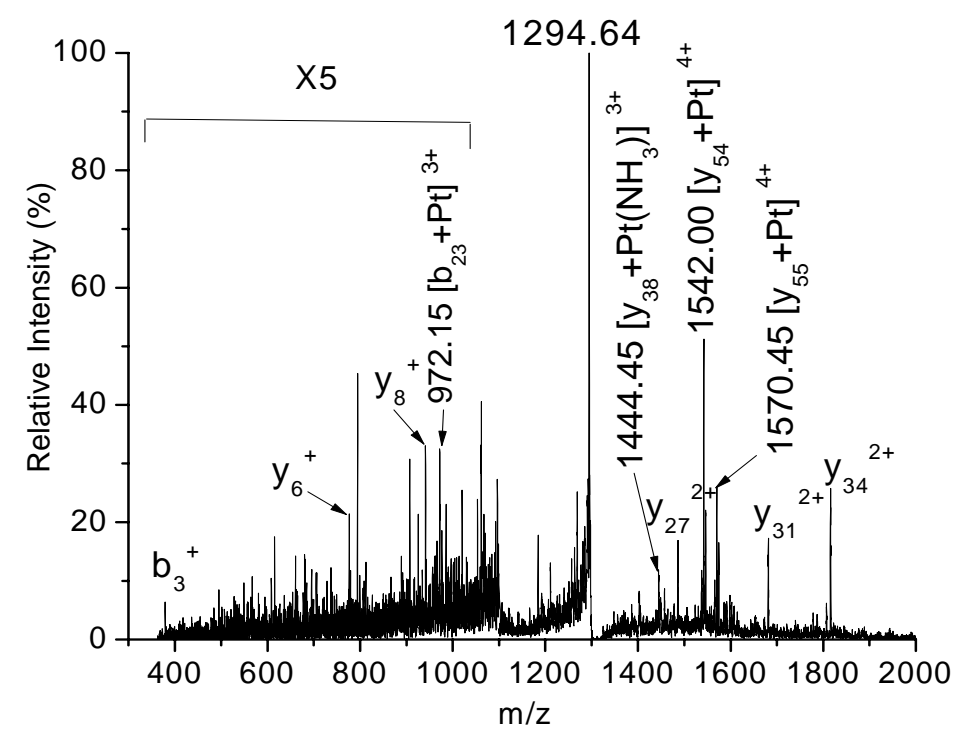

Figure 4.10. The product-ion spectrum of the $1313.27^{5+}$ ion. The peptide sequence of the 1313.27 $7^{5+}$ ion: (His97-Gly153) HKIPIKYLEFISDAIIHVLHSKHPGDFG ADAQGAMTKALE LFRNDIAAKYKELGFQG

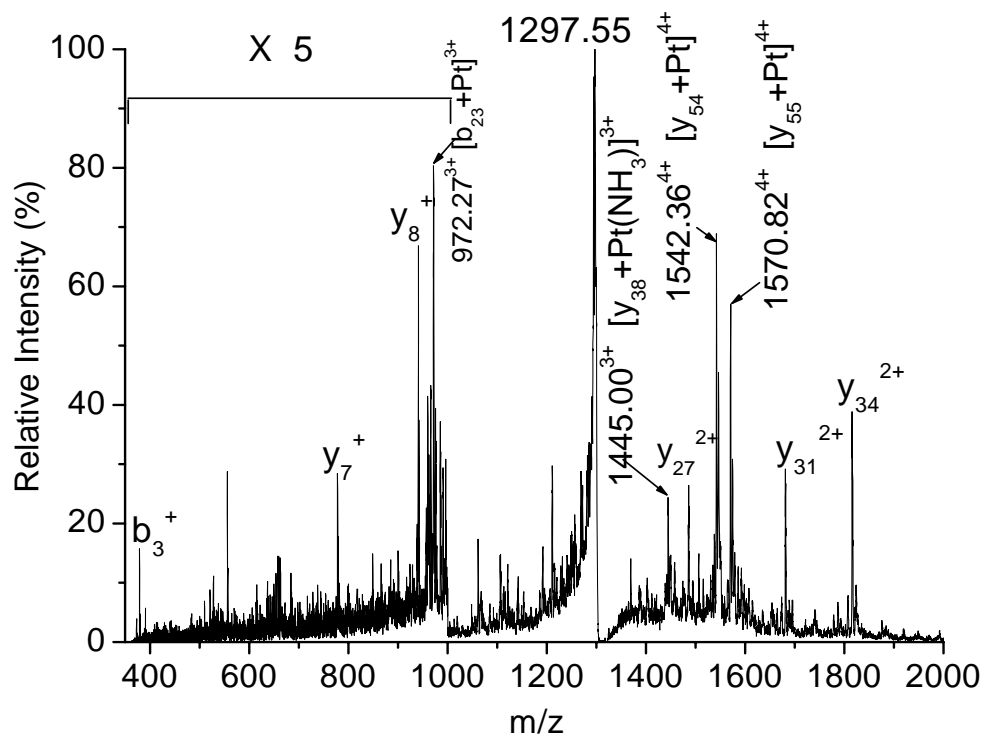

Figure 4.11. The product-ion spectrum of the $1316.68^{5+}$ ion. The peptide sequence of the $1316.68^{5+}$ ion: (His97-Gly153) HKIPIKYLEFISDAIIHVLHSKHPGDFGADAQGAMTK ALEL FRNDIAAKYKELGFQG 


\subsubsection{Identification of the peptide sequence of the $1313.27^{5+}$ ion}

The structure of the $1313.27^{5+}$ ion as a $\mathrm{Pt}\left(\mathrm{NH}_{3}\right)$ bound peptide His97-Gly153 is identified by the assigned sequence ions $\left(\mathrm{b}_{3}{ }^{+}, \mathrm{y}_{6}{ }^{+}, \mathrm{y}_{8}{ }^{+}, \mathrm{y}_{27}{ }^{2+}, \mathrm{y}_{31}{ }^{2+}\right.$, and $\left.\mathrm{y}_{34}{ }^{2+}\right)$ and two Pt-containing fragment ions $\left(1542.00^{4+}\right.$ and $\left.1570.45^{4+}\right)$ in the product-ion spectrum of the MS/MS analysis of the $1313.27^{5+}$ ion, Figure 4.10 .

(I) The abundant sequence ions $\mathrm{y}_{27}{ }^{2+}, \mathrm{y}_{31}{ }^{2+}$ and $\mathrm{y}_{34}{ }^{2+}$

The $\mathrm{y}_{27}{ }^{2+}, \mathrm{y}_{31}{ }^{2+}$, and $\mathrm{y}_{34}{ }^{2+}$ ions in Figure 4.10. are assigned by the $\mathrm{MS}^{3}$ analyses of the $1313.27^{5+}$ ion at these three ions. The product-ion spectra of $\mathrm{MS}^{3}$ analyses of the $1313.27^{5+}$ ion at the $\mathrm{y}_{27}{ }^{2+}, \mathrm{y}_{31}{ }^{2+}$, and $\mathrm{y}_{34}{ }^{2+}$ ions are displayed in Figure 4.12., 4.13., and 4.14., respectively. The peaks corresponding to the $\mathrm{y}_{27}{ }^{2+}$ and $\mathrm{y}_{31}{ }^{2+}$ ions are abundant in the product-ion spectrum of the $\mathrm{MS}^{3}$ analysis of the $1313.27^{5+}$ ion at $\mathrm{y}_{34}{ }^{2+}$, Figure 4.14., suggesting that the sequence of the $\mathrm{y}_{34}{ }^{2+}$ ion includes the sequences of the $\mathrm{y}_{27}{ }^{2+}$ and $\mathrm{y}_{31}{ }^{2+}$ ions. Similarly, the peak corresponding to the $\mathrm{y}_{27}{ }^{2+}$ ion is intense in the product-ion spectrum of the $\mathrm{MS}^{3}$ analysis of the $1313.27^{5+}$ ion at the $\mathrm{y}_{31}{ }^{2+}$ ion, Figure 4.13. Meanwhile, other $\mathrm{y}$ ions from $\mathrm{y}_{7}^{+}$to $\mathrm{y}_{11}{ }^{+}$of the peptide His97-Gly153 are also observed in the $\mathrm{MS}^{3}$ analyses of the $1313.27^{5+}$ ion at the $\mathrm{y}_{27}{ }^{2+}$ and $\mathrm{y}_{31}{ }^{2+}$ ions which confirm the peptide sequence of the $1313.27^{5+}$ ion as His97-Gly153. Significantly, the identification of the intense $\mathrm{y}$ ions, $\mathrm{y}_{27}{ }^{2+}, \mathrm{y}_{31}{ }^{2+}$, and $\mathrm{y}_{34}{ }^{2+}$, indicates that $\mathrm{Pt}\left(\mathrm{NH}_{3}\right)$ in the $1313.27^{5+}$ ion is not attached to the amino acid residues from Pro120 to Gly153. In addition, the abundance of the $\mathrm{y}_{27}{ }^{2+}$ and $\mathrm{y}_{31}{ }^{2+}$ ions in Figure 4.10. might arise from 
selective cleavage at Asp122 Phe123 and Asp126 Ala127 due to "aspartic acid effect" 15 . "Proline effect"15 leads to the selective cleavage at His119 Pro120 during the MS/MS analysis of the $1313.27^{5+}$ ion, yielding the abundant $\mathrm{y}_{34}{ }^{2+}$ ion in Figure 4.10 .

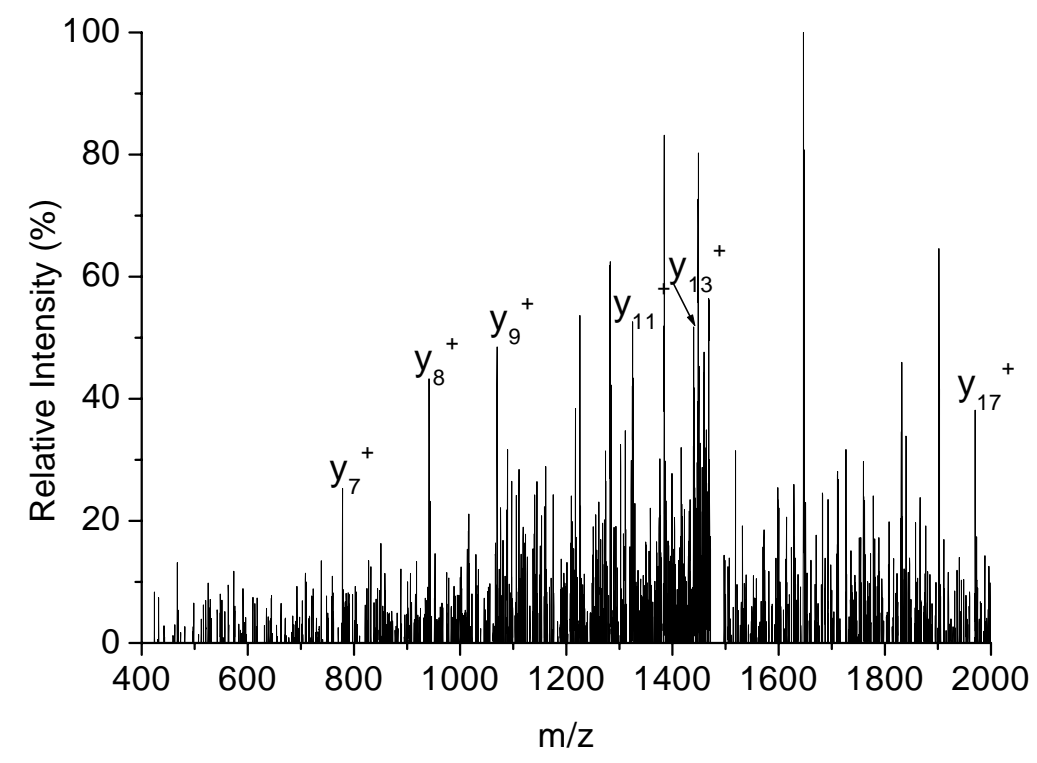

Figure 4.12. The product-ion spectrum of the $\mathrm{MS}^{3}$ analysis of the $1313.27^{5+}$ ion at the $\mathrm{y}_{27}{ }^{2+}$ ion. The peptide sequence of the $\mathrm{y}_{27}{ }^{2+}$ ion: AQGAMTKALELFRNDIAAKYKELGFQG 


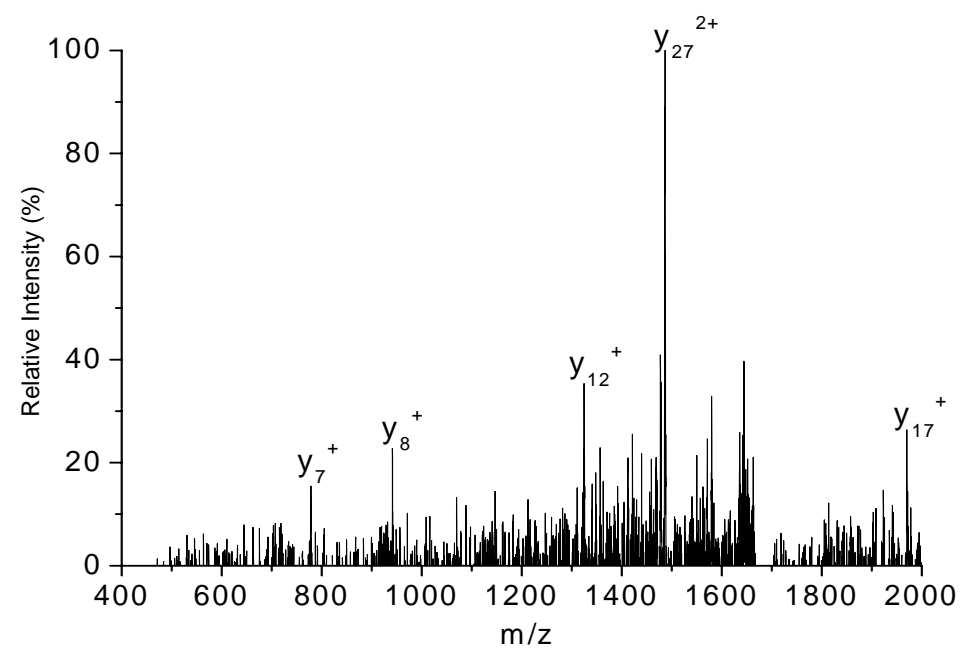

Figure 4.13. The product-ion spectrum of the $\mathrm{MS}^{3}$ analysis of the $1313.27^{5+}$ ion at the $\mathrm{y}_{31}{ }^{2+}$ ion. The peptide sequence of the $\mathrm{y}_{31}{ }^{2+}$ ion: FGADAQGAMTKALELFRNDIAAKYKELGFQG

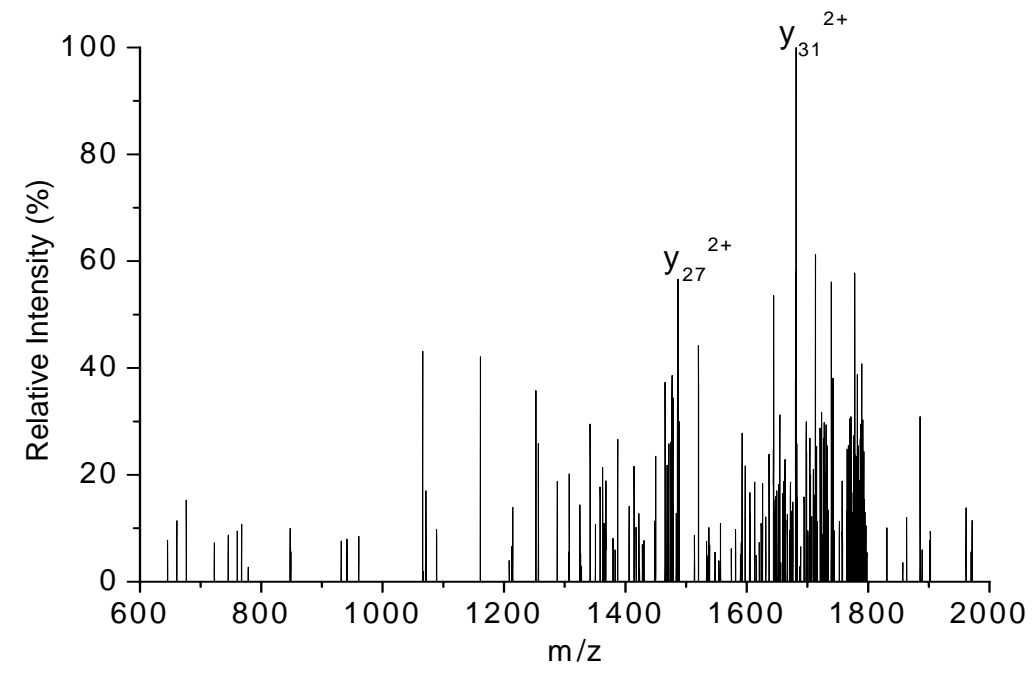

Figure 4.14. The product-ion spectrum of the $\mathrm{MS}^{3}$ analysis of the $1313.27^{5+}$ ion at the $\mathrm{y}_{34}{ }^{2+}$ ion. The peptide sequence of the $y_{34}{ }^{2+}$ ion: PGDFGADAQGAMTKALELFRNDIAAKYKELGFQG 


\section{(II) The abundant Pt-containing ions}

Two abundant ions at m/z 1542.00 and 1570.45 are two Pt-containing fragment ions with charges states of $4+$ according to their charge state distributions in Figure 4.15. Several $\mathrm{y}$ ions in Figure 4.15. including the $\mathrm{y}_{27}{ }^{2+}, \mathrm{y}_{31}{ }^{2+}$, and $\mathrm{y}_{34}{ }^{2+}$ ions are observed in the product-ion spectra of the $\mathrm{MS}^{3}$ analysis of the $1313.27^{5+}$ ion at $\mathrm{m} / \mathrm{z}$ 1542.00 and 1570.45, which are displayed in Figure 4.16. and Figure 4.17., suggesting that the $1542.00^{4+}$ and $1570.45^{4+}$ ions correspond to Pt bound y ions. The mass difference between the $1542.00^{4+}$ and $1570.45^{4+}$ ions is $113.80 \mathrm{Da}$, which is the residue mass of Ile/Leu. The $1542.00^{4+}$ and $1570.45^{4+}$ ions are produced by losing fragments with total mass of 398.35 and 284.55 Da respectively from the $1313.27^{5+}$ ion during CID, which are close to theoretical mass of $\left[\mathrm{b}_{3}+\mathrm{NH}_{3}\right]^{+}(396.27 \mathrm{Da})$ and $\left[\mathrm{b}_{2}+\mathrm{NH}_{3}\right]^{+}(283.19 \mathrm{Da})$ respectively. The peak corresponding to the $\mathrm{b}_{3}{ }^{+}$ion is observed at $\mathrm{m} / \mathrm{z} 379.27$ in Figure 4.10 . Therefore, the $1542.00^{4+}$ and $1570.45^{4+}$ ions are assigned as $\left[\mathrm{y}_{54}+\mathrm{Pt}\right]^{4+}$ and $\left[\mathrm{y}_{55}+\mathrm{Pt}\right]^{4+}$ produced by cleaving the peptide bonds at Ile99 Pro100 and Lys98 Ile99 combined with losing the $\mathrm{NH}_{3}$ ligand on the $\mathrm{Pt}\left(\mathrm{NH}_{3}\right)$ compound during the MS/MS analysis of the $1313.27^{5+}$ ion. The high intensity of the $1542.00^{4+}$ and $1570.45^{4+}$ ions also indicates selective cleavage at Ile99 Pro100 and Lys98 Ile99 due to the two basic residues, Pro100 and Lys98 ${ }^{15}$. Consequently, the analysis of the $1542.00^{4+}$ and $1570.45^{4+}$ ions further confirms the structure of the $1313.27^{5+}$ ion as a $\mathrm{Pt}\left(\mathrm{NH}_{3}\right)$-bound peptide His97-Gly153. 

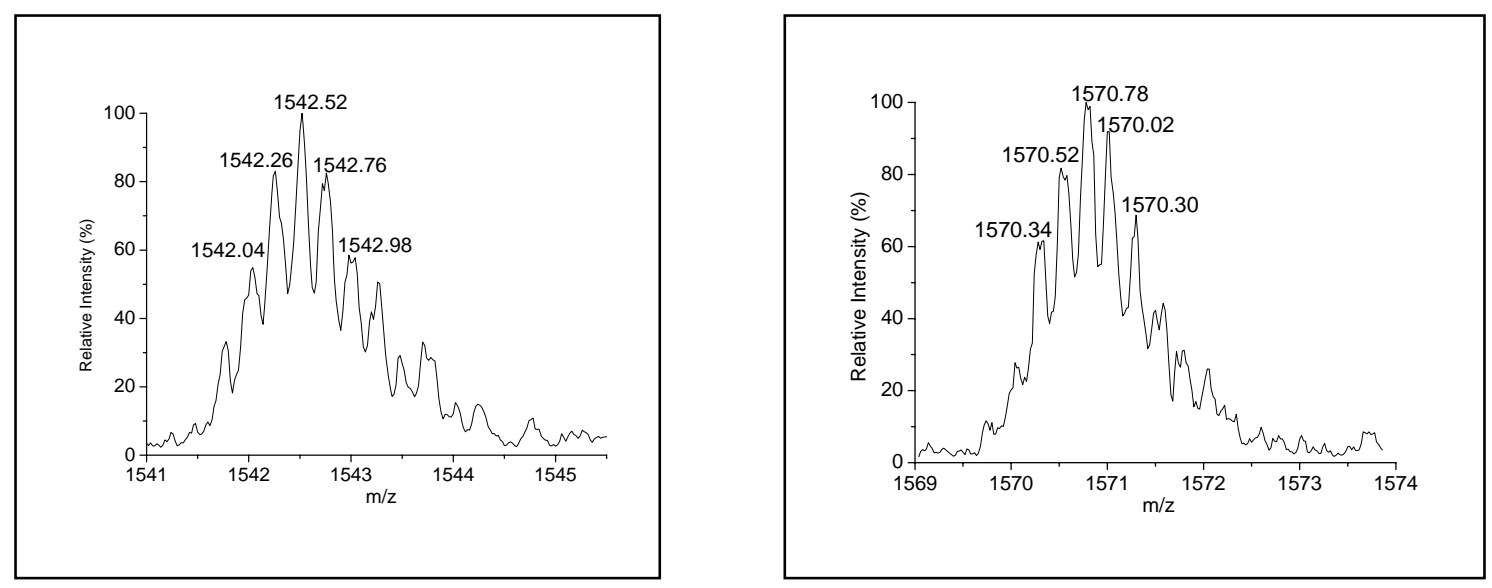

Figure 4.15. The isotope distributions of the $1542.00^{4+}$ and $1570.45^{4+}$ ions in Figure 4.10.

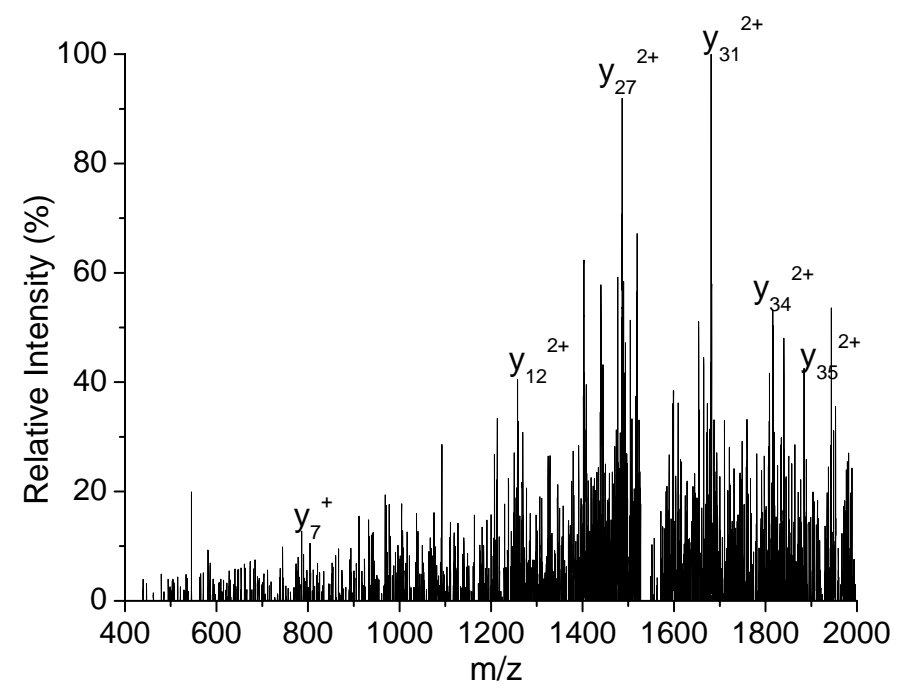

Figure 4.16. The product-ion spectrum of the $M S^{3}$ analysis of the $1313.27^{5+}$ ion at $\mathrm{m} / \mathrm{z}$ 1542.00. The peptide sequence of the $1542.00^{4+}$ ion: PIKYLEFISDAIHVLHSKHPGDFGADA QGAMTKALELFRNDIAA KYKELGFQG 


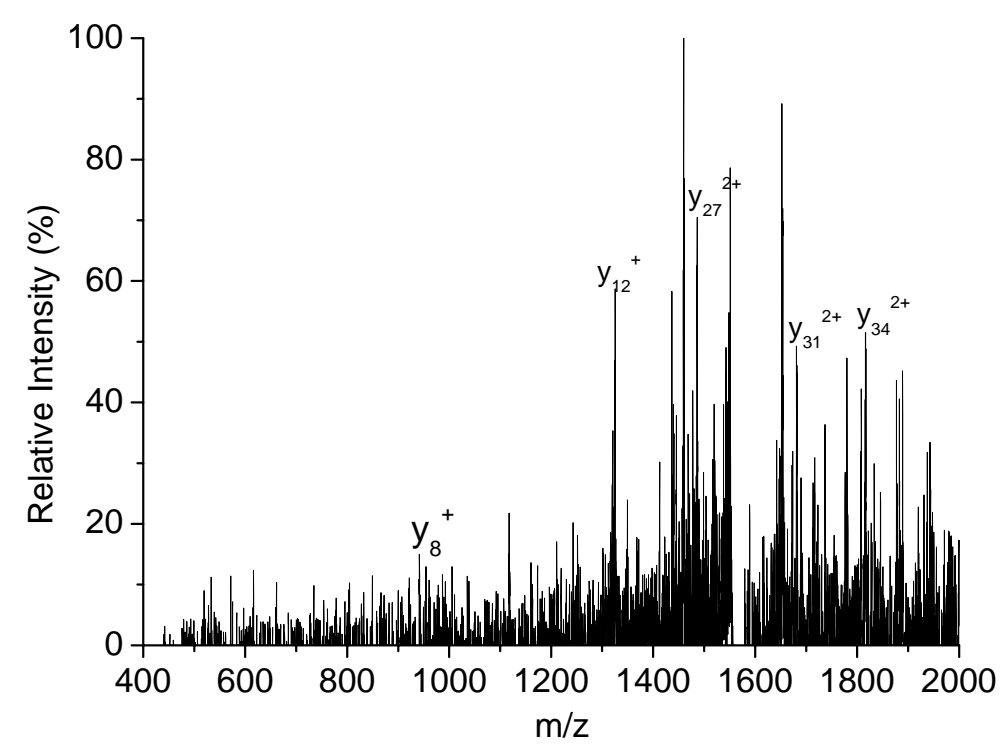

Figure 4.17. The product-ion spectrum of the $\mathrm{MS}^{3}$ analysis of the $1313.27^{5+}$ ion at $\mathrm{m} / \mathrm{z}$ 1570.45. The peptide sequence of the $1570.45^{4+}$ ion: IPIKYLEFISDAIIHVLHSKHPGDFGAD AQGAMTKALELFRNDIAAKYKELGFQG

\subsubsection{Determination of the $\mathrm{Pt}\left(\mathrm{NH}_{3}\right)$ binding site on His97-Gly153}

The binding site of $\mathrm{Pt}\left(\mathrm{NH}_{3}\right)$ on the peptide His97-Gly153 is determined by the $\mathrm{MS}^{3}$ analyses of the $1313.27^{5+}$ ion at two Pt-containing fragment ions $972.15^{3+}$ and $1445.07^{3+}$ in Figure 4.10

(I) The $\mathrm{MS}^{3}$ analysis of the $1313.27^{5+}$ ion at $\mathrm{m} / \mathrm{z} 972.15$

Figure 4.18. shows the isotope distribution of the $972.15^{3+}$ ion and the product-ion spectrum of the $\mathrm{MS}^{3}$ analysis of the $1313.27^{5+}$ ion at $\mathrm{m} / \mathrm{z} 972.15$. The isotope distribution of the $972.15^{3+}$ ion indicates it is a triply charged Pt-containing fragment ion. According to the mass of the $1313.27^{5+}$ ion, the $972.15^{3+}$ ion is the 
counterpart of the $\mathrm{y}_{34}{ }^{2+}$ ion $(\mathrm{m} / \mathrm{z}$ 1815.91) in Figure 4.10, estimated to be a Pt-containing $\mathrm{b}_{23}{ }^{3+}$ ion according to the structure of the $1313.27^{5+}$ ion. Several $\mathrm{b}$ ions of the $1313.27^{5+}$ ion in Figure 4.18., such as $\mathrm{b}_{3}{ }^{+}, \mathrm{b}_{17}{ }^{2+}, \mathrm{b}_{18}{ }^{2+}$, and $\mathrm{b}_{19}{ }^{2+}$ ions, confirm the structure of the $972.15^{3+}$ ion as the $b_{23}{ }^{3+}$ ion. In Figure 4.18 , the $1268.73^{2+}$ ion is the counterpart of the $\mathrm{b}_{3}{ }^{+}$ion $(\mathrm{m} / \mathrm{z} 379.27)$ based on the mass of the $972.15^{3+}$ ion. $1388.82^{2+}$ and $1325.45^{2+}$ ions are produced by losing $\mathrm{H}$ and $\mathrm{HK}$ residues from the $972.15^{3+}$ ion respectively, consistent with the peptide sequence of the $972.15^{3+}$ ion as His97-His119 starting with $\mathrm{HK}$ residues at the $\mathrm{N}$ terminus. Importantly, the appearance of the intense $\mathrm{b}_{19}{ }^{2+}$ ion at $\mathrm{m} / \mathrm{z} 1116.55$ indicates that $\mathrm{Pt}$ is not bound to the amino acid residues from His98 to Lys116, but bound to the side chains of HSKH residues. The expected mass of the Pt bound HSKH fragment is 683.35 Da. However, the $666.09^{+}$ion is observed, arising from neutral loss of either a $\mathrm{H}_{2} \mathrm{O}$ or a $\mathrm{NH}_{3}$ from the HSKH residues during the $\mathrm{MS}^{3}$ analysis. 


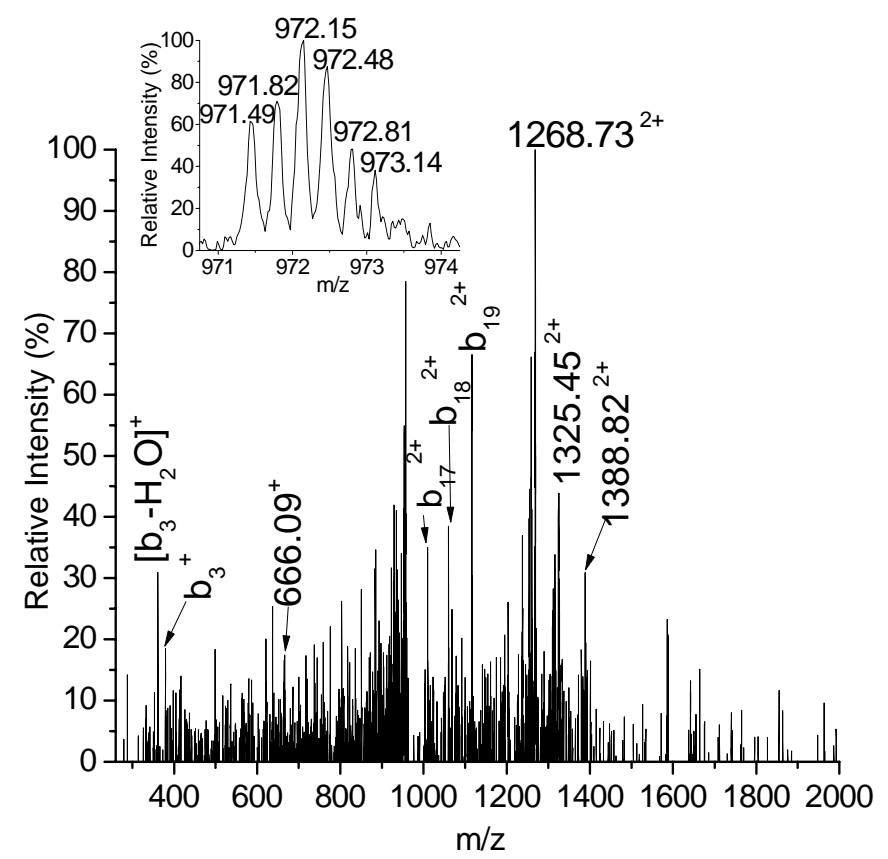

Figure 4.18. The isotope distribution of the $972.15^{3+}$ ion and the $\mathrm{MS}^{3}$ analysis of the $1313.27^{5+}$ ion at $\mathrm{m} / \mathrm{z}$ 972.15. The peptide sequence of the $972.15^{3+}$ ion: (His97-His119) HKIPIKYLEFISD AlIHVLHSKH

(II) The $\mathrm{MS}^{3}$ analysis of the $1313.27^{5+}$ ion at $\mathrm{m} / \mathrm{z} 1444.45$

The $1444.45^{3+}$ ion is a Pt-containing $\mathrm{y}$ ion at the $\mathrm{C}$ terminus according to its isotope distribution and the $\mathrm{y}$ ions $\left(\mathrm{y}_{8}{ }^{+}, \mathrm{y}_{12}{ }^{+}, \mathrm{y}_{27}{ }^{2+}, \mathrm{y}_{31}{ }^{2+}\right.$ and $\left.\mathrm{y}_{34}{ }^{2+}\right)$ of the peptide His97-Gly153 in the product-ion spectrum of the $\mathrm{MS}^{3}$ analysis of the $1313.27^{5+}$ ion at $\mathrm{m} / \mathrm{z}$ 1444.45, Figure 4.19. In Figure 4.19., $1361.64^{+}$and $971.55^{+}$ions are complementary to the $\mathrm{y}_{27}{ }^{2+}(\mathrm{m} / \mathrm{z} 1486.45)$ and $\mathrm{y}_{31}{ }^{2+}(\mathrm{m} / \mathrm{z} 1681.27)$ ions, respectively. The high abundance of the $\mathrm{y}_{34}{ }^{2+}$ ion $(\mathrm{m} / \mathrm{z} 1816.55)$ indicates that $\mathrm{Pt}$ is not bound to the amino acid residues from Pro120 to Gly153. The expected mass of the counterpart of 
the $\mathrm{y}_{34}{ }^{2+}$ ion is $700.25 \mathrm{Da}$, very close to the theoretical mass of the $\operatorname{Pt}\left(\mathrm{NH}_{3}\right)$ compound bound HSKH residues (theoretical mass 700.23). However, an abundant ion at $\mathrm{m} / \mathrm{z}$ 684.55 appears in Figure 4.19., the mass of which differs from 700.25 Da by -15.70 Da, suggesting that the $684.55^{+}$ion might be produced by losing the $\mathrm{NH}_{3}$ on the $\operatorname{Pt}\left(\mathrm{NH}_{3}\right)$ compound. Hence, $\operatorname{Pt}\left(\mathrm{NH}_{3}\right)$ in the $1313.27^{5+}$ ion is bound to the side chains of the HSKH residues in the peptide His97-Gly153. HSKH is the common binding site for cisplatin and transplatin on $\mathrm{Mb}$.

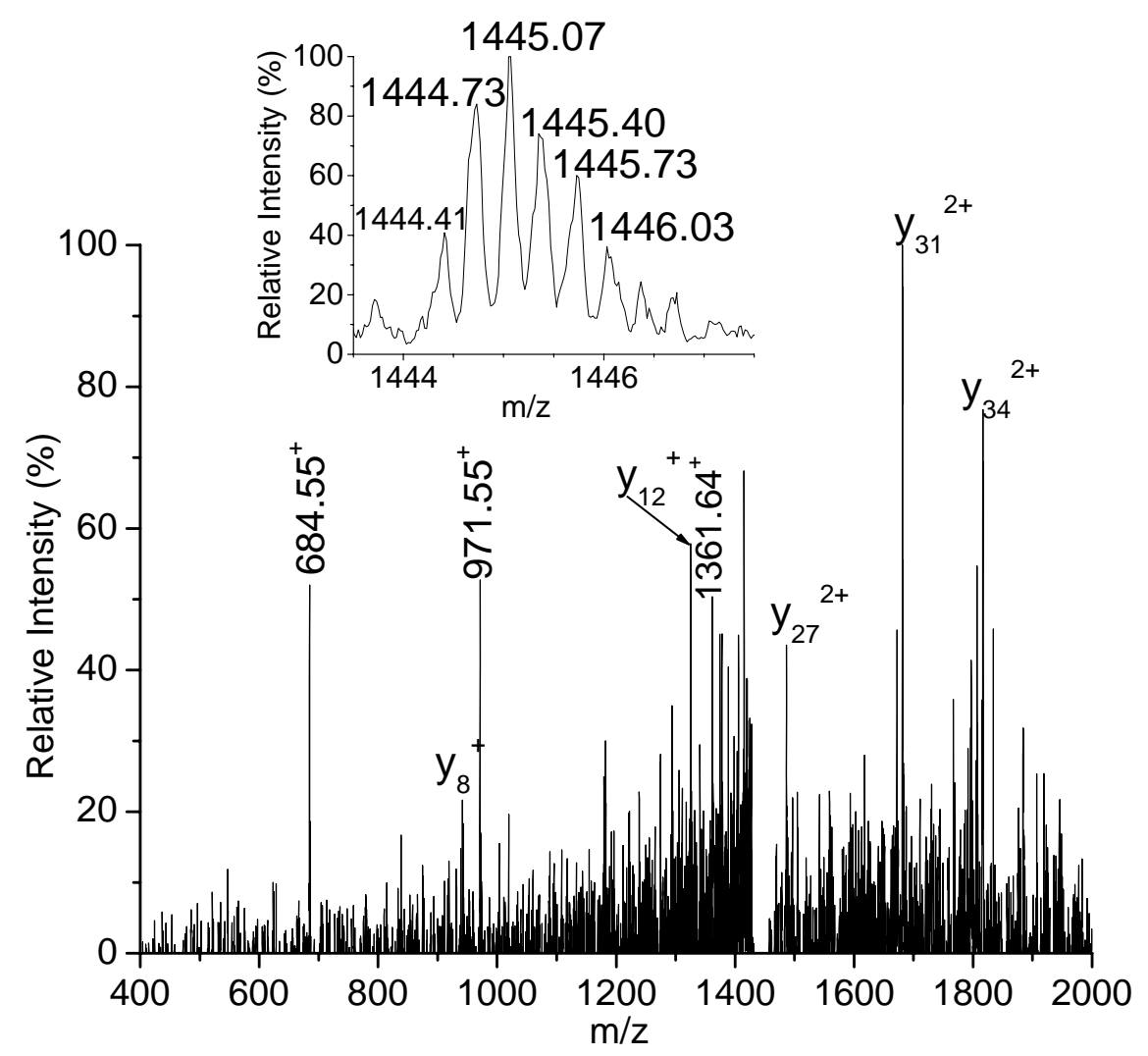

Figure 4.19. The isotope distribution of the $1444.45^{3+}$ ion and the $\mathrm{MS}^{3}$ analysis of the $1313.27^{5+}$ ion at $\mathrm{m} / \mathrm{z} 1444.45$ and. The peptide sequence of the $1444.45^{3+}$ ion: (His116-Gly153) HSKHPGDFGADAQGAMTK ALELFRNDIAAKYKELGFQG 


\subsubsection{The assignment of the residues coordinated to $\operatorname{Pt}\left(\mathrm{NH}_{3}\right)$ in the HSKH residues}

The primary adducts of cisplatin and transplatin with $\mathrm{Mb}$ are bidentate adducts, suggesting there are two residues in the HSKH residues coordinated to $\operatorname{Pt}\left(\mathrm{NH}_{3}\right)_{2}$. Because Lys118 is protonated at $\mathrm{pH} 6.8, \mathrm{Pt}\left(\mathrm{NH}_{3}\right)_{2}$ binds to two residues among His116, Ser117, and His119.

The possibility of His 116 Ser117 attached to $\mathrm{Pt}\left(\mathrm{NH}_{3}\right)_{2}$ was examined by reacting a dipeptide His $\sim$ Ser with cisplatin and transplatin respectively for $30 \mathrm{~h}$. Both reactions yielded several adducts. Monoadduct, the $\mathrm{Pt}\left(\mathrm{NH}_{3}\right)_{2}\left(\mathrm{H}_{2} \mathrm{O}\right)$ bound His $\sim \mathrm{Ser}$, is the primary adduct, suggesting Pt primarily coordinates to His in the dipeptide His $\sim$ Ser. Therefore, $\mathrm{Pt}\left(\mathrm{NH}_{3}\right)_{2}$ originated from cisplatin and transplatin are not coordinated to the adjacent amino acid residues His116 Ser117 in Mb. His116 and His119 are the two possible residues coordinated to $\mathrm{Pt}\left(\mathrm{NH}_{3}\right)_{2}$ in the $\mathrm{Mb}$-cisplatin and Mb-transplatin adducts.

The three dimensional (3-D) structure of the polypeptide chain of native $\mathrm{Mb}$ is shown in Figure 4.20. His116, Ser117, and Lys118 are located at the last turn of Helix $\mathrm{G}$ and His 119 is located at the random coil between Helix $\mathrm{G}$ and Helix $\mathrm{H}^{12}$. As shown in Figure 4.20, the side chains of His116 and His119 are exposed to the solvent and close to each other in space, which makes it possible for $\mathrm{Pt}\left(\mathrm{NH}_{3}\right)_{2}$ connect these two residues in space to form bidentate adducts. The identification of His116 and His 119 as the binding residues is consistent with the detection of the Pt bound 
HSKH fragment ions during the $\mathrm{MS}^{3}$ analyses of the $1313.27^{5+}$ ion.

Based on the above results, the bidentate Mb-cisplatin and Mb-transplatin adducts are formed by substituting $\mathrm{H}_{2} \mathrm{O}$ of the hydrolyzed cisplatin and transplatin with the side chains of His116 and His119 on Mb. The arrangement of His116 and His119 on $\mathrm{Mb}$ is more suitable to interact with cisplatin than with tranpslatin, leading to more cooperative interactions between cisplatin and $\mathrm{Mb}$. In addition, the binding site at His116 and His119 is probably the primary binding site of cisplatin and transplatin because the $1313.27^{5+}$ and $1316.68^{5+}$ ions are the most abundant Pt-containing fragments observed in the adduct digests.

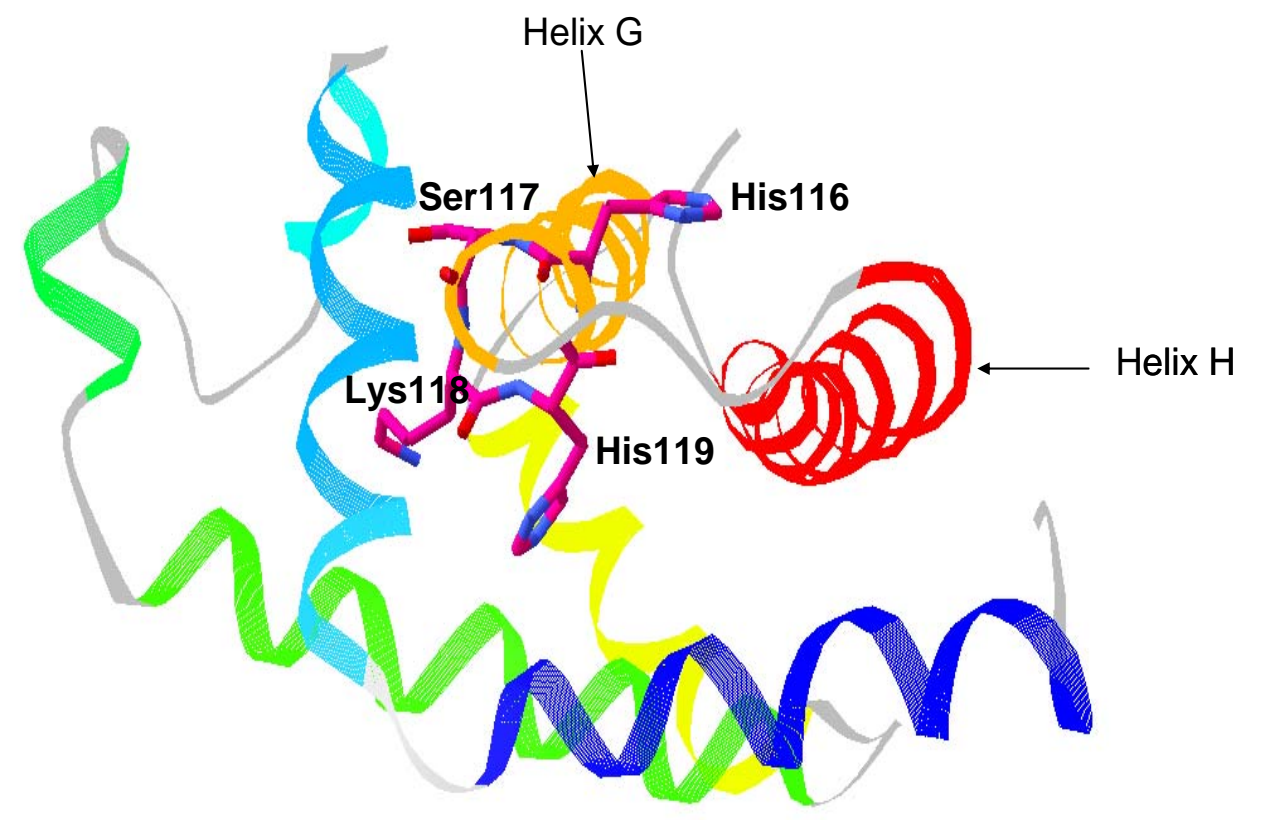

Figure 4.20. The Ribbon diagram of the 3-D structures of the Mb polypeptide chain under native conditions with the side chains of the HSKH residues displayed ${ }^{12}$. 


\subsubsection{The stability of the Mb-cisplatin and the Mb-transplatin adducts}

GMP is a good nucleophile for cisplatin and transplatin because it has several nitrogens in its structure. In order to examine the stability of the Mb-cisplatin and Mb-transplatin adducts, GMP is mixed with the Mb-cisplatin and Mb-transplatin adducts at (GMP:the total $\mathrm{Mb}$ ) molar ratio of $5: 1$ to compete $\mathrm{Pt}\left(\mathrm{NH}_{3}\right)_{2}$ on the $\mathrm{Mb}$ adducts as a nucleophile. The monoadduct-GMP adducts [(1:1 Mb-cisplatin)-GMP and (1:1 Mb-transplatin)-GMP $]$ and the diadduct-GMP adducts $[(1: 2$ Mb-cisplatin)-GMP and (1:2 Mb-transplatin)-GMP] are observed in both the Mb-cisplatin and Mb-transplatin solutions. Figure 4.21a. and Figure 4.21b. show the percentages of each $\mathrm{Mb}$ species in both solutions at different time over 3 days. The percentage of each species in both solutions changes similarly. A slight change occurs for free $\mathrm{Mb}$, but the $\mathrm{Mb}$ monoadducts $(1: 1 \mathrm{Mb}$-cisplatin and 1:1Mb-transplatin) and the $\mathrm{Mb}$ diadducts (1:2 Mb-cisplatin and 1:2 Mb-transplatin) decrease sharply in half a day and then remains constant, corresponding to the rapid formation of the monoadduct-GMP adducts and the diadduct-GMP adducts. Despite the binding of GMP to the $\mathrm{Mb}$ adducts, no Pt compounds are released from $\mathrm{Mb}$ according to the slight change of the percentage of free $\mathrm{Mb}$, which indicates the stability of the $\mathrm{Mb}$-cisplatin and Mb-transplatin adducts. 

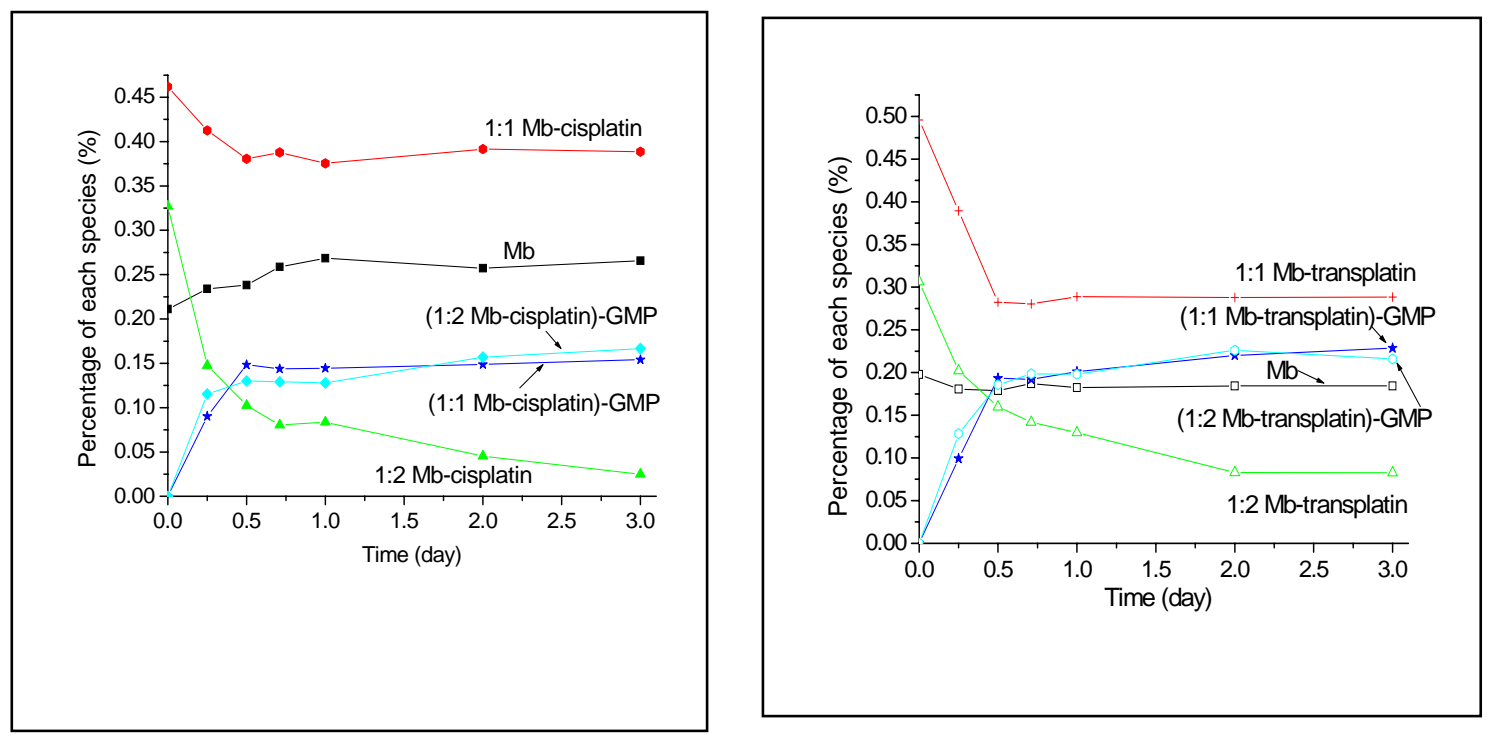

Figure 4.21. The percentage of each $\mathrm{Mb}$ species after reacting the Mb adducts with 5'-GMP for different hours over 3 days: (a) The reaction of Mb-cisplatin adducts with 5'-GMP; (b) The reaction of Mb-transplatin adducts with 5'-GMP 


\subsection{Conclusions}

Similar results are obtained in the comparison of the Mb-cisplatin and $\mathrm{Mb}$-transplatin interactions. The bidentate monoadducts and diadducts are the primary adducts, yielded by coordinating $\mathrm{Pt}\left(\mathrm{NH}_{3}\right)_{2}$ to $\mathrm{Mb}$ over 30 hours' interactions. However, the formation of the Mb-cisplatin adducts is faster and more cooperative than the formation of the Mb-transplatin adducts. In the determination of the binding sites, two fragment ions, the $1313.27^{5+}$ and $1316.68^{5+}$ ions corresponding to $\mathrm{Pt}\left(\mathrm{NH}_{3}\right)$ and $\mathrm{Pt}\left(\mathrm{NH}_{3}\right)_{2}$ bound His97-Gly153 respectively, are observed in both the Mb-cisplatin and $\mathrm{Mb}$-transplatin adduct digests. The $\mathrm{MS}^{3}$ analyses of the $1313.27^{5+}$ and $1316.68^{5+}$ ions indicate that cisplatin and transplatin have a common binding site and are attached to two residues of HSKH in the peptide His97-Gly153. The interactions of cisplatin and transplatin with the dipeptide His $\sim$ Ser and the 3 -D structure of native $\mathrm{Mb}$ suggest cisplatin and transplatin are coordinated to His116 and His119 on Mb. Both the Mb-cisplatin and Mb-transplatin adducts were proved to be stable because little changes occurred in the percentage of free $\mathrm{Mb}$ during the reactions between GMP with the Mb-cisplatin and Mb-transplatin adducts respectively over three days. 


\subsection{References}

(1) Jamieson, E. R.; Lippard, S. J. Chem. Rev. 1999, 99, 2467-2498.

(2) Lippert, B. Metal Ions in Biological Systems 1996, 33, 105-141.

(3) Espinosa, E.; Feliu, J.; Zamora, P.; Gonzalez Baron, M.; Sanchez, J. J.; Ordon ez, A.; Espinosa, J. Lung Cancer. 1995, 12, 67-76.

(4) Holding, J. D.; Lindup, W. E.; Van Laer, C.; Vreeburg, G. C.; Schilling, V.; Wilson, J. A.; Stell, P. M. Br. J. Clin. Pharmacol. 1992, 33, 75-81.

(5) Reedijk, J. Chem. Rev. 1999, 99, 2499-2510.

(6) Appleton, T. G. Coord. Chem. Rev. 1997, 166, 313-359.

(7) Ivanov, A. I.; Christodoulou, J.; Parkinson, J. A.; Barnham, K. J.; Tucker, A.; Woodrow, J.; Sadler, P. J. J. Biol. Chem. 1998, 273, 14721-14730.

(8) Calderone, V.; Casini, A.; Mangani, S.; Messori, L.; Orioli, P. L. Angew. Chem. Int. Ed.2006, 45, 1267-1269.

(9) Gibson, D.; Costello, C. E. Eur. Mass Spectrom.1999, 5, 501-510.

(10) Peleg-Shulman, T.; Gibson, D. JACS. 2001, 123, 3171-3172.

(11) Peleg-Shulman, T.; Najajreh, Y.; Gibson, D. J. Inorg. Biochem. 2002, 91, 306-311.

(12) Evans, S. V.; Brayer, G. D. J. Mol. Biol. 1990, 213, 885-97.

(13) Zhao, T.; King, F. L. J. Am. Soc. Mass Spectrom. 2009, 20, 1141-1147.

(14) Najajreh, Y.; Gibson, D. Metal Compounds in Cancer Chemotherapy. 2005, 285-320.

(15) Paizs, B.; Suhai, S. Mass Spectrom. Rev. 2005, 24, 508-548. 


\section{Chapter 5. A Mass Spectrometric Comparison of the}

Binding Sites of Cisplatin on Native and Denatured Ub:

Evidence of the Effect of Protein Conformation on Protein

Platination

\subsection{Introduction}

Blood plasma protein-cisplatin interactions play important roles in drug efficacy of cisplatin as an antitumor drug because the blood plasma protein-cisplatin adducts might serve as a Pt reservoir for DNA platination. However, some of the blood plasma protein-cisplatin interactions are irreversible, leading to the accumulation of cisplatin inside tissues and inducing side effects ${ }^{1}$. Because of the therapeutic effects of the blood plasma protein-cisplatin interactions on the cisplatin efficacy, there has been an increasing interest in determining the binding sites of cisplatin on model proteins in order to provide insight into their interactions.

Mass spectrometry (MS) based bottom-up and top-down approaches are useful tools for determination of protein modification sites ${ }^{2}$. The bottom-up approach is conducted by proteolytic digestion of the proteins, followed by liquid 
chromatograpy-tandem mass spectrometry (LC-MS/MS) of the obtained digests. The top-down approach involves direct fragmentation of the proteins in gas phase without the protein digestion. The obtained fragments are analyzed by high-resolution mass spectrometry for accurate mass measurement. Because peptides are more suitable for fragmentation in gas phase than the intact proteins, the bottom-up approach is more often used for determination of the cisplatin binding sites on the proteins. Dyson et al. firstly employed the bottom-up approach to determine the binding site of cisplatin on transferrin ${ }^{3,4}$. Later, the binding sites of carboplatin ${ }^{5}$ and $\mathrm{Pt}(\mathrm{II})$ iminoethers ${ }^{6}$ on cytochrome c (cyt c) were determined. However, the application of the bottom-up approach in determination of the binding sites of cisplatin on ubiqutin was unsuccessful (Ub) ${ }^{7}$. Recently, the top-down approach revealed that Metl was the primary binding site of cisplatin on $\mathrm{Ub}^{8}$, which was consistent with the results suggested by Ub modification ${ }^{7,9,10}$.

More recently, our group introduced a strategy to directly determine the primary binding site of cisplatin on cyt c by coupling Fourier transform mass spectrometry (FT-MS) with tandem mass spectrometry (MS/MS and $\left.\mathrm{MS}^{3}\right)^{11}$. The high-resolving power of FT-MS enabled direct analyses of the digests of free cyt $\mathrm{c}$ and cyt $\mathrm{c}$ adduct without the LC purification step. The unique fragments in the adduct digest were characterized by $\mathrm{MS} / \mathrm{MS}$ and $\mathrm{MS}^{3}$. The primary binding site of cisplatin on cyt $\mathrm{c}$ was determined through interpretation of the product-ion spectra. The proposed method was successfully applied to determine the primary binding sites of cisplatin on myoglobin $(\mathrm{Mb})^{12}$. 
Although both cyt $\mathrm{c}$ and $\mathrm{Mb}$ contain Met and His residues, the primary binding sites of cisplatin on these two proteins are quite different. Cisplatin is primarily bound to the Met65 residue in cyt c, but His116 and His119 residues are assigned as the primary residues on $\mathrm{Mb}$ attached to cisplatin. Because Met65 in cyt $\mathrm{c}$ is exposed to the solvent and the Met residues in native $\mathrm{Mb}$ are located in the hydrophobic core, the two completely different results suggest that the cisplatin binding sites on a protein are affected by the protein conformation and cisplatin prefers to bind to the residues on the surface of the protein ${ }^{13}$.

Because of the influence of the protein conformation on the cisplatin binding sites and the fact that Met1 is partially folded inside the Ub polypeptide chain, cisplatin is expected to bind to residues located at the surface of native Ub other than Met1. Consistent with this expectation, the interactions of Pt compounds with $\mathrm{Ub}$ yielded several monoadducts under native conditions ${ }^{7-10,14,15}$. However, only the Met1 residue was identified as the cisplatin binding site on Ub under physiological conditions ${ }^{8}$.

This paper presents a complete study of the cisplatin binding sites on native $\mathrm{Ub}$ and denatured $\mathrm{Ub}$ based on the method reported before ${ }^{11}$. Comparison of the binding sites of cisplatin on native $\mathrm{Ub}$ and fully denatured Ub provides evidence regarding the dependence of the cisplatin binding sites on the conformation of the protein. 


\subsection{Experimental}

\subsubsection{Materials}

Ubiquitin (bovine erythrocytes), cisplatin, and ammonium bicarbonate were purchased from Sigma (St. Louis, MO). Sequencing-grade modified trypsin and all other chemicals were obtained from Fisher Scientific (Pittsburgh, PA). The Ub sequence is shown in Figure 5.1.

\begin{tabular}{|rllll|}
\hline 1 & MQIFVKTLTG & KTITLEVEPS & DTIENVKAKI & 30 \\
31 & QDKEGIPPDQ & QRLIFAGKQL & EDGRTLSDYN & 60 \\
61 & IQKESTLHLV & LRLRGG & & 76 \\
& & & & \\
\hline
\end{tabular}

Figure 5.1. The Ub sequence

\subsubsection{Formation of native and denatured Ub-cisplatin adducts}

Native and denatured Ub-cisplatin adducts were prepared by reacting $100 \mu \mathrm{M} \mathrm{Ub}$ with cisplatin at 1:10 $\mathrm{Ub}$ :cisplaitn molar ratio under native and denatured conditions, respectively. Water and a $50 \% \mathrm{MeOH}-1 \%$ HAc aqueous solution ${ }^{16}$ were used as the solvents under native and denatured conditions, respectively. The formation of the adducts was examined over $30 \mathrm{~h}$ by ESI-MS. Prior to ESI-MS analyses, the native and denatured Ub solutions were diluted to $300 \mathrm{nM}$ by a $30 \% \mathrm{MeOH}-0.3 \% \mathrm{HAc}$ solution. 


\subsubsection{Trypsin digestion of the Ub-cisplatin adducts}

The native and denatured Ub-cisplatin adducts, prepared by incubating the mixtures of $\mathrm{Ub}$ and cisplatin under native and denatured conditions for $27 \mathrm{~h}$, were digested by trypsin under the same conditions as free Ub. All the Ub solutions were denatured by a 4 -fold volume of a $70 \% \mathrm{MeOH}-25 \mathrm{mM} \mathrm{NH}_{4} \mathrm{HCO}_{3}$ solution for 10 min. Subsequently, free $\mathrm{Ub}$ and the $\mathrm{Ub}$ adducts were digested by trypsin at a protein to protease ratio of $50: 1(\mathrm{w} / \mathrm{w})$ at $37^{\circ} \mathrm{C}$. The digestion proceeded for $75 \mathrm{~min}$ and the obtained digests were diluted with the same volume of the $50 \% \mathrm{MeOH}-0.3 \% \mathrm{HAc}$ solution for FT-MS analysis.

\subsubsection{ESI-MS and FT-MS analyses}

A quadrupole ion trap mass spectrometer (Finnigan $\mathrm{LCQ}^{\mathrm{TM}}$, San Jose, CA) was used to examine the formation of the Ub adducts. The digests of free $\mathrm{Ub}$ and the $\mathrm{Ub}$ adducts were analyzed on a hybrid linear ion trap Fourier transform (FT) mass spectrometer (Thermo Finnigan LTQ-FT ${ }^{\mathrm{TM}}$, San Jose, CA). The same operating conditions were employed for electrospray the ion source on both of the mass spectrometers. The spray voltage was set to $4 \mathrm{kV}$. The heated metal capillary was maintained at $200^{\circ} \mathrm{C}$. The solutions were introduced by direct infusion at a flow rate of $3 \mu \mathrm{L} / \mathrm{min}$.

In ESI-MS analyses of the Ub adducts on LCQ, ion optics were optimized at $\mathrm{m} / \mathrm{z}$ 1257. The ion injection time was 5 ms. ESI-MS mass spectra of the Ub adducts were 
collected in a mass range of $\mathrm{m} / \mathrm{z}$ 50-2000. MagTran software ${ }^{17}$ was used to deconvolute the acquired ESI-MS spectra. OriginPro 8 software (OriginLab Corporation, Northampton, MA) was applied to plot the deconvoluted spectra in the same coordinate.

The digests of free $\mathrm{Ub}$ and the $\mathrm{Ub}$ adduct digests were analyzed by FT-MS to determine mass and charge of each species in the digests. The unique fragments in the adduct digests with characteristic Pt isotope distributions were further analyzed by $\mathrm{MS} / \mathrm{MS}$ and $\mathrm{MS}^{3}$ in the linear ion trap to obtain their structural information. During $\mathrm{MS} / \mathrm{MS}$ and $\mathrm{MS}^{3}$, the isolation width was set at $5 \mathrm{~m} / \mathrm{z}$ and $35 \%$ of normalized collision energy (NCE\%) was applied to dissociate ions. All the product-ion spectra were recorded in a full mass range and the isotope distributions of the product ions were obtained using zoom scan. ExPASy Proteomics Server was used to search the Ub sequence and perform theoretical mass calculation for peptides and sequence ions.

\subsection{Results and Discussion}

\subsubsection{Formation of the Ub-cisplatin adducts under the native and denatured conditions}

The Ub-cisplatin adducts were prepared by reacting Ub and cisplatin at a molar ratio of 1:10 (Ub:cisplatin) under the native and denatured conditions, respectively. Figure 5.2. displays the percentage changes of the formed monoadducts in the total $\mathrm{Ub}$ of both solutions over $30 \mathrm{~h}$. As shown in Figure 5.2., the reaction under the denatured solution not only has a faster reaction rate but also produces more adducts 
than those yielded under the native solution. But the percentages of the formed monoadducts in both the solutions increase similarly over $30 \mathrm{~h}$. In both solutions, the formed monoadducts increase sharply in $8 \mathrm{~h}$ and then gradually increase until $18 \mathrm{~h}$, after which there is a little change in the percentages of the monoadducts. Therefore, $24 \mathrm{~h}$ was used to prepare the Ub-cisplatin adducts under both the native and denatured conditions.

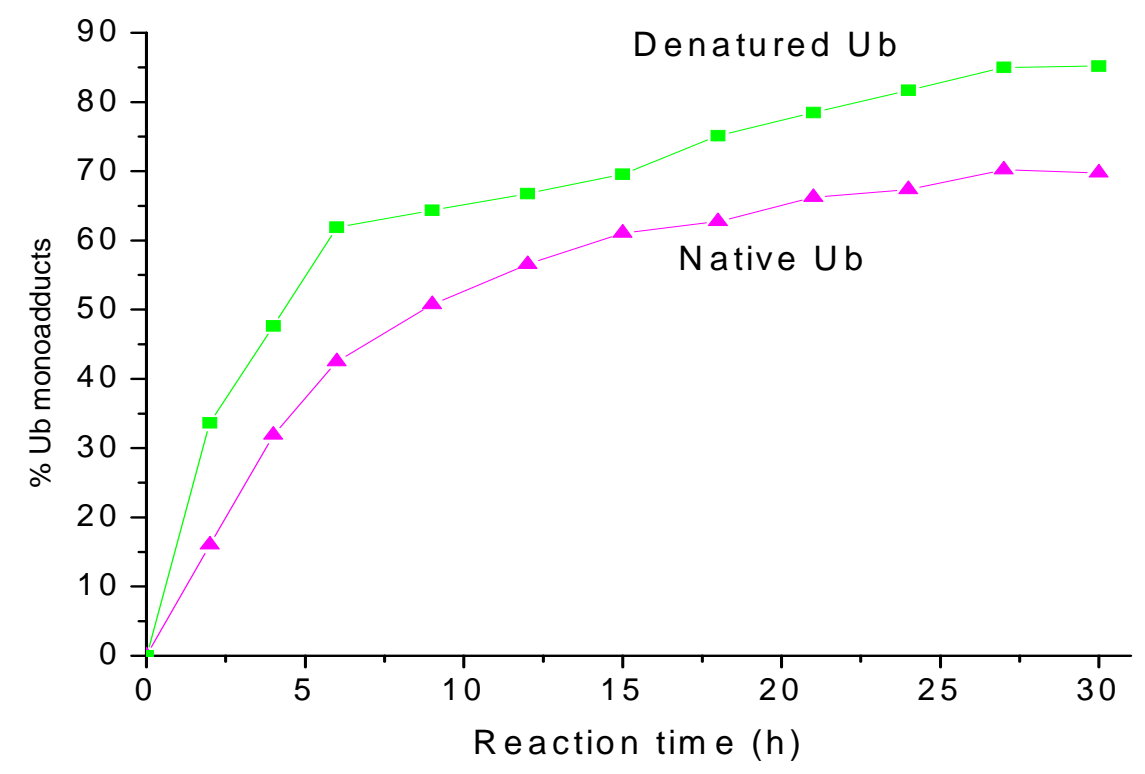

Figure 5.2. The percentages of the formed Ub-cisplatin monoadducts under the native and denatured conditions in 30 hours

Figure 5.3. shows the deconvoluted ESI-MS spectra of the Ub-cisplatin adducts yielded by the Ub-cisplatin interactions for $12 \mathrm{~h}$ and $24 \mathrm{~h}$ under the native and denatured conditions, respectively. Comparison of the deconvoluted ESI-MS spectra between the native and denatured solutions in Figure 5.3. indicates that more free Ub is converted into the $\mathrm{Ub}$ adducts under the denatured conditions than under the native 
conditions over $24 \mathrm{~h}$. Monoadducts are the only adducts observed under the denatured conditions. However, a small amount of diadduct is also observed under the native conditions.

The monoadducts in both solutions are assigned in detail, shown in Figure 5.3. Under the native conditions, the peaks at 8757.4 Da, 8774.1 Da, 8792.0 Da, 8812.0 $\mathrm{Da}$, and $8828.0 \mathrm{Da}$, correspond to five monoadducts, (b) Ub-Pt, (c) Ub-Pt( $\left.\mathrm{NH}_{3}\right)$, (d) $\mathrm{Ub}-\mathrm{Pt}\left(\mathrm{NH}_{3}\right)_{2}$, (e) $\mathrm{Ub}-\mathrm{Pt}\left(\mathrm{NH}_{3}\right)_{2}\left(\mathrm{H}_{2} \mathrm{O}\right)$, and (f) $\mathrm{Ub}-\mathrm{Pt}\left(\mathrm{NH}_{3}\right)_{2}\left(\mathrm{H}_{2} \mathrm{O}\right)_{2}$, respectively, according to their mass shifts from (a) free Ub (8564.0 Da). Under denatured conditions, only three peaks at 8757.4 $\mathrm{Da}, 8774.1 \mathrm{Da}$, and 8833.0 $\mathrm{Da}$ are observed and assigned as the monoadducts (b) Ub-Pt, (c) Ub-Pt( $\left.\mathrm{NH}_{3}\right)$, and (g) $\mathrm{Ub}-\mathrm{Pt}\left(\mathrm{NH}_{3}\right)\left(\mathrm{CH}_{3} \mathrm{CO}_{2}\right)$.

The peaks corresponding to the monoadducts yielded under the native and denatured conditions in Figure 5.3. exhibit different distribution patterns. Under the native conditions, the peak arising from the bifunctional adduct $\mathrm{Ub}-\mathrm{Pt}\left(\mathrm{NH}_{3}\right)_{2}$ is the most intense peak among the five monoadducts and the intensity of the peaks corresponding to the other four monoadducts is much less intense. However, the peak corresponding to the trifunctional mononadduct $\mathrm{Ub}-\mathrm{Pt}\left(\mathrm{NH}_{3}\right)$ is the most abundant monoadduct, followed by the peak corresponding to the Ub-Pt adduct under the denatured conditions. 


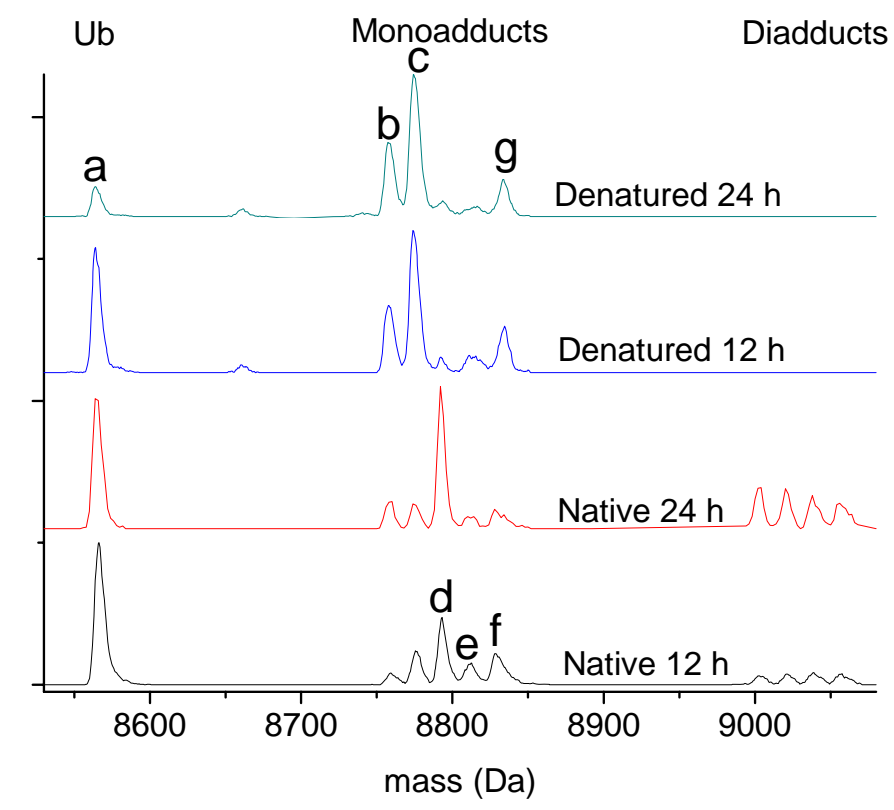

Figure 5.3. The deconvoluted ESI mass spectra of the Ub monoadducts yielded by the Ub-cisplatin interactions under native and denatured conditions over $12 \mathrm{~h}$ and $24 \mathrm{~h}$, respectively. Peak assignment: (a) free Ub; (b) Ub-Pt; (c) Ub-Pt( $\left(\mathrm{NH}_{3}\right)$; (d) Ub-Pt( $\left(\mathrm{NH}_{3}\right)_{2}$; (e) $\mathrm{Ub}-\mathrm{Pt}\left(\mathrm{NH}_{3}\right)_{2}\left(\mathrm{H}_{2} \mathrm{O}\right) ;$ (f) Ub-Pt $\left(\mathrm{NH}_{3}\right)_{2}\left(\mathrm{H}_{2} \mathrm{O}\right)_{2} ;(\mathrm{g}) \mathrm{Ub}-\mathrm{Pt}\left(\mathrm{NH}_{3}\right)\left(\mathrm{CH}_{3} \mathrm{CO}_{2}\right)$.

\subsubsection{Determination of the cisplatin binding sites on Ub under the native and denatured conditions}

$\mathrm{Ub}$ is a tightly folded protein and unable to be digested under the native conditions. Therefore, a 4 -fold volume of a $70 \% \mathrm{MeOH}-25 \mathrm{mM} \mathrm{NH}_{4} \mathrm{HCO}_{3}$ solution was added to the native $\mathrm{Ub}$ solution in order to denature $\mathrm{Ub}$ before trypsin digestion. The Ub adducts in the denatured condition were diluted by the same method in order to increase $\mathrm{pH}$ and ionic strength of the solution for trypsin digestion. Afterwards, the $\mathrm{Ub}$ species in both the $\mathrm{Ub}$ solutions were digested by trypsin for $75 \mathrm{~min}$. Free $\mathrm{Ub}$ was digested under the same conditions and its digest was used as the control. 
The FT-MS spectra of the digests of free $\mathrm{Ub}$ and the $\mathrm{Ub}$ adduct digests are displayed in Figure 5.4., 5.5., and 5.6. The FT-MS spectra of the Ub adduct digests are quite different from the FT-MS spectrum of the free Ub digest. Most fragments in the free $\mathrm{Ub}$ digest are multiply charged (3+-5+) and observed at over m/z 1000 in Figure 5.4., suggesting the incomplete digestion of free $\mathrm{Ub}$ under the experimental conditions. In contrast, the digestion of the Ub adducts yielded under both the native and denatured conditions was more complete because most of fragments in the adduct digests have low charge states (1+ to $3+$ ) and are observed below m/z 1200 in Figure 5.5. and Figure 5.6. The more complete digestion of the adducts than the digestion of the free $\mathrm{Ub}$ suggests that the binding of cisplatin on $\mathrm{Ub}$ might promote $\mathrm{Ub}$ denaturation. 


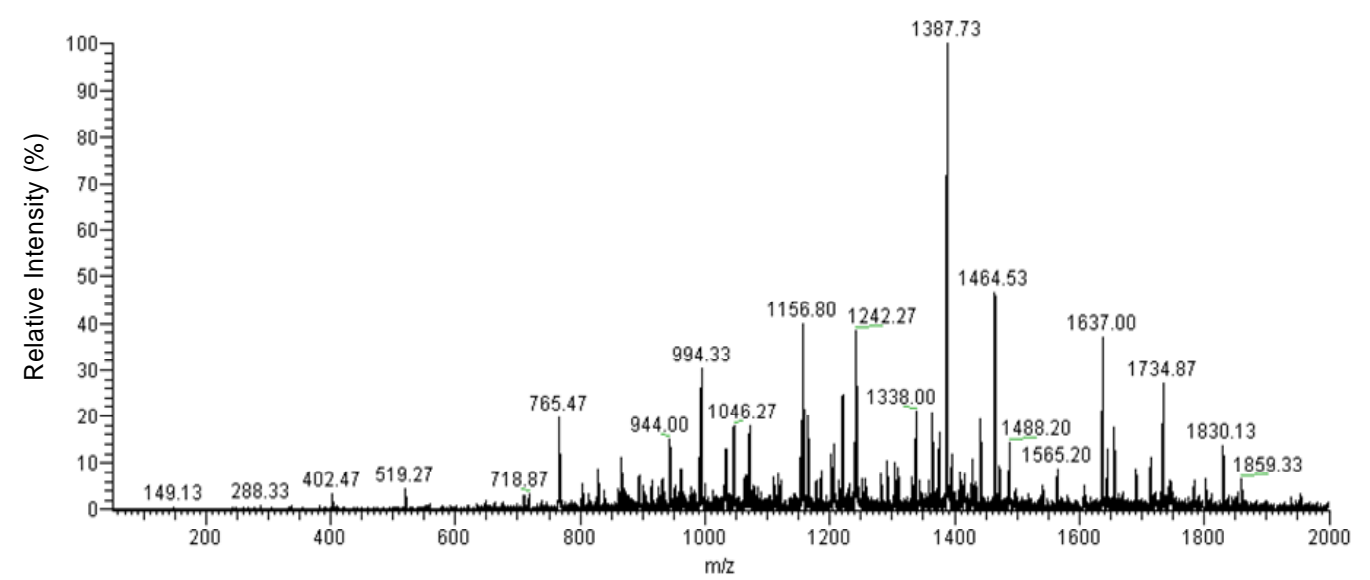

Figure 5.4. The free Ub digest

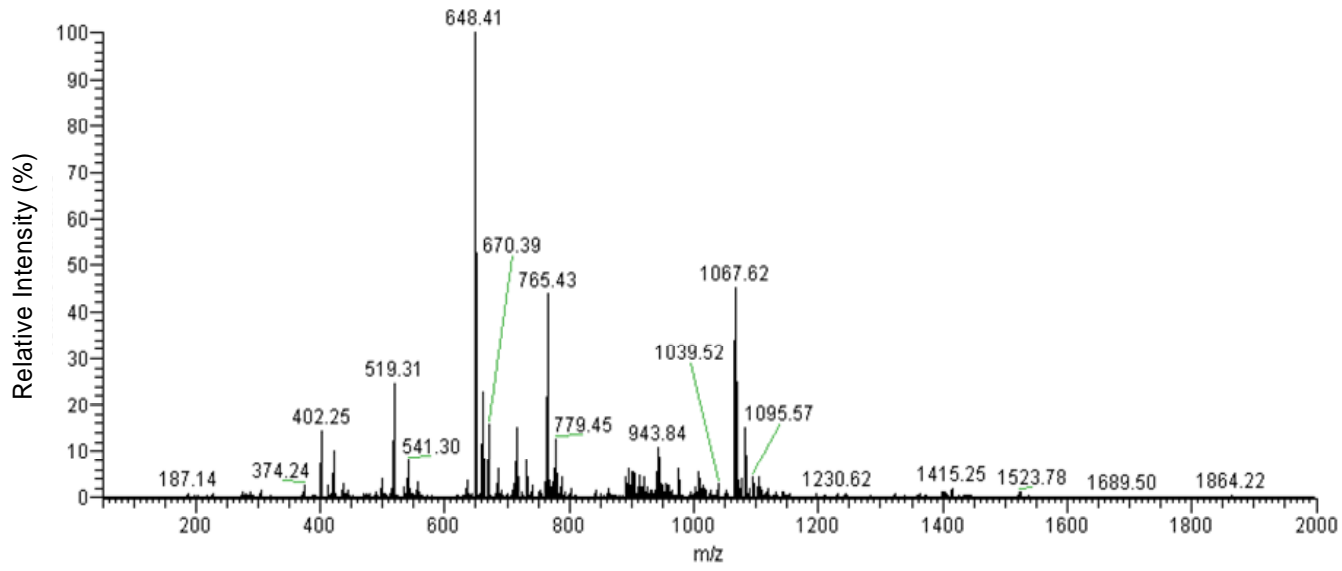

Figure 5.5. The digest of the Ub adduct obtained under the native conditions

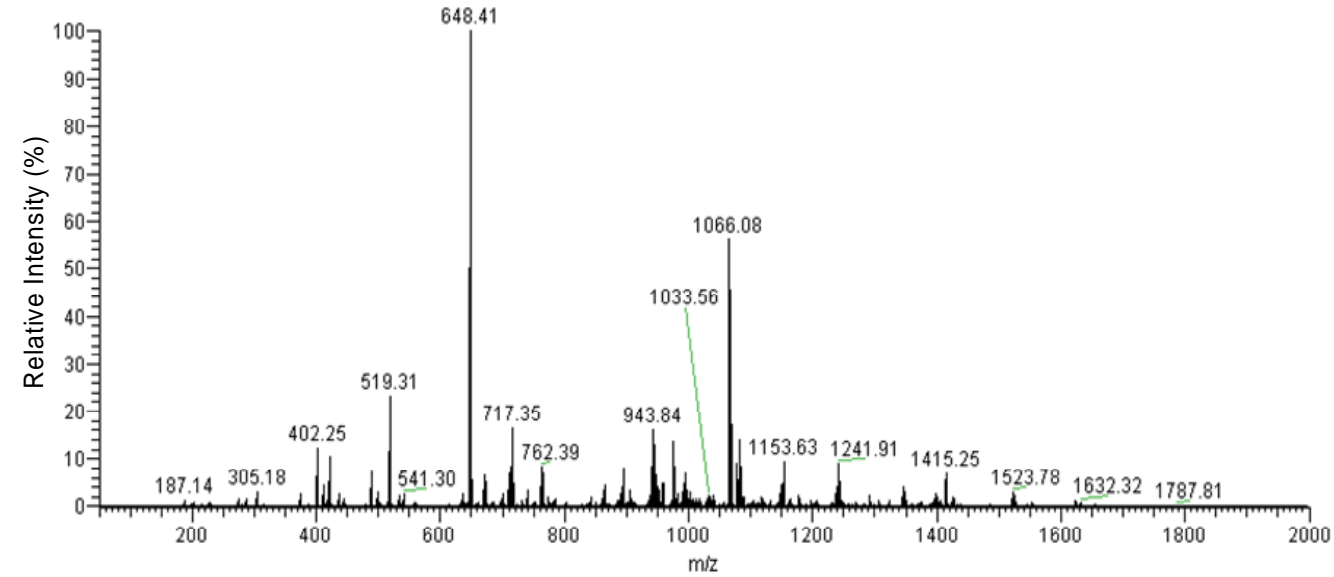

Figure 5.6. The digest of the Ub adduct obtained under the denatured conditions 
Because most fragments in the adduct digests have low molecular weight, platination of a fragment can be indicated by a broader isotope distribution of the fragment than a peptide of similar size. After careful examination of the isotope distributions of the fragments in Figure 5.5. and Figure 5.6., the $876.40^{2+}, 975.41^{+}$, and $1008.47^{2+}$ ions in Figure 5.5. and the $975.41^{+}, 1148.92^{3+}$, and $1631.83^{2+}$ ions in Figure 5.6. were identified as the Pt-compound containing fragments according to the characteristic Pt isotope distributions, displayed in Figure 5.7. and Figure 5.8. All these ions were subjected to $\mathrm{MS} / \mathrm{MS}$ and $\mathrm{MS}^{3}$ analyses in order to locate the platination sites on the corresponding peptides and thereby determine the binding sites of cisplatin on the native and denatured Ub.
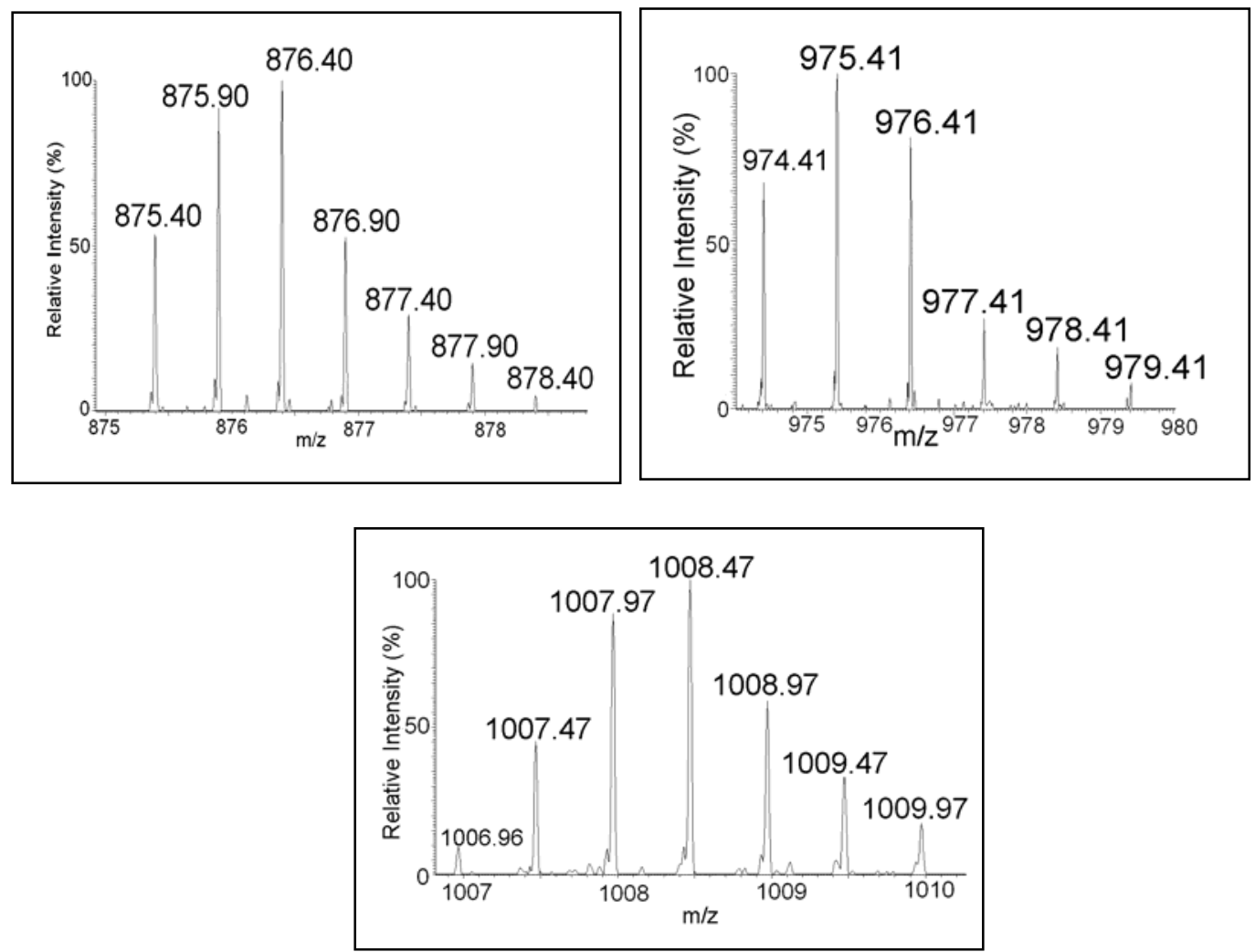

Figure 5.7. The isotope distributions of three Pt-compound containing fragments, the $876.40^{2+}$, $975.41^{+}$, and $1008.47^{2+}$ ions, in the native $\mathrm{Ub}$ adduct digest. 

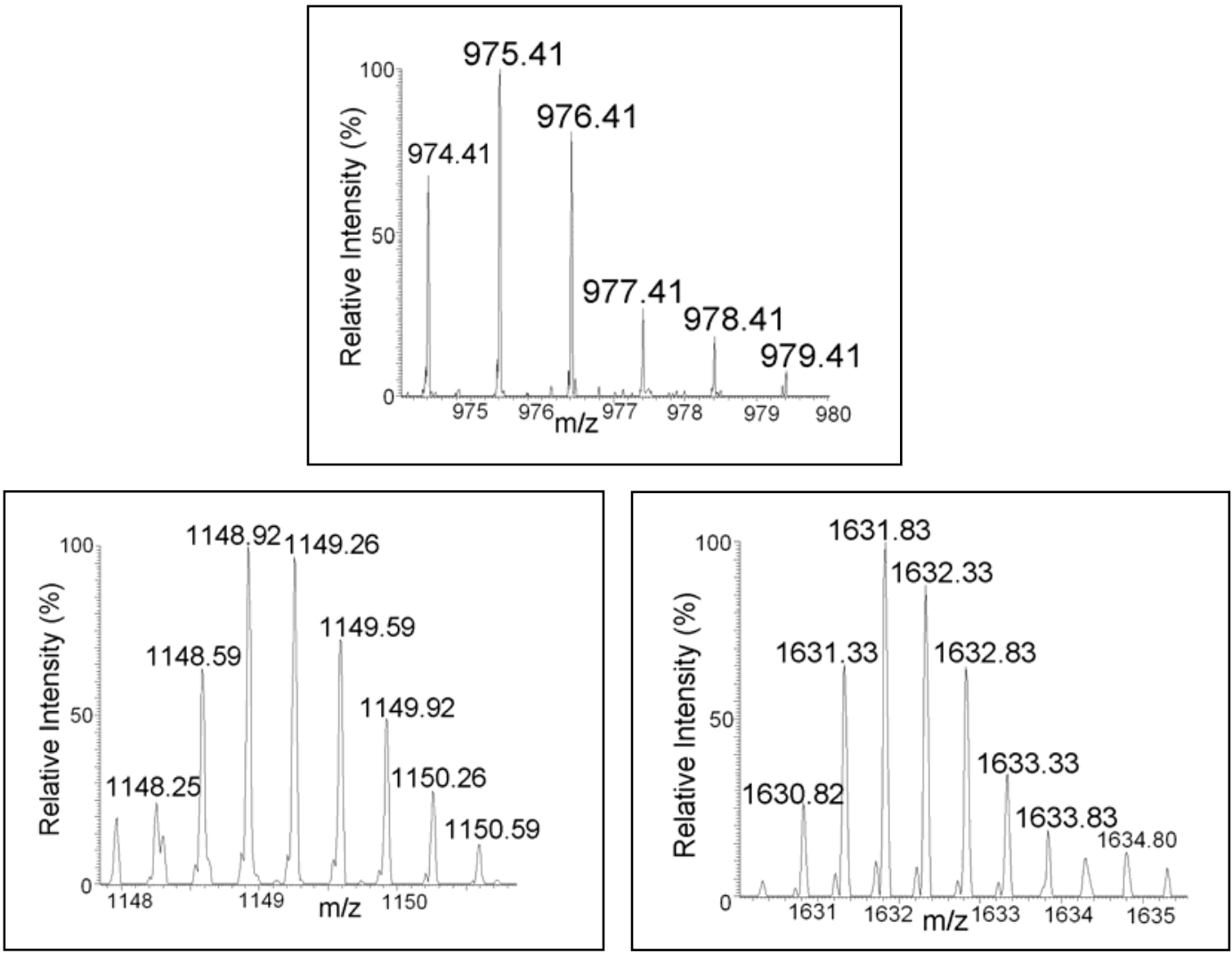

Figure 5.8. The isotope distributions of three Pt-compound containing fragments, the $975.41^{+}$, $1148.92^{3+}$, and $1631.83^{2+}$ ions, in the denatured $U b$ adduct digest

\subsubsection{Determination of cisplatin binding sites on native Ub}

\subsection{The binding site of $\mathrm{Pt}\left(\mathrm{NH}_{3}\right)_{2}$ on the $876.40^{2+}$ ion}

Figure 5.9. shows the product-ion spectrum of the MS/MS analysis of the $876.40^{2+}$ ion, in which two fragment ions at m/z 678.18 and 977.36 exhibit Pt isotope distributions. The most abundant $858.82^{2+}$ ion arises from neutral loss of the parent ion. Mass difference between the fragment ions assigned as $\mathrm{y}_{6}^{+}, \mathrm{y}_{8}^{+}, \mathrm{y}_{9}^{+}$, and $\mathrm{y}_{10}{ }^{+}$in Figure 5.9. enabled identification of KEGI (L) residues in the $876.40^{2+}$ ion. Because 
the residues KEGI is only present in the peptide I30-R42 yielded by trypsin digestion of $\mathrm{Ub}$, the peptide I30-R42 is assigned as the peptide of the $876.40^{2+}$ ion. The mass of the peptide I30-R42 (theoretical mass44 1522.77 Da) differs from the mass of the $876.40^{2+}$ ion by 228.014 Da, suggesting the $876.40^{2+}$ ion (measured mass $1750.80 \mathrm{Da}$ ) arises from the $\mathrm{Pt}\left(\mathrm{NH}_{3}\right)_{2}$ bound peptide I30-R42 (theoretical mass $1750.79 \mathrm{Da}$ ).

The binding site of $\mathrm{Pt}\left(\mathrm{NH}_{3}\right)_{2}$ on the peptide I30-R42 was determined by the $\mathrm{MS}^{3}$ analysis of the $876.40^{2+}$ ion at $\mathrm{m} / \mathrm{z}$ 977.36, the result of which is displayed in Figure 5.10. In Figure 5.9. and Figure 5.10., most of the assigned Pt-containing sequence ions exhibit the loss of a single proton, suggesting that one proton on the amino acid residue side chains might be displaced by $\mathrm{Pt}$.

The assigned Pt-containing $a_{n}, b_{n}$, and $c_{n}$ sequence ions in Figure 5.10. confirm the peptide sequence of the $876.40^{2+}$ ion. The abundance of the $\left[\mathrm{c}_{3}+\mathrm{Pt}-\mathrm{H}\right]^{+}$and $\left[\mathrm{b}_{4}+\mathrm{Pt}-\mathrm{H}\right]^{+}$ions suggests that $\mathrm{Pt}$ is not associated with the amino acid residues from E34-R42. In Figure 5.9., several abundant y ions $\left(\mathrm{y}_{3}{ }^{+}, \mathrm{y}_{6}{ }^{+}, \mathrm{y}_{9}{ }^{+}\right.$, and $\left.\mathrm{y}_{10}{ }^{+}\right)$also indicate that the binding site of $\operatorname{Pt}\left(\mathrm{NH}_{3}\right)_{2}$ is not at the $\mathrm{C}$ terminus but at the $\mathrm{N}$ terminus of the peptide I30-R42. Therefore, the MS/MS and $\mathrm{MS}^{3}$ analyses of the $876.40^{2+}$ ion indicate that the binding sites of $\mathrm{Pt}\left(\mathrm{NH}_{3}\right)_{2}$ are in the residues I30-K33. Because I30 is a nonpolar residue and $\mathrm{K} 33$ is protonated in solution, Q31 and D32 are assigned as the residues associated with $\mathrm{Pt}\left(\mathrm{NH}_{3}\right)_{2}$ to form the $\mathrm{Ub}-\mathrm{Pt}\left(\mathrm{NH}_{3}\right)_{2}$ bifunctional monoadduct. 


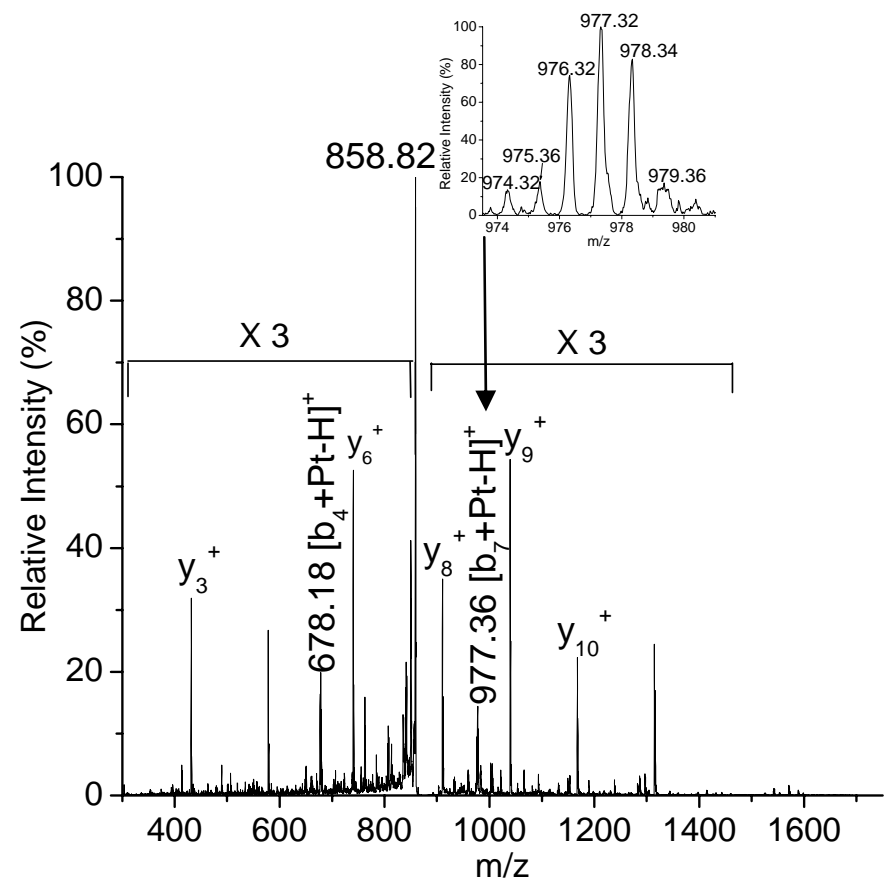

Figure 5.9. The product-ion spectrum of the MS/MS analysis of the $876.40^{2+}$ ion, overlaid with the isotope distribution of the $977.36^{+}$product ion. The peptide sequence of the $876.40^{2+}$ ion: (I30-R42) IQDKEGIPPDQQR

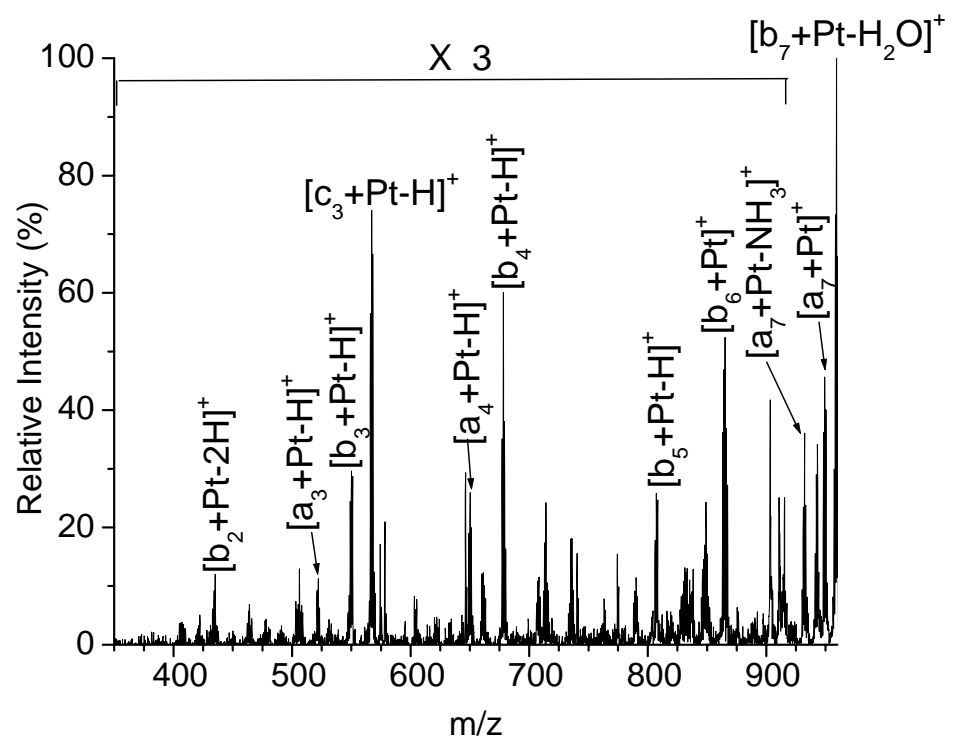

Figure 5.10. The product-ion spectrum of the $\mathrm{MS}^{3}$ analysis of the $876.40^{2+}$ ion at $\mathrm{m} / \mathrm{z}$ 977.36. The peptide sequence of the $977.36^{+}$ion: (I30-I36) IQDKEGI 


\subsection{The binding sites of $\mathrm{Pt}\left(\mathrm{NH}_{3}\right)$ on the $975.41^{+}$ion}

The product-ion spectrum of MS/MS analysis of the $975.41^{+}$ion is displayed in Figure 5.11. Most of the product ions in Figure 5.11. are associated with Pt according to their isotope distributions. The base peak at $\mathrm{m} / \mathrm{z} 958.27$ arises from neutral loss of one $\mathrm{NH}_{3}$ from the $975.41^{+}$ion. The $812.18^{+}$ion is produced by the loss of the $\mathrm{K}$ residue (theoretical mass $146.11 \mathrm{Da}$ ) at the $\mathrm{C}$ terminus from the $958.27^{+}$ion according to the mass difference $(146.09 \mathrm{Da})$ between the $958.27^{+}$and $812.18^{+}$ions. The mass difference between the $713.09^{+}$and $958.27^{+}$ions is $245.18 \mathrm{Da}$, indicating that the $713.09^{+}$ion arises from the loss of the VK residues (theoretical mass $245.17 \mathrm{Da}$ ) from the $958.27^{+}$ion at the $\mathrm{C}$ terminus. The $\mathrm{VK}$ residues are observed in the peptides M1-K6 (theoretical mass $764.42 \mathrm{Da}$ ) and the mass of the $975.41^{+}$ion exactly matches the mass of one $\mathrm{Pt}\left(\mathrm{NH}_{3}\right)$ bound peptide M1-K6 (theoretical mass 975.41Da), which indicates that the $975.41^{+}$ion arises from the $\mathrm{Pt}\left(\mathrm{NH}_{3}\right)$ bound the peptide M1-K6. The Pt-compound containing $\mathrm{b}$ ions and $\mathrm{y}_{3}{ }^{+}$ion in Figure 5.11. confirm the identification of the $975.41^{+}$ion.

The high intensity of the $713.09^{+}$ion indicates that the peptide bond F4 V5 is ready to fragment, suggesting $\mathrm{Pt}$ is associated to the M1-F4 residues. The low intensity of $\mathrm{Pt}$ bound $\mathrm{b}_{2}{ }^{+}$and $\mathrm{b}_{3}{ }^{+}$ions suggests the tight association of $\mathrm{Pt}$ with the M1-F4 residues stabilized the peptide bonds Q2 I3 and I3 F4. According to the structures of the peptide residues M1-K6 and Pt chemistry, the $\operatorname{Pt}\left(\mathrm{NH}_{3}\right)$ moiety may interact with $\mathrm{S}$ in the $\mathrm{M} 1$ residue, $\mathrm{N}$ in the amino group at the $\mathrm{N}$ terminus, and $\mathrm{N}$ in 
the Q2 residue, leading to the formation of the trifunctional $\mathrm{Ub}-\mathrm{Pt}\left(\mathrm{NH}_{3}\right)$ adduct in the solution.

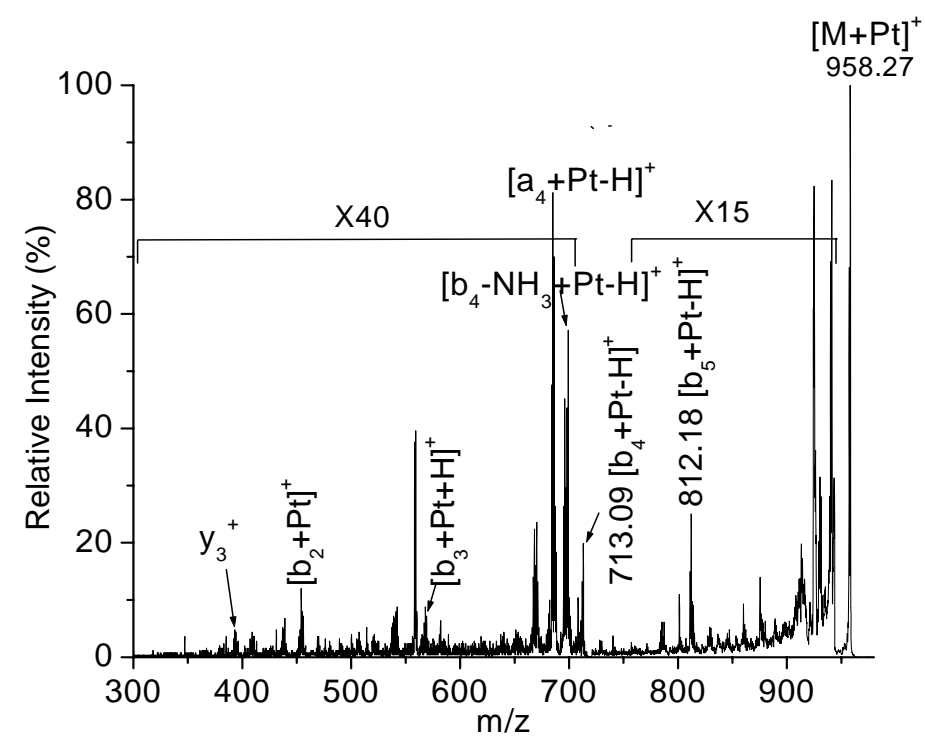

Figure 5.11. The product-ion spectrum of the MS/MS analysis of the $975.41^{+}$ion. The peptide sequence of the $975.41^{+}$ion: (M1-K6) MQIFVK

\subsection{The $\mathrm{Pt}\left(\mathrm{NH}_{3}\right)_{2}$ binding sites on the $1008.47^{2+}$ ion}

Figure 5.12. shows the product-ion spectrum of the MS/MS analysis of the $1008.47^{2+}$ ion. The mass difference of the assigned $\mathrm{y}_{3}{ }^{+}, \mathrm{y}_{4}{ }^{+}, \mathrm{y}_{5}{ }^{+}, \mathrm{y}_{6}{ }^{+}, \mathrm{y}_{11}{ }^{+}, \mathrm{y}_{12}{ }^{+}, \mathrm{y}_{13}{ }^{+}$, and $\mathrm{y}_{14}{ }^{+}$sequence ions in Figure 5.12. indicates that the peptide sequence of the $1008.47^{2+}$ ion is T12-K27. According to the mass difference (228.01 Da) between the $1008.47^{2+}$ ion and the peptide T12-K27 (theoretical mass $1786.93 \mathrm{Da}$ ), $\mathrm{Pt}\left(\mathrm{NH}_{3}\right)_{2}$ (theoretical mass $228.03 \mathrm{Da}$ ) is assigned as the Pt moiety in the $1008.47^{2+}$ ion.

The abundant $y$ ions in Figure 5.12. suggest the binding site of the $\operatorname{Pt}\left(\mathrm{NH}_{3}\right)_{2}$ moiety is at the $\mathrm{N}$ terminus. The $622.18^{+}$ion, assigned as the $\left[\mathrm{b}_{4}+\mathrm{Pt}-\mathrm{H}\right]^{+}$ion, is 
complementary to the abundant $\mathrm{y}_{12}{ }^{+}$ion at $\mathrm{m} / \mathrm{z} 1359.64$ because the mass sum of these two ions is $1981.82 \mathrm{Da}$, which is $35.12 \mathrm{Da}$ less than the mass of the $1008.47^{2+}$ ion, arising from neutral loss of the parent ion during the MS/MS analysis. The $\mathrm{MS}^{3}$ analysis of the $1008.47^{2+}$ ion at $\mathrm{m} / \mathrm{z} 622.18$ indicates that the $622.18^{+}$ion is very stable in gas phase and unable to fragment in $\mathrm{MS}^{3}$ analysis to provide detailed structural information. Because the $\mathrm{Pt}\left(\mathrm{NH}_{3}\right)_{2}$ moiety binds to two residues to form bifunctional adducts and both $\mathrm{I}$ and $\mathrm{L}$ in the TITL residues in the $622.18^{+}$ion are nonpolar residues, T12 and T14 residues in the $1008.47^{2+}$ ion are determined as the residues associated with the $\operatorname{Pt}\left(\mathrm{NH}_{3}\right)_{2}$ moiety.

To sum up, three cisplatin binding sites were identified by MS/MS and $\mathrm{MS}^{3}$ analyses of the $876.40^{2+}, 975.41^{+}$, and $1008.47^{2+}$ ions in the native $\mathrm{Ub}$ adduct digest. Among these three fragments, the peak corresponding to the $1008.47^{2+}$ ion is the most intense and the peak corresponding to the $876.40^{2+}$ ion is the least intense in the FT-MS spectrum, suggesting T12 and T14 residues are the most possible binding sites, followed by M1 and some residues at the $\mathrm{N}$ terminus, and Q31 D32 residues . 


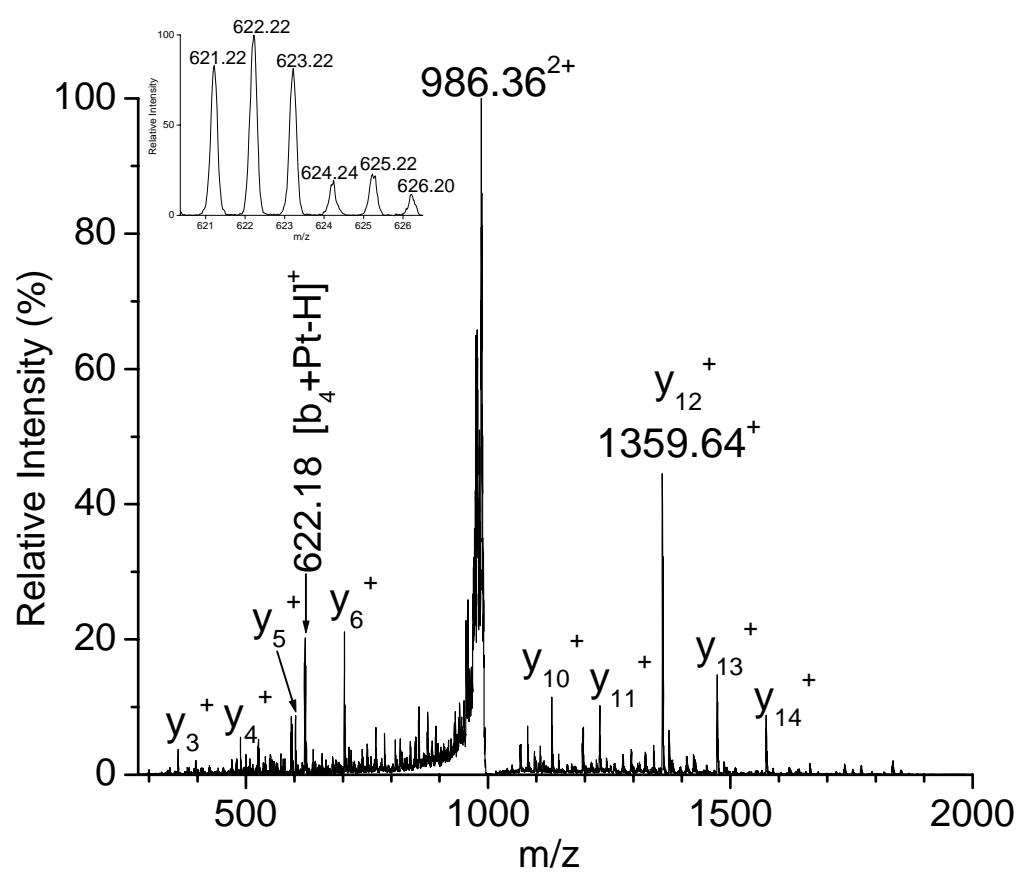

Figure 5.12. The product-ion spectrum of MS/MS analysis of the $1008.47^{2+}$ ion, overlaid with the isotope distribution with the product ion $622.18^{+}$. The sequence of the $1008.47^{2+}$ ion: (T12-K27) TITLEVEPSDTIENVK

\subsubsection{Determination of the cisplatin binding site on denatured Ub}

The $975.41^{+}, 1148.92^{3+}$, and $1623.32^{2+}$ ions arising from three Pt-containing fragments are observed in the FT-MS spectra of the denatured Ub adduct digest, Figure 5.6. The peak corresponding to the $975.41^{+}$ion, identified as the $\operatorname{Pt}\left(\mathrm{NH}_{3}\right)$ bound M1-K6 by Figure 5.9., is the most abundant and its intensity covers over $80 \%$ of the peak intensity of all the three peaks corresponding to the Pt-containg fragments in Figure 5.6. 
Figure 5.13. and Figure 5.14. show the MS/MS analyses of the $1148.92^{3+}$ and $1623.32^{2+}$ ions, respectively. The $713.09^{+}$fragment ion corresponding to the $\left[\mathrm{b}_{4}+\mathrm{Pt}-\mathrm{H}\right]^{+}$ion in Figure 5.9. was also observed in both Figure 5.13. and Figure 5.14., indicating that the $1148.92^{3+}$ and $1623.32^{2+}$ ions are the same as the $975.41^{+}$ion that arises from the binding of $\operatorname{Pt}\left(\mathrm{NH}_{3}\right)$ to three residues at the N-terminal of $\mathrm{Ub}$. According to Figure 5.13. and Figure 5.14., the $1148.92^{3+}$ and $1623.32^{2+}$ ions are assigned as the $\operatorname{Pt}\left(\mathrm{NH}_{3}\right)$ bound peptide $\mathrm{M} 1-\mathrm{K} 29$ and the $\operatorname{Pt}\left(\mathrm{NH}_{3}\right)$ bound peptide M1-K27. The result indicates that M1 is the specific cisplatin binding site under the denatured conditions. $\mathrm{Pt}\left(\mathrm{NH}_{3}\right)$ binds to the $\mathrm{S}$ atom of $\mathrm{M} 1$, the $\mathrm{N}$ atom of the amino group at the $\mathrm{N}$ terminus, and the $\mathrm{N}$ atom of the side chain of $\mathrm{Q} 2$ under denatured conditions.

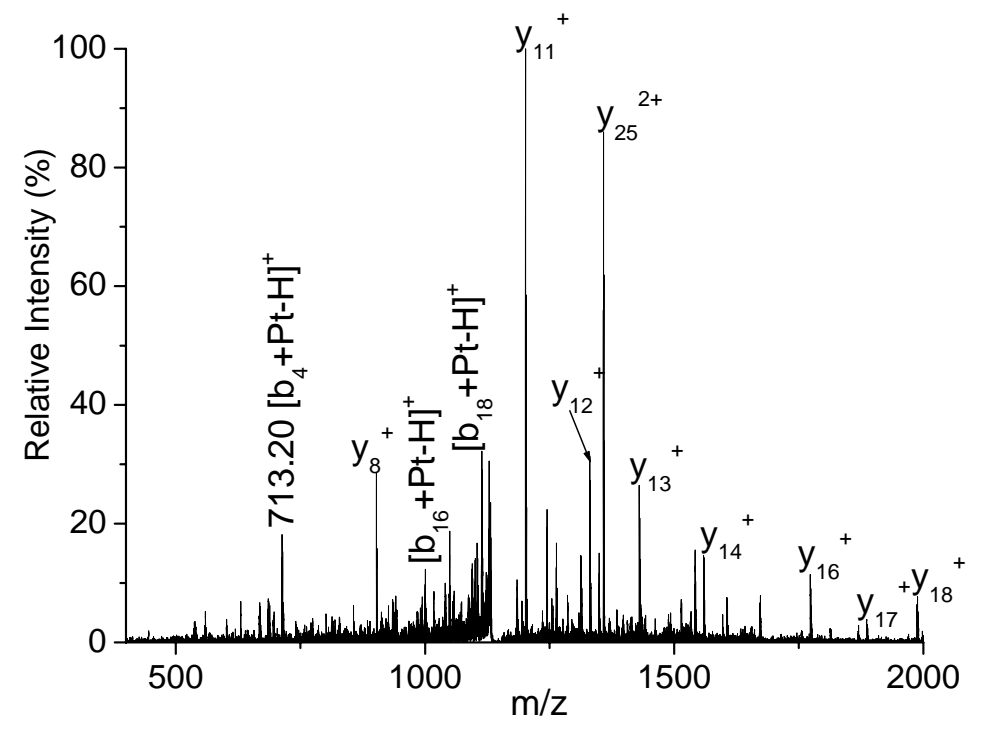

Figure 5.13. The product-ion spectrum of the MS/MS analysis of the $1148.92^{3+}$ ion. The peptide sequence of the $1148.92^{3+}$ ion: M1-K29 MQIFVKTLTGKTITLEVEPSDTIENVKAK 


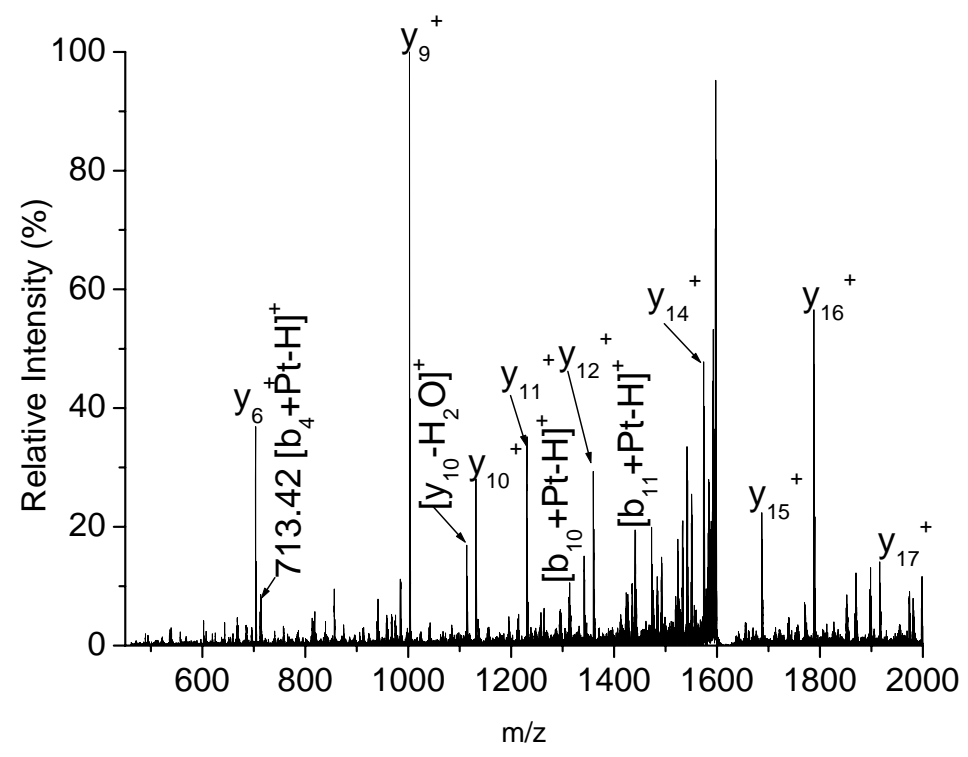

Figure 5.14. The product-ion spectrum of the MS/MS analysis of the $1623.32^{2+}$ ion. The peptide sequence of the $1623.32^{2+}$ ion: M1-K27 MQIFVKTLTGKTITLEVEPSDTIENVK

In short, three different binding sites of cisplatin on $\mathrm{Ub}$ are observed under the native conditions, but only one cisplatin binding site is determined for the denatured Ub. Under native conditions, the residues T11 and T13 located on the surface of the Ub polypeptide chain are identified as the primary binding sites due to the steric effects. But M1 at N-terminus is the single binding site of cisplatin on Ub under denatured conditions. 


\subsection{Conclusions}

Although the Ub-cisplatin interactions are more complete under denatured conditions than under native conditions, the variety of monoadducts obtained under denatured conditions is less than that obtained under native conditions. Five types of monoadducts were observed under native conditions and three types of monoadducts were observed under denatured conditions. Consistent with this result, more cisplatin binding sites are identified on native Ub than denatured Ub. Under native conditions, Ub has three binding sites T12 and T14, M1, and Q31 and D32, but M1 is the only binding site determined for denatured Ub.

The comparison of the binding sites of cisplatin on native and denatured $\mathrm{Ub}$ indicates that cisplatin has high affinity to M1 without steric hindrance. However, for a tightly folded protein, cisplatin will interact with the nucleophiles at surface, even the oxygen containing side chains to form bifunctional adducts instead of overcoming the steric effects to bind to the M1 residue partly buried in the interior of the protein structure. As a result, the conformation of a protein has a strong effect on the cisplatin binding sites. This rule is important in our understanding of interactions between cisplatin and blood plasma proteins in biological fluids. 


\subsection{References}

(1) Reedijk, J. Chem. Rev. 1999, 99, 2499-2510.

(2) Wehr, T. LCGC North America. 2006, 24, 1004-1010.

(3) Khalaila, I.; Allardyce, C. S.; Verma, C. S.; Dyson, P. J. ChemBioChem. 2005, 6, 1788-1795.

(4) Allardyce, C. S.; Dyson, P. J.; Coffey, J.; Johnson, N. Rapid Commun. Mass Spectrom. 2002, 16, 933-935.

(5) Yang, G.; Miao, R.; Jin, C.; Mei, Y.; Tang, H.; Hong, J.; Guo, Z.; Zhu, L. J. Mass Spectrom. 2005, 40, 1005-1016.

(6) Casini, A.; Gabbiani, C.; Mastrobuoni, G.; Pellicani, R. Z.; Intini, F. P.; Arnesano, F.; Natile, G.; Moneti, G.; Francese, S.; Messori, L. Biochemistry. 2007, 46, 12220-12230.

(7) Gibson, D.; Costello, C. E. Eur. Mass Spectrom. 1999, 5, 501-510.

(8) Hartinger, C. G.; Tsybin, Y. O.; Fuchser, J.; Dyson, P. J. Inorg. Chem. 2008, 47, 17-19.

(9) Peleg-Shulman, T.; Gibson, D. JACS. 2001, 123, 3171-3172.

(10) Peleg-Shulman, T.; Najajreh, Y.; Gibson, D. J. Inorg. Biochem. 2002, 91, 306-311.

(11) Zhao, T.; King, F. L. J. Am. Soc. Mass Spectrom. 2009, 20, 1141-1147.

(12) Zhao, T.; King, F. L. Submitted to J. Inorg. Biochem.

(13) Cox, M.C.; Barnham, K.J.; Frenkiel, T.A.; Hoeschele, J.D.; Mason, A.B.; He, Q.Y.; Woodworth, R.C.; Sadler, P. J. J. Bio. Inorg. Chem. 1999, 4, 621-631.

(14) Najajreh, Y.; Ardeli-Tzaraf, Y.; Kasparkova, J.; Heringova, P.; Prilutski, D.; Balter, L.; Jawbry, S.; Khazanov, E.; Perez, J. M.; Barenholz, Y.; Brabec, V.; Gibson, D. J. Med. Chem. 2006, 49, 4674-4683.

(15) Hartinger, C. G.; Ang, W. H.; Casini, A.; Messori, L.; Keppler, B. K.; Dyson, P. J. J. Anal. Atom. Spectrom. 2007, 22, 960-967.

(16) Kodali Ravindra Babu, A. M., Douglas, D. J. J. Am. Soc. Mass Spectrom. 2001, 12, 317-328.

(17) Zhang, Z.; Marshall, A. G. J. Am. Soc. Mass Spectrom. 1998, 9, 225-233. 


\section{Future Directions}

In this dissertation, a mass spectrometric method was developed for determination of the primary binding site of cisplatin on various proteins by coupling Fourier transform mass spectrometry (FT-MS) with tandem mass spectrometry (MS/MS and $\mathrm{MS}^{3}$ ). This approach was successfully applied to determine the primary binding sites of cisplatin on cytochrome $\mathrm{c}$ (cyt c), cisplatin and transplatin on $\mathrm{Mb}$ and the major binding sites of cisplatin on ubiquitin (Ub). These results suggest the developed approach can be potentially applied to determine the major binding sites of Pt metallodrugs on a wide variety of proteins. Because a large protein will result in a more complex adduct digest, liquid chromatography (LC) may be necessary before FT-MS analysis of the adduct digest for larger proteins such as the most abundant protein in the blood plasma, human serum albumin (HSA).

The interactions of cisplatin and transplatin with $\mathrm{Mb}$ were also compared in binding kinetics, the formed adducts, and their primary binding sites on $\mathrm{Mb}$. The results indicate that cisplatin and transplatin have similar interactions with $\mathrm{Mb}$. Because $\mathrm{Mb}$ has a tight globular structure, similar to HSA, this result might suggest that the completely different anticancer activity between cisplatin and transplatin are not caused by the different interactions of cisplatin and transplatin with the blood plasma proteins. The above conclusion may be tested by comparing the interactions of cisplatin and transplatin with HSA using the similar mass spectrometric approaches 
employed in this dissertation.

Finally, the obtained results in determination of cisplatin binding sites on model proteins indicate that the binding sites of cisplatin on proteins are influenced by the conformation of the proteins. Cisplatin is primarily attached to the Met65 residue in cyt c, but His116 and His 119 residues are the residues that are bound to cisplatin on $\mathrm{Mb}$ because of the tight folding of $\mathrm{Mb}$. The conformation effect on the binding sites of cisplatin on a protein was tested by comparing the binding sites of cisplatin on native and denatured $\mathrm{Ub}$. Three binding sites are observed for native ubiquitin because of the partial folding of Metl inside native Ub. Met1 is the specific binding site of cisplatin on fully denatured $\mathrm{Ub}$. Therefore, the results suggest the protein conformation needs to be considered during prediction of the binding sites of Pt metallodrugs on proteins.

In conclusion, the developed mass spectrometric methods and the results can provide insights into the interactions of Pt metallodrugs with blood plasma proteins. 